Aus der Abteilung Mund-, Kiefer- und Gesichtschirurgie

(Prof. Dr. med. Dr. med. dent. H. Schliephake)

im Zentrum für Zahn-, Mund- und Kieferheilkunde

der Medizinischen Fakultät der Universität Göttingen

\title{
Retrospektive Untersuchung der digital bestimmten relativen Knochendichte nach Defektauffüllungen im Mund- Kiefer-Gesichtsbereich mittels phasenreinen Hydroxyl- apatits unter Berücksichtigung der klinischen Verläufe
}

\author{
INAUGURAL - DISSERTATION \\ zur Erlangung des Doktorgrades \\ für Zahnheilkunde \\ der Medizinischen Fakultät der \\ Georg-August-Universität zu Göttingen
}

vorgelegt von

\section{Manuel Henry Geiger \\ aus \\ Münden, jetzt Hann. Münden}


Dekan:

Referent:

Ko-Referent/in:

Drittreferent/in:

Datum der mündlichen Prüfung:
Prof. Dr. rer. nat. H. K. Kroemer

Priv.-Doz. Dr. med. Dr. med. dent. A. Ludwig Prof. Dr. med Christian Oliver Ritter

Prof. Dr. med Martin Oppermann

18.02.2020 
Hiermit erkläre ich, die Dissertation mit dem Titel „Retrospektive Untersuchung der digital bestimmten relativen Knochendichte nach Defektauffüllungen im Mund-Kiefer-Gesichtsbereich mittels phasenreinen Hydroxylapatits unter Berücksichtigung der klinischen Verläufe" eigenständig angefertigt und keine anderen als die von mir angegebenen Quellen und Hilfsmittel verwendet zu haben.

(Unterschrift) 


\section{Inhaltsverzeichnis}

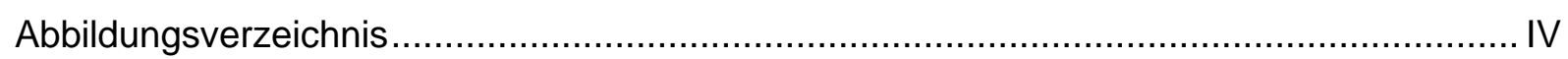

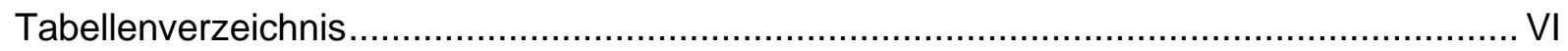

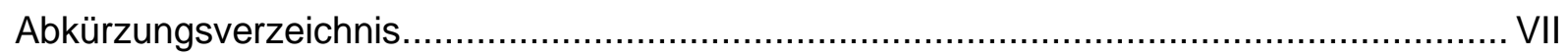

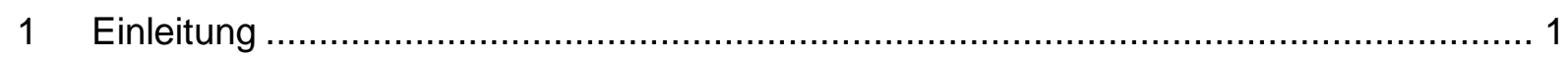

$1.1 \quad$ Knochen und Knochendefekte ................................................................... 1

1.2 Mechanismen der Knochenregeneration ................................................... 3

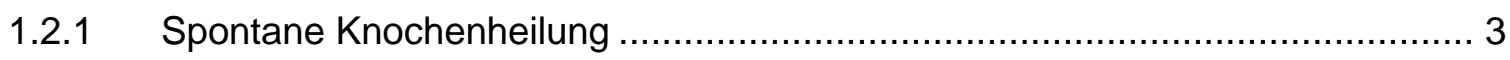

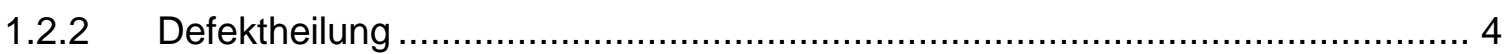

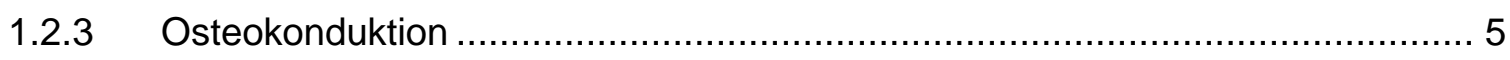

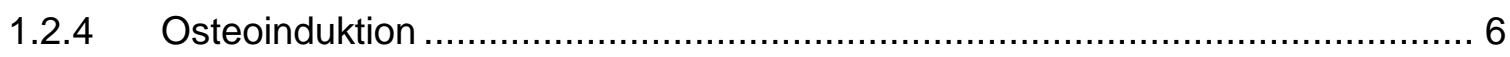

1.3 Knochentransplantate und Knochenersatzmaterialien ..................................... 7

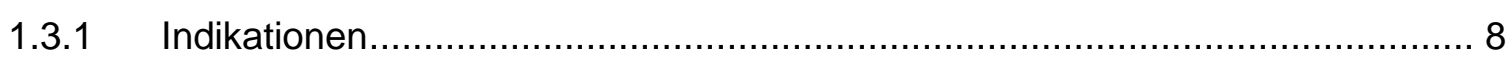

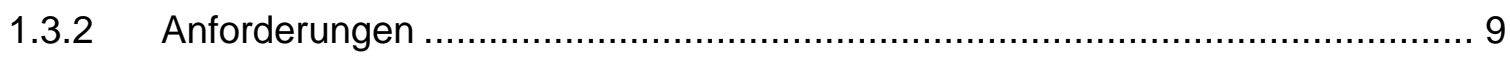

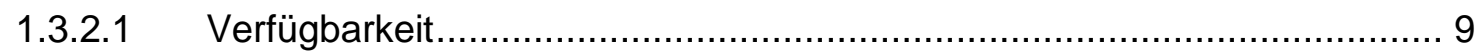

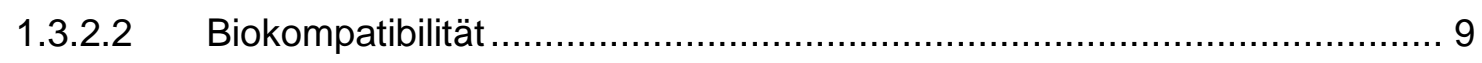

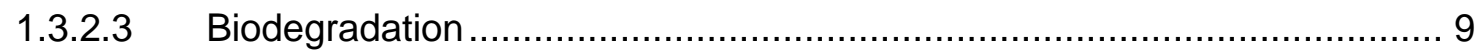

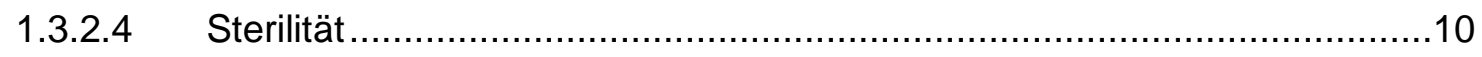

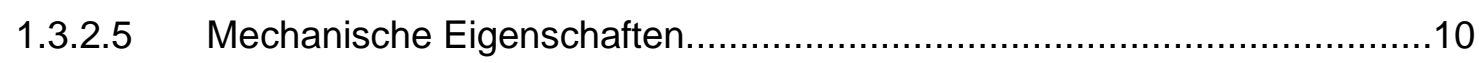

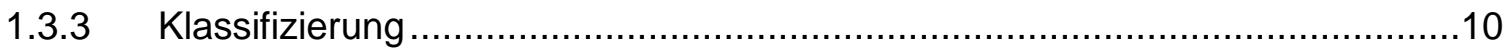

1.3.3.1 Autogene Knochentransplantate .................................................11

1.3.3.2 Allogene Knochentransplantate und Knochenersatzmaterialien ...............12

1.3.3.3 Xenogene Materialen ....................................................................... 14

1.3.3.4 Synthetische Knochenersatzmaterialien ......................................... 14

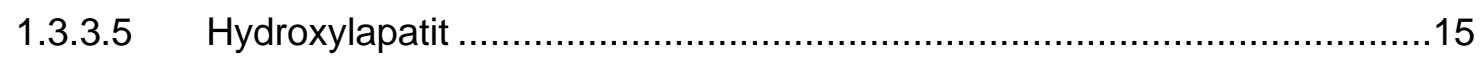

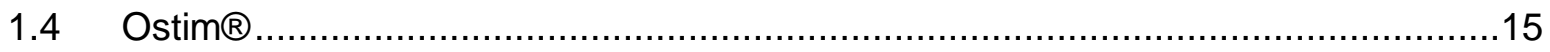

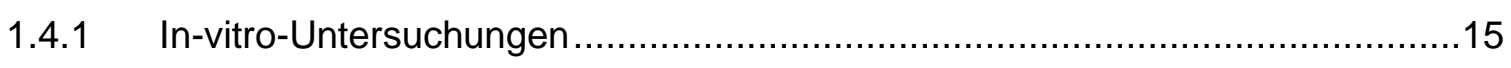

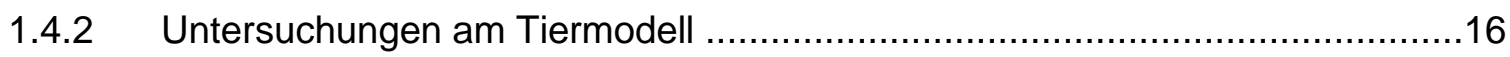

1.4.3 Klinische Anwendungsgebiete...............................................................

1.5 Knochendichte und radiologische Bildanalyseverfahren ...................................18 
1.5.1 Dual energy $x$-ray absorptiometry .................................................... 18

1.5.2 Computertomographie und digitale Volumentomographie .............................18

1.5.3 Messung der relativen Knochendichte......................................................19

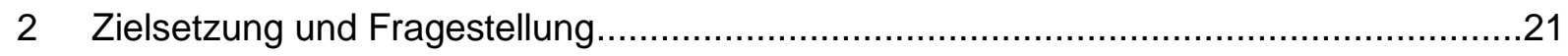

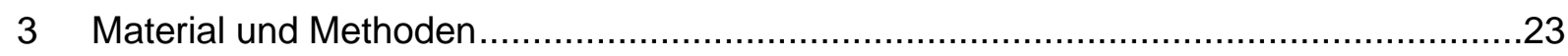

3.1 Bildanalyseverfahren und Voruntersuchung hinsichtlich der Reproduzierbarkeit ....23

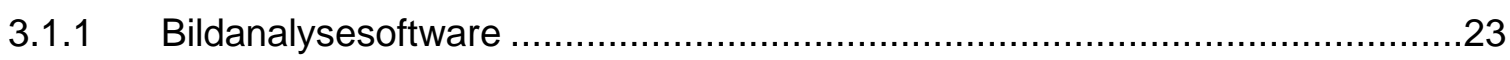

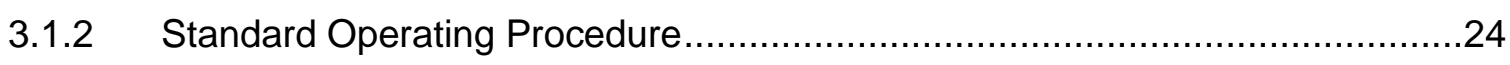

3.1.3 Untersuchung der Reproduzierbarkeit .....................................................25

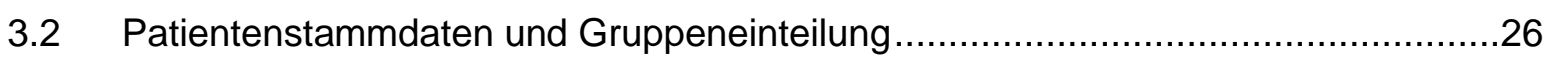

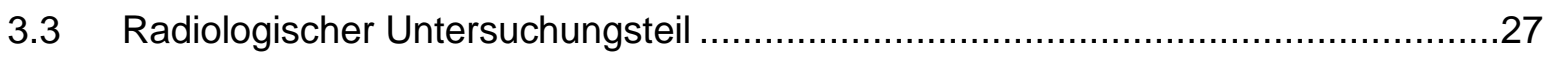

3.3.1 Grauwertmessungen und Bestimmung der relativen Röntgendichten ............29

3.4 Erfassung der Klinischen Verläufe.........................................................29

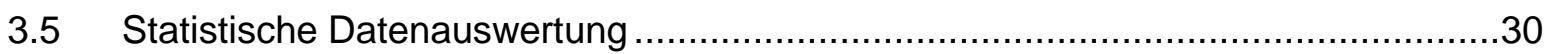

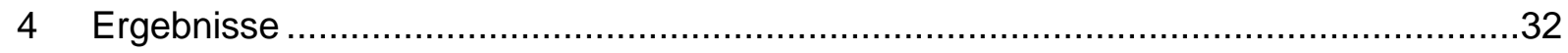

4.1 Ergebnisse der Voruntersuchung der Reproduzierbarkeit von Messungen mittels

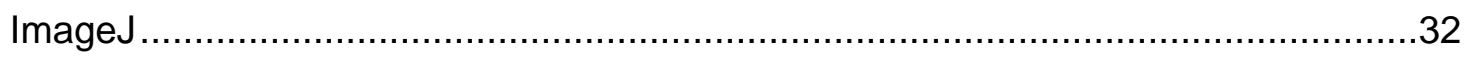

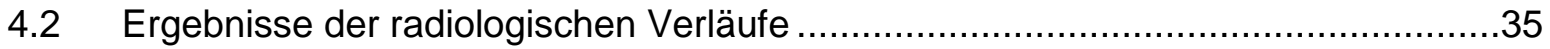

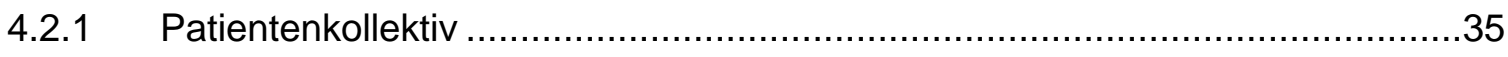

4.2.2 Messungen der relativen Röntgendichte .............................................. 38

4.2.2.1 Messergebnisse der relativen Röntgendichte ....................................42

4.3 Ergebnisse der klinischen Verläufe ........................................................ 43

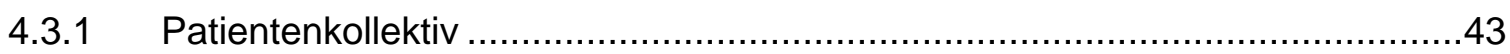

4.3.2 Beschreibung der klinischen Verläufe ...................................................... 45

4.3.2.1 Gesamtkollektiv zu den einzelnen Untersuchungszeiträumen ................45

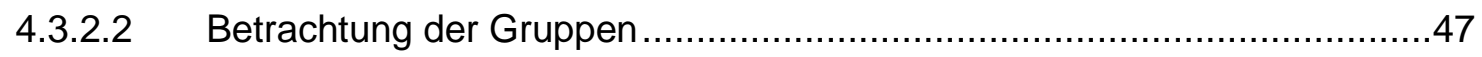

4.4 Vergleich zwischen relativer Röntgendichte und klinischem Verlauf.....................51

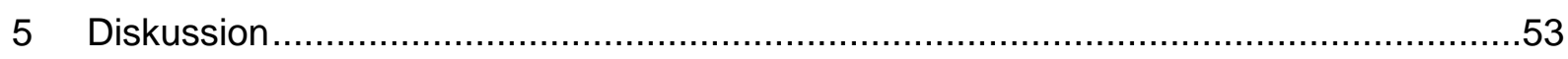

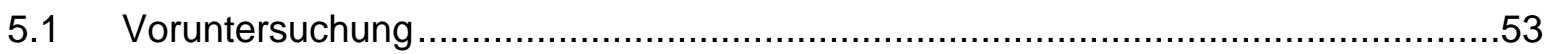

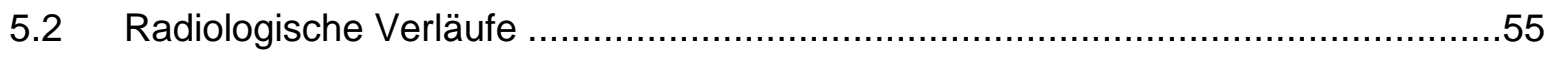




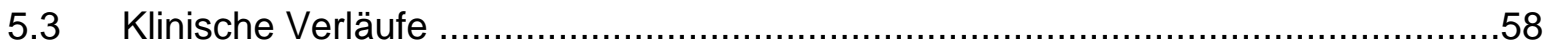

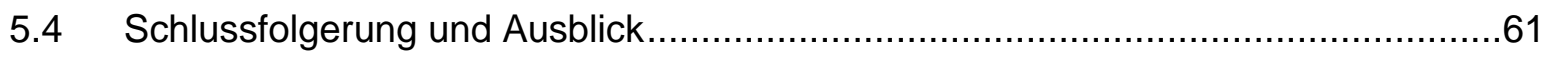

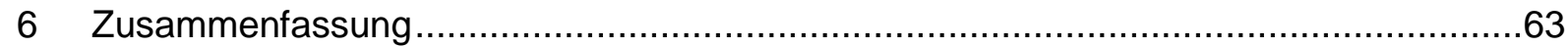

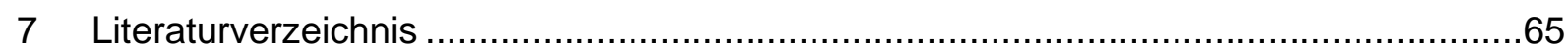




\section{Abbildungsverzeichnis}

Abbildung 1: Selektion der Messregionen und Probemessung von Bild 4 der Voruntersuchung.

Abbildung 2: Klinisches Bild zur Durchführung einer socket preservation. .27

Abbildung 3: Klinische Bilder nach Wurzelspitzenresektion und Zystektomie Zahn 12 und Defektauffüllung mit Ostim ${ }^{\circledR}$ und die dazugehörige postoperative Röntgenaufnahme. .28

Abbildung 4: Vergrößerter Ausschnitt von Bild 1 der Voruntersuchung. 32

Abbildung 5: Vergrößerter Ausschnitt des OPGs von Fall 2 mit den umfahrenen Untersuchungsregionen von den verschiedenen Untersuchern. .34

Abbildung 6: Klinisches Bild nach Implantatinsertion und lateraler Augmentation mit Ostim ${ }^{\circledR}$ und Membrantechnik vor Wundverschluss.

Abbildung 7: Vergrößerter Ausschnitt des postoperativen OPGs desselben Falles wie Abbildung 6 nach Implantatinsertion und lateraler Augmentation im Unterkieferfrontzahnbereich. .35

Abbildung 8: Vergrößerter Ausschnitt eines postoperativen OPGs nach Zystektomie und Defektauffüllung einer Nasopalatinalzyste.

Abbildung 9: Boxplotdarstellung der Ergebnisse der relativen Röntgendichtemessung postoperativ und zum Kontrollzeitpunkt. ..38

Abbildung 10: Scatterplotdarstellung der Korrelation zwischen Röntgendichte zum Kontrollzeitpunkt und Röntgendichte postoperativ.

Abbildung 11: Scatterplotdarstellung der Korrelation zwischen Delta und Alter zum Operationszeitpunkt. .40

Abbildung 12: Scatterplotdarstellung der Korrelation zwischen Delta und dem Beobachtungszeitraum.

Abbildung 13: Boxplotdarstellung der mittleren relativen Röntgendichte in den einzelnen Gruppen postoperativ und zum Kontrollzeitpunkt.

Abbildung 14: Diagramm zur Häufigkeit und prozentualen Verteilung der klinischen Verläufe innerhalb des Gesamtkollektivs im Untersuchungszeitraum T1. ...45

Abbildung 15: Diagramm zur Häufigkeit und prozentualen Verteilung der klinischen Verläufe innerhalb des Gesamtkollektivs im Untersuchungszeitraum T2. ...46

Abbildung 16: Diagramm zur Häufigkeit und prozentualen Verteilung der klinischen Verläufe innerhalb des Gesamtkollektivs im Untersuchungszeitraum T3. ...47

Abbildung 17: Komplikationsraten der einzelnen Gruppen im Vergleich. .48

Abbildung 18: Diagramm zur Verteilung der Fälle mit negativem Delta auf die einzelnen Gruppen. 
Abbildung 19: Diagramm zu den Klinischen Verläufen zum Zeitraum T3 bei Fällen mit negativem Delta. 


\section{Tabellenverzeichnis}

Tabelle 1: Mögliche Heilungsverläufe nach Wurzelspitzenresektionen nach Andreasen und Rud (1972) und Rud et al. (1972) .................................................. 4

Tabelle 2: $\quad$ Studien zum Einwachsverhalten von Knochen in poröse Strukturen ............ 6

Tabelle 3: Indikationen der in der Voruntersuchung benutzten Bilddateien ..................25

Tabelle 4: Zahlencodierung zur Auswertung der klinischen Verläufe .........................30

Tabelle 5: $\quad$ Ergebnisse der Grauwertmessungen der Voruntersuchung .......................33

Tabelle 6: $\quad$ Ergebnisse der Varianzanalye (Type 3 Tests of Fixed Effects)....................34

Tabelle 7: Gesamtkollektiv der röntgenologisch untersuchten Defekte..........................37

Tabelle 8: Verteilung der röntgenologisch untersuchten Defekte innerhalb der Gruppen

Tabelle 9: Ergebnisse der uni- und multivariaten linearen Regressionsmodelle für Röntgendichte.postOP 38

Tabelle 10: Übersicht über die Ergebnisse der Röntgendichtemessungen in den einzelnen Gruppen

Tabelle 11: Gesamtkollektiv der nachverfolgten klinischen Verläufe ............................44

Tabelle 12: Verteilung in Gruppen sowie Durchschnittsalter und Geschlecht................44

Tabelle 13: Ergebnisse der multivariaten logistischen Regression für Komplikationen Ja/Nein bei T1.

Tabelle 14: Nachuntersuchungsquote der einzelnen Gruppen zu den jeweiligen

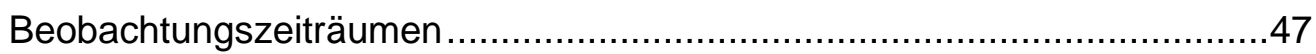

Tabelle 15: Komplikationsrate der einzelnen Gruppen zu den jeweiligen Beobachtungszeiträumen ..........................................................48

Tabelle 16: Klinische Verläufe zahlencodiert mit prozentualer Häufigkeit nach Gruppen sortiert.

Tabelle 17: Ergebnisse der statistischen Auswertung von Korrelationen zwischen beiden Teilstudien

Tabelle 18: Vergleich von Fällen mit Zahn- oder Implantatverlust und klinisch unauffälligen Fällen in Gruppe II und III hinsichtlich Delta und Röntgendichte zum Kontrollzeitpunkt 


\section{Abkürzungsverzeichnis}

\begin{tabular}{|l|l|}
\hline BMP & bone morphogenetic protein \\
\hline BRD & Bundesrepuplik Deutschland \\
\hline CSD & critical size defect \\
\hline CT & Computertomographie \\
\hline DBM & demineralized bone matrix \\
\hline DICOM & digital imaging and communications in medicine (Dateiformat) \\
\hline DNA & Desoxyribonukleinsäure \\
\hline DVT & Digitale Volumentomographie \\
\hline DXA & dual energy $x$-ray absorptiometry \\
\hline EDV & Elektronische Datenverarbeitung \\
\hline HBV & Hepatitis-B-Virus \\
\hline HCV & Hepatitis-C-Virus \\
\hline HIV & Humanes Immundefizienz-Virus \\
\hline HTLV & Humanes T-Zell-Leukämie-Virus \\
\hline JPEG & joint photographic experts group (Dateiformat) \\
\hline OPG & Orthopantomogramm \\
\hline RNA & Ribonukleinsäure \\
\hline RöKntr & Kontrollröngenbild \\
\hline RöPostOP & Postoperatives Röntgenbild \\
\hline SOP & standard operation procedure \\
\hline TGF- 3 & transforming growth factor beta \\
\hline TIFF & tagged image file format (Dateiformat) \\
\hline WSR & \\
\hline
\end{tabular}




\section{Einleitung}

Die Heilung der Kieferknochen nach Extraktionen und anderen kieferchirurgischen Eingriffen ist seit jeher Thema intensiver Forschung (Albrektsson und Johansson 2001, Amler 1969, Andreasen und Rud 1972, Rud et al. 1972). Am Ende des Heilungsprozess steht in vielen Fällen ein Verlust an Knochenvolumen (Tan et al. 2012, van der Weijden et al. 2009). Die Vermeidung oder Verringerung dieses Verlustes durch socket preservation (Hammerle et al. 2012) sowie die Augmentation im Zusammenhang mit dentalen Implantationen stellen Anwendungsgebiete für Knochentransplantate und Knochenersatzmaterialien dar (Esposito et al. 2006). Autologe Knochentransplante gelten als „Goldstandard“, müssen aber zunächst gewonnen werden und stehen nur in begrenztem Maße zur Verfügung. Um erforderliche Zweiteingriffe und die damit einhergehenden Komplikationen (Jäger et al. 2005) zu vermeiden, wäre die Entwicklung eines unbegrenzt verfügbaren Knochenersatzmaterials mit vergleichbaren Eigenschaften wünschenswert (Rueger 1998). Es existiert inzwischen eine Vielzahl an Materialien, die sich hinsichtlich der Herstellung und chemischen Zusammensetzung teilweise stark unterscheiden (Moore et al. 2001, Sogal und Tofe 1999, Tomford 2000). Aufgrund der chemischen Ähnlichkeit zum mineralischen Knochenanteil werden calziumphosphatbasierte Knochenersatzmaterialien als vielversprechende Alternativen angesehen (Schnettler et al. 2004). Zu dieser Gruppe gehört das synthetische alloplastische Knochenersatzmaterial Ostim ${ }^{\circledR}$ [Heraeus Kulzer, Hanau, Deutschland]. Es besteht aus phasenreinem nanokristallinen Hydroxylapatit in einer wässrigen Dispersion (Tadic und Epelle 2004). In einigen In-vitro-, In-vivo- und klinischen Studien konnten die Eigenschaften von Ostim ${ }^{\circledR}$ bereits charakterisiert und das Verhalten während des Heilungsprozesses beschrieben werden. Im Bereich der Mund-Kiefer-Gesichtschirurgie wurden bereits Anwendungen im Zusammenhang mit dentalen Implantationen (Dottore et al. 2014, Smeets et al. 2008, Strietzel et al. 2007), Defektauffüllungen nach Zystektomien (Bezrukov et al. 1998, Gerlach und Niehues 2007) und Behandlungen parodontaler Knochendefekte durchgeführt (Chitsazi et al. 2011, Kasaj et al. 2008a, Schwarz et al. 2006).

\subsection{Knochen und Knochendefekte}

Das Knochengewebe erfüllt im menschlichen Körper nicht nur Aufgaben als Stütz-, Bewegungs-, Schutz- sowie formgebendes Gewebe, sondern auch als Speicher für Calzium und Phosphat. Diese Mineralien sind zum überwiegenden Teil als nanokristallines Hydroxylapatit, ein Calziumphosphat mit der Strukturformel $\mathrm{Ca}_{10}\left(\mathrm{PO}_{4}\right)_{6}(\mathrm{OH})_{2}$, in der extrazellulären Matrix eingelagert. Es bildet den Großteil der anorganischen Bestandteile des Knochens, die etwa 65 Prozent des Gesamtgewichts darstellen (Soldner und Herr 2001). Die Hydroxylapatit- 
Kristalle präzipitieren bei der Knochenbildung in dem zuvor sezernierten organischen Grundgerüst, dem Osteoid, an den Phosphatgruppen von Kollagen und anderen Phosphoproteinen. Dabei entsteht durch lonenaustausch ein unreiner Apatit, mit einer Kristallgröße von 3,5-25 nm $\times$ 2,5-5 nm, in dem $\mathrm{Ca}^{2+}, \mathrm{OH}^{-}$und $\mathrm{PO}_{4}{ }^{3-}$ teilweise durch Metallionen im kationischen und $\mathrm{Cl}^{-}, \mathrm{F}^{-}$oder $\mathrm{CO}_{3}{ }^{2-}$ im anionischen Teil des Kristallgitters substituiert sind. Aus der hohen spezifischen Oberfläche und den Unregelmäßigkeiten im Kristallgitter ergibt sich eine erhöhte Löslichkeit gegenüber phasenreinem Hydroxylapatit (Posner 1985). Der organische Anteil des Knochens besteht zum überwiegenden Anteil aus Kollagen Typ I. Dazu kommen nichtkollagene Proteoglykane, strukturelle Glykoproteine, Phosphoproteine und verschiedene Polypeptide. Diese erfüllen Aufgaben als Wachstums- und Differenzierungsfaktoren (Soldner und Herr 2001). Knochen ist ein vitales, dynamisches Gewebe, welches einem stetigen Anpassungsprozess an die aktuellen Bedingungen und Anforderungen unterliegt. Nach dem „Wolffschen Gesetz“ adaptiert sich Knochen entsprechend den mechanischen Belastungen, denen er ausgesetzt ist. Biege- und Zugbelastungen, wie sie bei den langen Röhrenknochen der Extremitäten, aber auch im Alveolarfortsatz durch die faserartige Aufhängung der Zähne vorkommen, führen zu Knochenwachstum und Apposition, fehlende Belastung zu Atrophie (Wolff 1892). Mit der „Mechanostat“-Theorie wurden diese Beobachtungen präzisiert:

- In gesundem Knochen herrscht ein Gleichgewicht zwischen Knochenaufbau und Knochenabbau, welches für Knochenwachstum, die benötigte Knochendichte und die Atrophie von nicht mehr benötigten Knochenstrukturen verantwortlich ist.

- Es existiert ein Rückkoppelungs-Mechanismus, der die Häufigkeit und Intensität der mechanischen Belastung, die auf einen Knochen in physiologischer Art und Weise ausgeübt wird, in ein Signal umwandelt, das auf Knochenauf- und -abbau einwirkt (Frost 1987).

Durch diesen Mechanismus werden die lasttragenden Knochen während des Wachstums in einen Zustand versetzt, in dem bei normalen gewohnheitsmäßigen Aktivitäten keine Frakturen oder Knochendefekte auftreten. Dabei sind Aufbau und Abbau voneinander unabhängige Prozesse, die durch verschiedene Stimuli oder krankhafte Prozesse sowie Toxine und Ernährungsfaktoren beeinflusst werden können (Frost 2003). Im Mund-KieferGesichtsbereich beobachtet man diesen Anpassungsprozess zum Beispiel nach Zahnextraktion oder unter unphysiologischem Druck auf den Kieferknochen, wie zum Beispiel das Tragen von mukosagetragenem Zahnersatz (Tallgren 1972). Neben der Atrophie können Knochendefekte auch durch entzündliche Prozesse, Trauma, Zysten und Tumoren sowie iatrogen hervorgerufen werden. In der Mund-Kiefer-Gesichtschirurgie hat die Behandlung und in wachsendem Maße auch die Vermeidung dieser Knochendefekte eine große Bedeutung (Rueger 1998). Knochendefekte können neben ihrer Ätiologie auch nach der Defekt- 
konfiguration eingeteilt werden. Je nachdem, wie viele knöcherne Wände der Defekt aufweist, ergibt sich eine ein- bis fünfwandige Defektkonfiguration (Goldman und Cohen 1958).

\subsection{Mechanismen der Knochenregeneration}

\subsubsection{Spontane Knochenheilung}

Durch die reichhaltige Durchblutung und die Präsenz von Vorläuferzellen besitzt Knochengewebe gute Voraussetzungen für die Heilung von Verletzungen oder Knochendefekten. Prinzipiell unterscheidet man die primäre und die sekundäre Heilung. Während die primäre Knochenheilung nur bei stabil reponierten Frakturen eine Rolle spielt, verheilen operative oder entzündliche Knochendefekte im Mund-Kiefer-Gesichtsbereich in der Regel durch eine sekundäre Heilung. Der Defekthohlraum füllt sich mit Blut, was die Auslösung der Gerinnungskaskade und die Bildung eines Blutgerinnsels zur Folge hat. Die Verletzung der Knochenstruktur, des Knochenmarks und der in inm verlaufenden Blutgefäße führt zur Freisetzung von lokalen Gewebefaktoren, die mesenchymale Stammzellen zur Differenzierung zu Osteoblasten anregen. Dieser Prozess ist vor allem in der ersten Woche nach der Knochenverletzung aktiv. Das Blutgerinnsel wird organisiert, mit Blutgefäßen durchsetzt und in ein Granulationsgewebe umgebaut. Anschließend beginnt von den Defekträndern her eine Geflechtknochenbildung. Abhängig von der mechanischen Stabilität wird dieser Geflechtknochen dann in lamellären Knochen umgebaut und an die lokalen funktionellen Bedürfnisse angepasst (Albrektsson und Johansson 2001, Giannoudis et al. 2007). Die Heilung von Extraktionsalveolen beim Menschen lässt sich in folgende zeitliche Abschnitte unterteilen:

- Wenige Minuten nach Extraktion bildet sich ein die Alveole ausfüllendes Blutgerinnsel, das innerhalb von sieben Tagen komplett durch Granulationsgewebe ersetzt wird.

- $A b$ dem vierten Tag beginnt ausgehend vom Alveolenboden das Einsprossen von Bindegewebe und vom Zahnfleischsaum aus die Proliferation des Epithelgewebes.

- Ab dem siebten Tag finden sich am Fundus der Alveole erste Anzeichen von Osteoid, das im weiteren Verlauf von apikal nach krestal zu Geflechtknochen umgebaut wird.

- Zwischen dem 25. und 35. Tag findet in der Regel das vollständige Verschmelzen des Epithels an der Oberfläche statt.

- 35 Tage nach der Extraktion sind etwa zwei Drittel der Alveole mit Geflechtknochen ausgefüllt (Amler 1969).

Dieser Heilungsprozess führt zu einem Verlust an Alveolarkammhöhe und -breite. Der durchschnittliche Verlust an Alveolarkammbreite drei bis zwölf Monate nach Extraktion von Prämolaren und Frontzähnen beläuft sich auf 3,87 mm, der Höhenverlust auf 1,67 - 2,03 mm (van der Weijden et al. 2009). Dabei ereignet sich der Hauptteil der Resorption innerhalb der ersten sechs bis sieben Monate (horizontaler Verlust nach drei Monaten 32\%, nach sechs 
Monaten 29 - 63\%; vertikaler Verlust nach sechs Monaten 11 - 22\%) (Tan et al. 2012). Der Verlust an Alveolarkammhöhe fällt an der bukkalen Alveolenwand größer aus als lingual oder palatinal, was unter anderem durch den Abbau von Bündelknochen entsteht. Die bukkalen, häufig dünnen Knochenlamellen bestehen vor allem im krestalen Bereich von oberen Frontzähnen und Prämolaren nur aus Bündelknochen, der nach Extraktion vollständig resorbiert wird (Araujo und Lindhe 2005). Bei oralchirurgischen Eingriffen können auch der Einfluss und die Regeneration von dentalen Strukturen eine Rolle bei der Heilung knöcherner Strukturen spielen. Nach Wurzelspitzenresektionen unterscheidet man die möglichen Arten der Heilung in drei Kategorien, wie Tabelle 1 zeigt (Andreasen und Rud 1972, Rud et al. 1972).

Tabelle 1: Mögliche Heilungsverläufe nach Wurzelspitzenresektionen nach Andreasen und Rud (1972) und Rud et al. (1972)

\begin{tabular}{|c|c|c|c|}
\hline & $\begin{array}{l}\text { Heilung mit } \\
\text { parodontaler } \\
\text { Regeneration }\end{array}$ & $\begin{array}{l}\text { Heilung mit fibrösem } \\
\text { Narbengewebe }\end{array}$ & $\begin{array}{l}\text { Persistierende } \\
\text { apikale } \\
\text { Parodontitis }\end{array}$ \\
\hline $\begin{array}{l}\text { Histologischer } \\
\text { Befund }\end{array}$ & $\begin{array}{l}\text { - entzündungsfreie } \\
\text { Verhältnisse } \\
\text { - Regeneration von } \\
\text { azellulärem } \\
\text { Zement, } \\
\text { parodontalem } \\
\text { Ligament } \\
\text { - intakte alveoläre } \\
\text { Lamina dura }\end{array}$ & $\begin{array}{l}\text { - häufig persistierende } \\
\text { Perforation der bukkalen } \\
\text { Kortikalis } \\
\text { - kollagenes, zellarmes } \\
\text { Narbengewebe, häufig in } \\
\text { direktem Kontakt zu den } \\
\text { Resektionsflächen und } \\
\text { unvollständige } \\
\text { Zementregeneration } \\
\text { - in einigen Fällen leichte } \\
\text { Entzündungszeichen und } \\
\text { Ankylose }\end{array}$ & $\begin{array}{l}\text { - moderate oder starke } \\
\text { entzündliche Prozesse } \\
\text { mit epithelialer } \\
\text { Proliferation von } \\
\text { Granulationsgewebe } \\
\text { - vereinzelte Zysten- } \\
\text { rezidive } \\
\text { - häufig Anzeichen für } \\
\text { Wurzelresorptionen }\end{array}$ \\
\hline $\begin{array}{l}\text { Radiologischer } \\
\text { Befund }\end{array}$ & $\begin{array}{l}\text { - durchgehender } \\
\text { Parodontalspalt mit } \\
\text { Lamina dura } \\
\text { - keine periapikale } \\
\text { Veränderung }\end{array}$ & $\begin{array}{l}\text { - durchgehender } \\
\text { Parodontalspalt ohne } \\
\text { Verbindung zu persistie- } \\
\text { render periapikaler } \\
\text { Aufhellung }\end{array}$ & $\begin{array}{l}\text { - persistierende } \\
\text { periapikale Aufhellung } \\
\text { mit direktem Übergang } \\
\text { zum Parodontalspalt }\end{array}$ \\
\hline
\end{tabular}

\subsubsection{Defektheilung}

Unter ungünstigen Bedingungen kann der Heilungsprozess nicht im Sinne einer knöchernen Überbrückung erfolgen. Stattdessen bildet sich im Zentrum des Defekts fibröses Bindegewebe. Man nennt diesen Zustand auch skelettale Nonunion. Ein critical size defect (CSD) definiert den kleinstmöglichen intraossären Defekt in einem bestimmten Knochen einer 
bestimmten Spezies, der in der Lebenszeit nicht durch spontane Knochenheilung ausheilt. Ein solcher Defekt stellt eine fehlgeschlagene Osteogenese dar, bei der der physiologische Reparaturmechanismus an einen Endpunkt gelangt. Folgende zwei Faktoren können bei steigender Größe zu einer solchen Defektheilung führen:

- Unter dem Weichteildruck fällt das Periost ein und bildet somit eine „Fibroblastenbarriere“, die ein weiteres Knochenwachstum verhindert.

- Ab einer gewissen Größe schlägt die Organisation des Blutgerinnsels fehl, der Defekt kann in Folge nicht komplett vaskularisiert und anschließend knöchern durchbaut werden (Schmitz und Hollinger 1986).

Dabei kann eine Verknappung bestimmter Gewebefaktoren wie bone morphogenetic protein (BMP) und Osteogenin im Defektinneren dazu führen, dass es im Defekt in geringerem Maße zur Proliferation von Osteoblasten kommt. Solche in Voruntersuchungen ermittelten CSDs stellen ein probates Mittel zum Erproben der Wirksamkeit von Defektfüllungsmaterialien und Methoden dar (Hollinger und Kleinschmidt 1990).

\subsubsection{Osteokonduktion}

Unter Osteokonduktion versteht man die Fähigkeit von Knochengewebe, einen implantierten Platzhalter bestimmter Struktur und Beschaffenheit vom Lagergewebe aus zu ersetzen. Schon 1893 beschrieb Barth bei Replantation von Knochenscheiben nach Trepanation ein Einwachsen von neuen Knochentrabekeln in Bereiche des alten nekrotischen Knochens. Dabei lagern sich die neuen Knochentrabekel direkt an die alten an, welche als Leitschiene für die Neubildung dienen. Nach und nach wird der nekrotische Knochen durch neuen ersetzt. Da sich diese Beobachtungen auch bei mazeriertem Knochengewebe feststellen ließ, formulierte er die These des „schleichenden Ersatzes“ (Barth 1893). Axhausen sah in diesem Prozess nur einen von mehreren Mechanismen der Einheilung von Knochentransplantaten, der nur bei ossifikationsfähigem Transplantatbett eine Rolle spielt (Axhausen 1908). Zur Beurteilung der Fähigkeit des Transplantatbettes einen „schleichenden Ersatz“ zu realisieren, teilte Lexer das Empfängergewebe in ersatzstarkes, ersatzschwaches und ersatzunfähiges Lagergewebe ein (Lexer 1914). Ein vergleichbarer Prozess findet bei der Implantation von porösen Strukturen in knöchernes Gewebe statt. Eine Untersuchung zum Einwachsverhalten von Weichgewebe und knöchernen Strukturen in Keramikblöcken zeigte eine bessere zelluläre Besiedelung bei porösen Strukturen als bei glatten Oberflächen gleichen Materials (Hulbert et al. 1972). Bei Tierversuchen konnte gezeigt werden, dass bei intaktem Knochenmark des Transplantatbettes, ein Einwachsen von Knochengewebe in die porösen Strukturen von Keramiken stattfindet (Uchida et al. 1984). Die Größe der Poren spielt in diesem Prozess eine wichtige Rolle, damit es nach der ersten Besiedelung und dem Einwachsen von Blutgefäßen und Bindegewebe auch zu einer Knochenbildung kommt. Ab einer Porengröße über $42 \mu \mathrm{m}$ findet ein rasches Einwachsen von Bindegewebe und Blut- 
gefäßen statt, welches die Voraussetzung für anschließende Knochenbildung darstellt (Hulbert et al. 1972). Über die minimale Porengröße, die ein Einwachsen von Knochengewebe erlaubt, finden sich in der Literatur unterschiedliche Angaben zwischen 50 und $100 \mu \mathrm{m}$. Studien die das Einwachsen von Knochengewebe in poröse Strukturen untersucht haben sind in Tabelle 2 aufgeführt. Neuere Forschungen bestätigen diese Daten, weisen aber darauf hin, dass eine Porengröße $>300 \mu \mathrm{m}$ zu einer höheren Oxygenierung und dadurch zu einer höheren Knochenbildung führt (Karageorgiou und Kaplan 2005).

Tabelle 2: Studien zum Einwachsverhalten von Knochen in poröse Strukturen

\begin{tabular}{|l|l|l|}
\hline Studie & Untersuchtes Material & $\begin{array}{l}\text { Ergebnisse zur } \\
\text { Porengröße }\end{array}$ \\
\hline Hulbert et al. 1970 & $\begin{array}{l}\text { poröse } \mathrm{AlO}_{2}-\mathrm{CaO}_{2-} \\
\text { Keramikblöcke }\end{array}$ & $\begin{array}{l}\text { Einwachsen von Knochen } \\
\text { ab } 100 \mu \mathrm{m} \\
\text { Osteonbildung ab } 150 \mu \mathrm{m}\end{array}$ \\
\hline Albrektsson und & $\begin{array}{l}\text { Spalt in intravitaler } \\
\text { Mikroskopieaparatur }\end{array}$ & $\begin{array}{l}\text { Einwachsen von Knochen } \\
\text { unterbleibt bei Spalten } \\
\leq 70 \mu \mathrm{m}\end{array}$ \\
\hline Bobyn et al. 1980 & $\begin{array}{l}\text { pulverbeschichtete poröse } \\
\text { Metalloberflächen von }\end{array}$ & $\begin{array}{l}\text { optimaler Knochenverbund } \\
\text { bei Porengrößen zwischen } \\
50 \text { und } 400 \mu \mathrm{m}\end{array}$ \\
\hline Nade et al. 1983 & $\begin{array}{l}\text { Co-Legierungen } \\
\text { poröse Al2O } 3^{-}, \text {CaO-Al }{ }_{2} \mathrm{O}_{3}-\end{array}$ & $\begin{array}{l}\text { Einwachsen von Knochen } \\
\text { Calziumphosphatkeramiken } 100 \mu \mathrm{m}\end{array}$ \\
\hline
\end{tabular}

Auch die Verbindung zwischen den Poren spielt eine Rolle, inwieweit ein Material von Zellen, Gefäßen und Knochen durchbaut werden kann. Poröse keramische Transplantate unterschiedlicher geometrischer Form mit interkonnektierenden Poren konnten ab einem Verbindungsdurchmesser von $20 \mu \mathrm{m}$ von Osteoblasten besiedelt und ab $50 \mu \mathrm{m}$ ein Einwachsen von Knochengewebe beobachtet werden (Lu et al. 1999). Granuläre Transplantate ohne entsprechende Verbindungen wurden weniger schnell besiedelt oder gar nicht (van Eeden und Ripamonti 1994).

\subsubsection{Osteoinduktion}

Unter Osteoinduktion versteht man den stimulierenden Effekt eines Stoffes auf die Differenzierung knochenbildender Zellen im Gewebe. Die Induktion ist definiert als die Differenzierung einer neuen Zellform, ausgelöst durch die Interaktion induzierender Zellen und Empfängerzellen. Durch dieses Zusammenspiel der beiden Zellgruppen können höher differenzierte Gewebe entstehen (Jacobson 1966). Dieses Prinzip wurde auch auf die Knochenbildung angewandt und die Existenz einer Substanz in der extrazellulären Matrix von Knochen, 
Knorpel und Dentin postuliert, die mesenchymale Stammzellen zur Differenzierung zu Osteoblasten anregt (Urist et al. 1967). Durch langsame Demineralisierung der dekalzifizierten interzellulären Knochenmatrix konnte diese Substanz freigesetzt und als BMP identifiziert werden (Urist und Strates 1971). Bei Implantation von BMP kann die Bildung von neuem Knochen sowohl als Homeoinduktion in bestehendem Knochengewebe als auch in anderen mesodermalen Geweben, im Sinne einer Autoinduktion beobachtet (Gruber et al. 2009). Inzwischen sind 20 verschiedene BMPs bekannt, die der TGF- $\beta$ Superfamilie zugeordnet werden (McCormack und O'Dea 2013). Neben ihrem stimulierenden Effekt auf die Zellproliferation bei der Knochenregeneration spielen die BMPs auch in der Embryogenese eine wichtige Rolle in der Bildung vieler Organsysteme. Durch gentechnische Verfahren ist es möglich, humane BMPs zu synthetisieren und mit synthetischen Knochenersatzmaterialien zu kombinieren (Kübler 1997, Sailer und Weber 2000). Osteoinduktion ist ein Prozess, der physiologisch bei Heilungsprozessen abläuft und therapeutisch durch Knochentransplantate ausgelöst werden kann (Albrektsson und Johansson 2001).

\subsection{Knochentransplantate und Knochenersatzmaterialien}

Knochentransplantate und der Einsatz von Knochenersatzmaterialien sollen die Heilung von Knochendefekten in positiver Weise beeinflussen und Defektheilung oder skelettale Nonunion verhindern. Das diamond concept von Giannouidis et al. (2007) bringt die vier zu beeinflussenden Größen in Zusammenhang:

- osteogene Zellen, wie Osteoblasten und mesenchymalen Stammzellen, die aus dem anliegenden Knochenmark und eröffneten Blutgefäßen in den Defekt und das sich bildende Blutgerinnsel einwandern oder sich in Knochentransplantaten befinden, sowie ihre Überlebenswahrscheinlichkeit vor Ort

- Gewebefaktoren, wie BMP, Interleukine und andere Wachstumsfaktoren, die sich in der extrazellulären Matrix des Knochens sowie im Blutgerinnsel befinden, oder künstlich im Defekt angereichert werden können

- osteokonduktive Leitschienen die das Einwachsen von Blutgefäßen und Knochentrabekeln fördern

- mechanische Stabilität, die vor allem die Umwandlung von Granulationsgewebe zu Geflechtknochen und im weiteren Verlauf zu lamellären Knochen beeinflusst

Knochentransplantate, Knochenersatzmaterialien und Operationstechniken sollten diese vier Eckpfeiler berücksichtigen und im Optimalfall in positiver Art und Weise beeinflussen, um eine sichere, schnelle und mechanisch stabile Knochenneubildung zu ermöglichen (Giannoudis et al. 2007). 


\subsubsection{Indikationen}

Indikationen für den Einsatz von Knochentransplantaten und Knochenersatzmaterialien in der Mund-, Kiefer-, Gesichts- und Oralchirurgie ergeben sich häufig erst aus der Planung des weiteren Behandlungsablaufes. Ist nach Zahnverlust eine anschließende oder einzeitige Implantation geplant, ist diese aufgrund von Knochenverlust und Atrophie häufig nur in Kombination mit vorhergehendem oder gleichzeitigem Einsatz von augmentativen Maßnahmen möglich (Smeets und Kolk 2011). Für Augmentationsmaßnahmen im Zusammenhang mit dentalen Implantationen wird Folgendes empfohlen:

- bei stark atrophiertem Unterkiefer mit einer Höhe von 6-12 mm ist der Einsatz kurzer Implantate aufgrund der besseren Implantatüberlebensrate, deutlich verringerter Kosten, postoperativer Komplikationen, operativem Aufwand, weniger Schmerz bei kürzerer Behandlungszeit vorzuziehen.

- Knochenersatzmaterialien sind im Hinblick auf die Ergebnisse bei Sinuslifts als genauso effizient anzusehen wie autologer Knochen.

- bone-split- und guided-bone-regeneration-Techniken können zur lateralen Augmentation von atrophischen Kieferkämmen genutzt werden. Die Komplikationen sind vergleichsweise häufig und können zu Implantatverlust führen.

Die Autoren beklagen allerdings die häufig mangelnde Qualität der eingeschlossenen Studien und betonen, dass für ein hohes Maß an Evidenz weitere kontrollierte Studien mit größeren Fallzahlen wünschenswert wären (Esposito et al. 2006). Neben den augmentativen Maßnahmen sind auch Maßnahmen der Defektvermeidung eine mögliche Indikation für den Einsatz von Knochentransplantaten und Knochenersatzmaterialien. Unter dem Begriff socket preservation werden Maßnahmen, welche die physiologische Knochenresorption post extraktionem reduzieren, oder durch die Extraktion entstandene Knochendefekte decken sollen, zusammengefasst. Dabei werden resorbierbare Membranen, Knochenersatzmaterialien oder beides in Kombination verwendet (Hammerle et al. 2012). Die Resorption nach Zahnextraktion kann durch diese Maßnahmen nicht komplett verhindert, aber signifikant reduziert werden (Horvath et al. 2013, ten Heggeler et al. 2011, Vittorini Orgeas et al. 2013). Primärer Wundverschluss mit oder ohne Membrantechniken führt zu geringerer Resorption als der alleinige Einsatz von autologem Knochen oder Knochenersatzmaterialien (Hammerle et al. 2012, Horvath et al. 2013, Vittorini Orgeas et al. 2013). Bei socket preservation verwendete Knochenersatzmaterialien sollten resorbierbar sein, um ein ideales Implantatbett nach Abheilen des Defektes darzustellen aber solange ihre Platzhalterfunktion ausüben können bis sich neuer Knochen in der Alveole gebildet hat (Hammerle et al. 2012). Die verfügbare Literatur und die große Heterogenität der verwendeten Techniken lassen bisher keine klaren Schlüsse über den Benefit und überlegene Techniken zu (Horvath et al. 2013, ten Heggeler et al. 2011). 
Um die Bildung von fibrösem Narbengewebe nach Wurzelspitzenresektionen zu vermeiden wird bei ausgedehnten Defekten von einigen Autoren der Einsatz von Membranen und Knochenersatzmaterialien empfohlen. Bei der Heilung von Knochendefekten nach Wurzelspitzenresektion und Zystektomie von großen radikulären Zysten zeigte sich anhand von radiologischen Untersuchungen, dass Defekte, die nach Zystektomie mit Membrantechniken verschlossen wurden, gegenüber einfachem primärem Wundverschluss besser abschnitten hinsichtlich Geschwindigkeit der Knochenbildung und Qualität der gebildeten Gewebe (Pecora et al. 1995). Bei der Anwendung von Calciumphosphatzement zur postoperativen Auffüllung von Zystektomiedefekten mit einer Ausdehnung von der vestibulären bis zur oralen Kortikalis zeigte sich nach zwölf Monaten Beobachtungszeit signifikant häufiger komplette Knochenheilung gegenüber der Kontrollgruppe mit konservativem Vorgehen (Pecora et al. 2001).

\subsubsection{Anforderungen}

Verschiedene Anforderungen werden an Knochentransplantate und Knochenersatzmaterialien gestellt, um einen erfolgreichen, sicheren und wirtschaftlich sinnvollen Einsatz zu ermöglichen. Verfügbarkeit, Biokompatibilität, Biodegradation, Sterilität und mechanische Eigenschaften stellen wichtige Faktoren für die Bewertung von Knochentransplantaten dar (Günther et al. 1998).

\subsubsection{Verfügbarkeit}

Komplikationsfreie Gewinnung, kostengünstige Aufbereitung beziehungsweise Herstellung, kommerzieller Vertrieb, sowie langfristige und einfache Lagerfähigkeit sind Faktoren, die die Verfügbarkeit von Implantationsmaterialien beeinflussen und die Kosten für Augmentationsmaßnahmen bestimmen. Diese Faktoren sind hinsichtlich problemloser Lagerung bei geringen Kosten zu optimieren (Günther et al. 1998).

\subsubsection{Biokompatibilität}

Da Knochentransplantate in direktem Kontakt zum lokalen, ortsständigen Knochen, und damit in den meisten Fällen auch zum Blutkreislauf stehen, sind höchste Anforderungen an die Biokompatiblität zu stellen. Zytotoxische, antigene und kanzerogene Effekte auf das umliegende Gewebe und den Gesamtorganismus müssen ausgeschlossen werden (Günther et al. 1998).

\subsubsection{Biodegradation}

Die Resorption des Materials sollte im selben Maße verlaufen, wie das Material von neuem Knochen durchbaut wird, um während dieses Prozesses weiterhin eine „optmiale Stabilität gegenüber dem bedeckenden Weichgewebe" aufweisen zu können (Gruber et al. 2008) und es nicht zur Ausbildung von „bindegewebigen, biomechanisch minderwertigen Strukturen“ kommt (Smeets und Kolk 2011). Weiterhin ist eine vollständige Resorption anzustreben, da 
verbleibendes Material zu einer dauerhaften biomechanischen Schwächung des Knochens führt (Kübler 1997). Im Defekt verbleibendes Knochenersatzmaterial kann dem physiologischen bone remodeling im Wege stehen und so die Ausbildung einer biomechanisch optimalen Spongiosastruktur stören (Günther et al. 1998).

\subsubsection{Sterilität}

Bei der Implantation von Fremdmaterial in den menschlichen Knochen kann es prinzipiell auch zu einer Übertragung von Krankheitserregern kommen. Dabei müssen zwei Infektionswege generell unterschieden werden. Einerseits besteht die Möglichkeit, dass nach Verunreinigung der Transplantate lokalen Infektionen auftreten, die zu Wundheilungsstörungen, ausbleibender Verknöcherung des Transplantates oder Osteomyelitis führen können (Khardori und Yassien 1995). Andererseits können bei Transplantation von einem auf ein anderes Individuum schwere chronische Infektionen vom Spender auf den Transplantatempfänger übertragen werden (Gürtler 1997, Kim et al. 2013, Rübsamen-Waigmann 1997). Für Knochentransplantate ist eine Herstellung und Applikationsmöglichkeit zu fordern, die beide Infektionsrisiken ausschließt (Günther et al. 1998).

\subsubsection{Mechanische Eigenschaften}

Relevante mechanische Eigenschaften sind unter anderem Konsistenz, Druckfestigkeit und Porösität. Je nach Indikation können die Anforderung an Konsistenz und Druckfestigkeit stark variieren. Sie sollten in Bezug auf das jeweilige Einsatzgebiet zu eine hohen Primärstabilität unter möglichst dichtem Kontakt von Implantatlager und Implantat erreichen. Mikrobewegungen oder zu große Hohlräume können zum Ausbleiben der Osteosynthese und Bildung von Bindegewebe führen (Röser et al. 1997). In Abhängigkeit der Indikation kann ein großer Weichgewebedruck auf das Material wirken. Die Druckfestigkeit sollte demnach so hoch sein, dass bis zum Ersatz des Materials durch neuen Knochen eine optimale Formstabilität gegeben ist (Gruber et al. 2008).

\subsubsection{Klassifizierung}

Knochentransplantate und Knochenersatzmaterialien werden nach ihrer Herkunft generell in vier Gruppen aufgeteilt:

- Autogene Knochentransplantate

- Allogene Knochentransplantate und Knochenersatzmaterialien

- Xenogene Knochenersatzmaterialien

- Synthetische oder alloplastische Knochenersatzmaterialien

Autogene, allogene und xenogene Transplantate werden auch als biologisch gewonnene Knochentransplantate zusammengefasst. Autogene Transplantate werden von einem Individuum auf dasselbe Individuum, allogene von einem Individuum auf ein anderes Individuum derselben Spezies und xenogene von einem Individuum auf ein Individuum einer 
anderen Spezies übertragen. Synthetische Materialien werden nach der Art des verwendeten Materials unterteilt. Kompositmaterialen stellen Kombinationen aus synthetisch hergestellten Trägerstoffen und biologisch gewonnenen Zellen oder Wachstumsfaktoren dar (Sailer und Weber 2000, Smeets und Kolk 2011).

\subsubsection{Autogene Knochentransplantate}

Autogene Knochentransplantate stellen immer noch den Goldstandard bei der Therapie von Knochendefekten dar. Schon 2005 wurden in der BRD jährlich ca. 71.000 autologe Knochentransplantationen durchgeführt (Jäger et al. 2005). Prinzipiell unterscheidet man zwischen gestielten Transplantaten, die mitsamt versorgenden Gefäßen verpflanzt und mikrochirurgisch an ortsständige Gefäße angeschlossen werden, und freien Transplantaten, die ohne Gefäßversorgung verpflanzt werden. Der Heilungsprozess nach autologen Knochentransplantaten ist seit Ende des 19. Jahrhunderts Objekt intensiver Forschung. Die osteokonduktive Wirkung von autologen Knochentransplantaten führt auch nach komplettem Absterben von Osteozyten, Knochenmarkszellen und Periost des Transplantates zu einem schleichenden Ersatz, vom Transplantatbett ausgehend (Barth 1893). Eine große Bedeutung für diesen Prozess stellt ersatzstarker Lagerknochens dar. Doch auch von intaktem Periost des Lagergewebes kann der Heilungsprozess des Transplantates ausgehen (Axhausen 1908). Wird Knochen innerhalb eines Individuums in anderes Knochengewebe Implantiert, können zwei voneinander grundlegend verschiedene Reparaturmechanismen stattfinden. In den meisten Fällen erfolgt eine Revaskularisierung durch neu gebildete Blutgefäße aus dem Transplantatbett. Die ersten Kapillaren mit einem Durchmesser von 6 - $7 \mu$ m wachsen mit einer Geschwindigkeit von etwa $0,5 \mathrm{~mm}$ pro Tag in die bindegewebigen Räume zwischen den Knochenbälkchen ein. Nach abgeschlossener Revaskularisierung der Markräume, mit Gefäßen zwischen 6 und $40 \mu \mathrm{m}$, erfolgt die Resorption von altem und Bildung von neuem Knochen (remodeling) (Albrektsson und Albrektsson 1978). Seltener kann es zu einer Rezirkulation in den bereits vorhandenen Blutgefäßen kommen. Auf Rezirkulation folgt ein beschleunigter remodeling-Prozess als bei Revaskulaisierung des Transplantats (Albrektsson 1980a). Die Geschwindigkeit der Revaskularisierung, die Überlebensrate von Osteozyten und die Geschwindigkeit der Knochenneubildung steigt, wenn das chirurgischen Trauma, das auf die Transplantate einwirkt, minimiert wird (Albrektsson 1980b). Zur Wiederherstellung von pseudarthrotisch verheilten Knochenfrakturen wurden seit Anfang des 20. Jahrhunderts autologe Knochentransplantate verwandt. Eine gründliche Fixation zwischen Transplantat und Transplantatbett ist dabei ein wichtiger Faktor für stabile Osteogenese (Albee 1921). Mit aufkommender Frakturfixierung mit Osteosyntheseplatten und Schraubensystemen (Stimson 1947) setzte sich auch die Fixation von autogenen Knochentransplantaten mit Titannetzen und Miniplattensystemen durch (Hidalgo 1989, Margolis et al. 1976). Autogene oder autologe Knochentransplantate müssen intraoperativ oder in einer 
gesonderten Operation gewonnen werden. Hierfür gibt es je nach Indikation, benötigter Menge und Form sowie Einsatzort prinzipiell unterschiedliche Möglichkeiten. Für größere formstabile kortikospongiöse freie ungestielte Transplantate hat sich das Beckenkammtransplantat vom anterioren oder posterioren Beckenkamm bewährt. Allerdings ist der Eingriff mit einem erhöhten Komplikationsrisiko behaftet. Mögliche Komplikationen sind persistierende Schmerzen, Hämatome, oberflächliche und tiefe Infektionen, Verletzung von Nerven und Gefäßen, Sensibilitätsstörungen, peritoneale Perforation, Instabilität im Iliosakralgelenk, Abrissfrakturen der spina Iliaca anterior superior, Wachstumsstörungen sowie die Herniation von Abdominalorganen durch den iliakalen Knochendefekt (Jäger et al. 2005). Die Komplikationsraten schwanken in der Literatur stark. Persistierende Schmerzen werden mit 10\% - 25\% angegeben (Goulet et al. 1997, Jäger et al. 2005). Nervenläsionen reichen von reversiblen Verletzungen oberflächlicher Hautnerven bis zu motorischen Nerven mit dauerhaftem Ausfall und werden mit bis zu 20\% angegeben. Frakturen des Beckens passieren in $<5 \%-6 \%$ der Fälle (Jäger et al. 2005). Für die intraorale Gewinnung von kleineren Mengen autologer Knochenspäne stehen viele Hilfsmittel zur Verfügung. Die Knochenspäne können entweder von der kortikalen Oberfläche durch schabende Bewegungen oder mithilfe von Trepanbohrern gewonnen werden. Eine andere Methode nutzt unterschiedliche Filter-systeme zum Auffangen von Knochenspänen bei der Implantatbettpräparation. Diese Knochenspäne sind jedoch trotz Einhaltung strenger Hygienevorschriften häufig bakteriell kontaminiert. Unter antibiotischer Abschirmung kommt es jedoch nicht zu Wundinfektionen oder Implantatverlust (Takamoto et al. 2013, Young et al. 2001).

\subsubsection{Allogene Knochentransplantate und Knochenersatzmaterialien}

Unter allogenen Knochentransplantaten versteht man die Verwendung von Knochensplittern, -pulver oder -blöcken von einem anderen Individuum derselben Spezies. Dabei wird im Gegensatz zu Organtransplantationen auf eine Verpflanzung von frischem, lebendigem Knochen aufgrund der zu erwarteten Abstoßungsreaktion verzichtet. Stattdessen wird Spendergewebe in Knochenbanken gesammelt, konserviert und aufbereitet (Kübler 1997). Als Konservierungsmethode haben sich hauptsächlich Kryokonservierung und Gefriertrocknung durchgesetzt, da hierbei die Struktur weitestgehend erhalten bleibt (Kübler 1997). Als Weiterentwicklung der allogenen Transplantate kann autolysierter antigenextrahierter allogener Knochen (AAA-Knochen) betrachtet werden (Sailer und Weber 2000). Durch eine Kette biochemischer Verfahren wird unter Erhalt der primären Struktur eine Autolyse der zellulären Bestandteile, DNA und RNA, sowie die Extraktion der potentiell antigenen Substanzen erreicht. Dabei sollen die osteoinduktiv wirkenden BMPs im Material erhalten bleiben. Die so entstandene biokompatible und resorbierbare Substanz kann je nach Indikation in verschiedenen Formen zur Augmentation und Defektfüllung verwendet werden 
(Kübler 1997). Inzwischen existieren viele verschiedene Aufbereitungsformen der osteoinduktiven Faktoren der BMP-Familie, wie demineralisierte Knochenmatrix (DBM) oder gentechnisch synthetisierte Wachstumsfaktoren auf Trägermaterialien, die zum Einsatz kommen können. Die schnelle Regenerationszeit, die diese Materialien ermöglichen, kann bei insuffizienter Vaskularisierung zu nicht ausreichender mechanischer Knochenqualität in der Defektregion führen (Smeets und Kolk 2011). Bei der Transplantation von einem auf ein anderes Individuum kann es prinzipiell auch zur Übertragung pathogener Krankheitserreger kommen. Die folgenden Erreger sind aufgrund der von ihnen ausgelösten schweren chronischen Infektionskrankheiten besonders relevant (Gürtler 1997):

\section{Viren}

- Hepatitis-B-Virus (HBV)

- Hepatitis-C-Virus (HCV)

- Humanes Immundefizienz-Virus (HIV)

- Parvovirus B-19

- Zytomegalievirus bei immunsupprimierten Patienten

- Humanes T-Zell-Leukämie-Virus (HTLV)

\section{Prionen}

- Creutzfeldt-Jakob-Erreger

\section{Bakterien}

- Mykobakterien

- Treponemen

- Borrelien

Das Risiko für eine Übertragung dieser Krankheiten kann durch Spenderselektierung und inaktivierende Maßnahmen verringert werden. In Deutschland müssen sich Knochenbanken an die von der Bundesärztekammer herausgegebenen Richtlinien zum Führen einer Knochenbank und die EU-Richtlinien 2004/23/EG und 2006/17/EG halten. Diese enthalten unter anderem Vorgaben zur anamnestischen Selektion der möglichen Spender hinsichtlich spezieller Risikogruppen und schreiben bestimmte Laboruntersuchungen der Leberenzyme, Antigen- und Antikörperserologie des Spenders vor (BÄK 2001, EU 2004, EU 2006). Trotz dieser Maßnahmen ist aufgrund des „diagnostischen Fensters“ und der Möglichkeit von immunologischen nonresponder eine Infektion durch allogenen Knochen nicht auszuschlieBen, sodass zusätzliche Inaktivierungsmaßnahmen empfohlen werden (RübsamenWaigmann 1997). Inaktivierende Maßnahmen wie $\mathrm{Y}$-Bestrahlung oder Hitzebehandlung erreichen eine Inaktivierung von HIV und HCV und eine Verminderung von HBV um 99,9\% (Gürtler 1997). Diese führen allerdings zu einer Verminderung oder kompletten Inaktivierung der osteoinduktiven Eigenschaften von allogenen Materialien (Herr et al. 1997, Kübler 1997). Die Häufigkeit von lokalen Infektionen nach Eingliederung allogener Knochentransplantate 
ist gut untersucht und wird zwischen $0 \%$ und 12,2\% angegeben, wobei eine ursächliche Beteiligung des Transplantates nur in den seltensten Fällen nachzuweisen ist (Kappe et al. 2010).

\subsubsection{Xenogene Materialen}

Xenogen bezeichnet die Herkunft eines Biomaterials von einer anderen Spezies. Hinsichtlich Knochenersatzmaterialien sind größtenteils poröse Hydroxilapatitverbindungen (Smeets und Kolk 2011), aber auch Kollagene (Sailer und Weber 2000) und Wachstumsfaktoren erhältlich (Kübler 1997). Als Quellen kommen vor allem bovine aber auch porcine und koralline Präparate in Frage, deren Derivate nach unterschiedlichen Aufbereitungsprozessen erhältlich sind (Kübler 1997). Vorteile von xenogenen Materialien sind die unbegrenzte Verfügbarkeit und teilweise sehr gut dokumentierte klinische Anwendung (Kübler 1997, Smeets und Kolk 2011). Nachteile sind mögliche immunologische Reaktionen auf speziesfremde Proteine (Sailer und Weber 2000) sowie mögliche Übertragung von Infektionserregern wie Viren und Prionen (Kübler 1997). Durch spezielle Auswahl der tierischen Quelle und biotechnologische Aufbereitung kann die Infektionsgefahr verringert werden, was eine sehr niedrige Infektionsgefahr nach sich zieht (Sogal und Tofe 1999). Allerdings können durch diesen Aufbereitungsprozess die Osteoinduktivität und Resorptionsfähigkeit negativ beeinflusst werden, sodass bei den Materialien vor allem osteokonduktive Eigenschaften verbleiben (Smeets und Kolk 2011).

\subsubsection{Synthetische Knochenersatzmaterialien}

Synthetische Knochenersatzmaterialien haben hinsichtlich der Anforderungen, die an Knochentransplantate gestellt werden, einige Vor- und Nachteile, die stark abhängig vom verwandten Material sind. Als generelle Vorteile sind zu nennen: Unbegrenzte Verfügbarkeit bei einfacher Lagerung, die Möglichkeit einer sterilen Herstellung, Verpackung, Distribution und Applikation, sowie die Möglichkeit für verschiedene Indikationen verschiedene Materialien zu benutzen, die den jeweiligen Anforderungen am ehesten entsprechen. Generelle Nachteile sind fehlende osteoinduktive Wirkung und stark schwankende Bioaktivität. Als Ziele für die Entwicklung von synthetischen Knochenersatzmaterialien wird die Verbesserung der Knochenheilung gegenüber autogenen Knochentransplantaten angestrebt in Bezug auf:

- Menge des neugebildeten Knochens

- Qualität des neugebildeten Knochens

- kurze Zeiteinheit, in der die Knochenneubildung und -heilung stattfindet

- mechanische Qualität, hin zu einem stabileren Implantat (Rueger 1998) 


\subsubsection{Hydroxylapatit}

Hydroxylapatit bildet mit etwa $50 \%$ des Trockengewichts einen großen Teil des menschlichen Knochens (Schiebler 2005). Es kann aus korallinen und tierischen Quellen gewonnen sowie durch Präzipitationsverfahren vollsynthetisch hergestellt werden und ist demnach entweder den xenogenen oder den synthetischen Knochenersatzmaterialien zuzuordnen. Je nach Weiterverarbeitung unterscheidet man Apatitkeramiken, Calziumphosphatzemente oder pastöse Hydroxylapatitsuspensionen (Schnettler et al. 2004). Apatitkeramiken werden thermisch gesintert und liegen in makroporösen Blocks vor. Der Sinterungsprozess bei ca. $1200{ }^{\circ} \mathrm{C}$ resultiert in einer vollständigen Entfernung aller organischen Bestandteile und damit auch einer Inaktivierung der osteoinduktiven Bestandteile. Apatitkeramiken zeigen eine hohe Biokompatibilität, bieten eine osteokonduktiv wirkende Leitstruktur und werden vom Defektrand ausgehend knöchern durchbaut. Allerdings kommt es in den meisten Fällen nur zu einem oberflächlichen Einwachsen von Lagerknochen (Battmann et al. 1997, Sailer und Weber 2000, Schnettler und Dingeldein 1997, Tröster und Liebendörfer 1997, Wilke et al. 1997). Sie gelten als bioinerte, nicht oder schlecht resorbierbare Materialien (Schnettler et al. 2004). Calziumphosphatzemente bestehen aus mikrokristallinen Hydroxylapatit, das nach Anmischen und Einbringen in den Defekt in einer Zementmatrix eingebettet vorliegt oder zu einem porösen Hydroxylapatit kristallisiert (Moore et al. 2001). Resorption und remodeling finden statt, verlaufen allerdings nur sehr langsam (über mehrere Jahre) (Schnettler et al. 2004). In Tierversuchen kam es teilweise zu starken Entzündungsreaktionen mit Bildung von bindegewebigen Trennschichten zwischen Knochen und Implantat (Moghadam et al. 2004). Beide Materialien konnten zwar in einigen Fällen mit klinisch zufriedenstellenden Ergebnissen eingesetzt werden, stellen aber kein ideales Knochenersatzmaterial dar. Das Verbleiben eines massiven Fremdkörpers im Knochen resultiert bei unvollständiger knöcherner Durchbauung in einer biomechnischen Schwächung (Kübler 1997, Sailer und Weber 2000).

\subsection{Ostim ${ }^{\circledR}$}

Ostim® wird vom Hersteller Heraeus Kulzer als vollsynthetisches nanokristallines phasenreines Hydroxylapatit in einer wasserhaltigen Paste beschrieben. Es liegt gebrauchsfertig in 1- und 2-ml-Fertigspritzen vor und kann direkt in den Knochendefekt appliziert werden. Es gehört somit zur Gruppe der synthetischen, alloplastischen Knochenersatzmaterialien (Rueger 1998, Sailer und Weber 2000).

\subsubsection{In-vitro-Untersuchungen}

Ostim® gehört zu den Calziumphosphat-basierten Knochenersatzmaterialien. Es liegt als Paste mit nanoskopischen Apatitpartikeln in wässriger Dispersion vor. Die thermogravimetrische Analyse der Zusammensetzung ergibt 40,4 Gewichtsprozent Wasser und 59,6 Gewichtsprozent phasenreines, karbonatfreies Hydroxylapatit. Die Kristallgröße liegt 
zwischen 19 und 35 nm (Tadic und Epelle 2004). Neben der geringen Kristallgröße wirkt sich auch die Art der Herstellung - durch kontinuierliche Präzipitation unter ständiger $\mathrm{pH}$ Wertkontrolle im Vergleich zur thermischen Behandlung von Hydroxylapatitkeramiken - positiv auf die Bioabbaubarkeit aus. Dies konnte unter Laborbedingungen, die der Osteoklastenresorption ähneln, gezeigt werden (Tadic et al. 2002). Die Dichte von Ostim®-Testzylindern liegt bei $1,29 \pm 0,09 \mathrm{mg} / \mathrm{mm}^{3}$. In der Mikro-CT zeigt sich eine poröse Struktur mit einem, im Vergleich zu anderen untersuchten Knochenersatzmaterialien, hohen Gesamtporenvolumen von 52,66 $\pm 10,14 \%$ und einer hohen Verbindungsdichte, Ausdruck für Verbindungen in trabekulären Strukturen, von 5,80 $\pm 0,84 / \mathrm{cm}^{3}$. Die Porengröße liegt zwischen 10 und $100 \mu \mathrm{m}$, wobei 95\% der Poren kleiner als $85 \mu \mathrm{m}$ sind. Die Autoren bewerteten die hohe Porosität und Verbindungsdichte als positiv, das Fehlen von Porenvolumen über $100 \mu \mathrm{m}$ allerdings als negativ für die Osteokonduktivität von Ostim® (van Lieshout et al. 2011). Die pastöse Konsistenz von Ostim $\AA$, welche eine gute Verarbeitbarkeit garantieren soll, hat eine geringe mechanische Stabilität und Kompressionsstärke zur Folge (Tadic und Epelle 2004, van Lieshout et al. 2011). In-vitro konnte ein proliferationssteigernder Effekt auf Zellen des parodontalen Ligamentes festgestellt werden (Kasaj et al. 2008b). Der hohe Wassergehalt wirkte sich in einer anderen in vitro Studie hingegen negativ auf die Zellüberlebensfähigkeit von Osteoblasten und myelomonozytären Zellen aus, die auf Knochenersatzmaterialien kultiviert wurden. Der hohe Wasseranteil von Ostim® führte im In vitro Modell zu einem Absinken des osmotischen Drucks und Entstehen von zytotoxischen Effekten (Herten et al. 2009).

\subsubsection{Untersuchungen am Tiermodell}

Zytotoxische Effekte konnten am Tiermodell nicht beobachtet werden. Weder bei intravitaler Floureszensmikroskopie (Laschke et al. 2007) noch bei histologischen Untersuchungen nach Implantation von Ostim® in Knochendefekte konnten Entzündungszeichen oder fibröse Trennschichten zwischen Ostim ${ }^{\circledR}$ und neu gebildetem Knochen beobachtet werden (Carmagnola et al. 2008, Thorwarth et al. 2005). Ostim® härtet im Vergleich zu Calziumphosphatzementen nach Implantation nicht aus, sondern zerfällt in verschieden große Agglomerate, die, ausgehend vom Implantatlager, rasch vaskularisiert werden (Kilian et al. 2008, Laschke et al. 2007, Spies et al. 2008). Dieser Zerfall des Ersatzstoffes in kleinere Granulae wird als essentieller Schritt für die Geweberegeneration angesehen, da hierdurch das Einwandern von Osteoblasten und somit die osteokonduktive Knochenneubildung begünstigt wird (Schnettler et al. 2004). Übereinstimmend mit dieser Hypothese zeigen die histologischen Nachuntersuchungen im Tiermodell osteokonduktive Knochenneubildung, die sich histomorphometrisch im Bereich von autologen Knochentransplantaten bewegt und auch bei CSD bis in das Defektzentrum vordringt (Carmagnola et al. 2008, Chris Arts et al. 2006, Spies et al. 2008, Thorwarth et al. 2005). Über die Resorption von Ostim® im 
Knochendefekt gibt es widersprüchliche Beobachtungen. Während Thorwart et al. nach Defektfüllung von CSD in der Kalotte des adulten Hausschweins eine vollständige Resorption der Ostim®-Implantate bereits nach sechs Monaten beobachteten (Thorwarth et al. 2005), zeigten sich in anderen Modellen, auch nach Standzeiten von bis zu zwölf Monaten, noch knöchern integrierte Ostim®-Partikel, die im engen Kontakt zu Knochentrabekeln und Knochenmarksgewebe standen, sodass in diesen Fällen von einer Verbundosteogenese gesprochen wird (Carmagnola et al. 2008, Chris Arts et al. 2006, Rothamel et al. 2008, Spies et al. 2008). Es wird vermutet, dass bei stabilen biomechanischen Verhältnissen keine weitere Resorption erfolgt. Weiterhin wird eine Optimierung der Materialzusammensetzung hin zu einer erhöhten Resorptionsrate gefordert (Spies et al. 2008). Die Bioaktivität und Resorbierbarkeit von Ostim ${ }^{\circledR}$ konnte im Tierversuch durch histologisch sichtbare Resorptionsprozesse am Ersatzstoff durch Osteoklasten beobachtet und nachgewiesen werden (Chris Arts et al. 2006, Spies et al. 2008). Als weitere Möglichkeit der Resorption wired der Abbau durch Makrophagen und Abtransport über lymphatische Gefäße diskutiert (Kilian et al. 2008). Die Zeit bis zur vollständigen Verknöcherung verschiedener CSDs lag zwischen sechs und zwölf Wochen (Spies et al. 2008, Thorwarth et al. 2005). Auch die spätere Implantation in aufgefüllte Knochendefekte wurde am Tiermodell untersucht. So fanden sich keine signifikanten Unterschiede zu autologem Knochentransplantat hinsichtlich der Osseointegration dentaler Implantate nach sechs Wochen (Carmagnola et al. 2008).

\subsubsection{Klinische Anwendungsgebiete}

Klinische Untersuchungen zu Ostim® finden sich aus den Bereichen der orthopädischen und zahnerhaltenden Chirurgie sowie vor allem der Mund-Kiefer-Gesichtschirurgie. Zu den dokumentierten Anwendungsgebieten zählen unter anderem die Defektfüllung nach Zystektomien großer Kieferzysten (Bezrukov et al. 1998, Gerlach und Niehues 2007), Defektüberbrückung nach Reposition und Fixierung von Frakturen des Fersenbeins sowie des distalen Radius (Huber et al. 2006), sowie die Behandlung von parodontalen und periimplantären Knocheneinbrüchen (Chitsazi et al. 2011, Kasaj et al. 2008a, Schwarz et al. 2006) und Augmentationen im Bereich der dentalen Implantation (Belouka und Strietzel 2016, Dottore et al. 2014, Smeets et al. 2008, Strietzel et al. 2007). Die Ergebnisse von klinischen und histologischen Untersuchungen, die an humanen Proben durchgeführt wurden, decken sich mit den Beobachtungen im Tiermodell hinsichtlich Entzündungsparametern, Osteokonduktivität und Resorptionsverhalten. Eine entzündungsfreie Osseointegration kleiner, granulär zerfallener Ostim®partikel in direktem Kontakt mit neu gebildetem Geflechtknochen konnte in mehreren Fällen beobachtet werden. Osteoidanlagerungen und der Nachweis von direkten Resorptionsprozessen am Ersatzstoff sprechen für ein aktives remodeling (Huber et al. 2006, Smeets et al. 2008). In Kontrollröntgenbildern nach Zystektomien großer Unterkieferzysten konnte nach drei bis zwölf Monaten, je nach Größe des Defektes, vollständige 
Regeneration (Gerlach und Niehues 2007) und eine verringerte Komplikationsrate gegenüber konservativem Vorgehen beobachtet werden (Bezrukov et al. 1998). Sowohl horizontale und laterale Augmentationen atrophischer Unterkiefer als auch Sinusbodenelevation wurden mit Zeitgleicher Implantation durchgeführt (Belouka und Strietzel 2016, Dottore et al. 2014, Smeets et al. 2008, Strietzel et al. 2007). Dabei zeigten lagernahe Bereiche bei größeren Augmentationen eine höhere Resorptionsrate als lagerferne Regionen (Strietzel et al. 2007). Knochenneubildung und Implantat-Überlebensraten in vertikal augmentierten Unterkiefern lagen im Bereich von Implantaten bei denen autologer Knochen verwendet wurde (Dottore et al. 2014). Bei der Behandlung und Defektauffüllung von parodontalen und periimplantären Knocheneinbrüchen ergaben sich signifikante Verbesserungen der Attachmentwerte (Chitsazi et al. 2011, Kasaj et al. 2008a, Schwarz et al. 2006), die im Fall von parodontalen Läsionen über denen der Kontrollgruppe mit konservativem Vorgehen lagen (Kasaj et al. 2008a). Die Auffüllung von Extraktionsalveolen im Sinne einer socket preservation führte in einer split-mouth-Studie zu einer signifikant schnelleren Epithelialisierung der Defekte und einer erhöhten Synthese von pro-osteogenen Faktoren (Canuto et al. 2013).

\subsection{Knochendichte und radiologische Bildanalyseverfahren}

Im Verlauf der knöchernen Heilung steigt die mineralische Dichte der Defektregion an, bis sie den physiologischen Wert des umgebenen Knochens wieder erreicht (Lane et al. 1984). Zur Beurteilung des Heilungsprozesses und der Knochendichte stehen prinzipiell histologische und radiologische Analyseverfahren zur Verfügung. Während die histomorphometrische Analyse von Knochengewebe den besten Überblick über Knochenstruktur, -dichte und -mineralisation bietet, kommen in der klinischen Praxis aufgrund der Invasivität primär radiologische Bildanalyseverfahren zum Einsatz. Es stehen verschiedene Verfahren zur Verfügung, die sich in Strahlenbelastung, apperativem Aufwand und Aussagekraft unterscheiden.

\subsubsection{Dual energy $x$-ray absorptiometry}

Die dual energy $x$-ray absorptiometry (DXA) ist ein Verfahren welches eine große Bedeutung in der Orthopädie zur Bestimmung der Knochendichte der Wirbelkörper bei der Diagnose von Osteoporose hat (Blake und Fogelman 2007). Im Craniomaxillären Bereich wurden Untersuchung zur Dichtemessung von Maxilla und Mandibula durchgeführt (Devlin et al. 1998). Im klinischen Altag spielt sie aufgrund der in der Regel nicht vorhandenen apparativen Ausstattung keine Rolle.

\subsubsection{Computertomographie und digitale Volumentomographie}

Die Computertomographie (CT) erlaubt das Erstellen von Schichtbildern aus einem radiologischen Datensatz und durch Analyseverfahren, wie quantitative Computertomographie, eine Berechnung der Knochendichte in Orthopädie (Cann und Genant 1980) sowie MundKiefer-Gesichtschirurgie und dentaler Implantologie (Norton und Gamble 2001). Als Maß- 
einheit für die Röntgenabsorption in CT-Datensätzen hat sich die Hounsfield-Einheit etabliert, die sich rechnerisch aus den jeweiligen CT-Werten und Referenzwerten für Wasser und Luft errechnen (Brooks 1977). Die digitale Volumentomographie (DVT) findet im Bereich der Mund-Kiefer-Gesichtschirurgie vermehrte Verwendung, da dreidimensionale Datensätze bei verminderter Strahlenbelastung gegenüber CT Untersuchungen erstellt werden können (Silva et al. 2008). Allerdings eignen sich die DVT-Datensätze nicht zur Messung der Mineraliendichte (Varshowsaz et al. 2016). Sowohl beim DVT als auch beim CT ist keine Beurteilung der Mikrostruktur des spongiösen Knochens möglich (Bilhan et al. 2012), neue Algorithmen sollen dies aber in Zukunft ermöglichen (Thomsen et al. 2016).

\subsubsection{Messung der relativen Knochendichte}

Digitale konventionelle Röntgenbilder sind heutzutage der Grundstein der radiologischen Diagnostik. Die Bilddaten der Röntgenbilder liegen im 8 Bit Graustufenmodus vor. Das bedeutet, dass jeder Bildpunkt (Pixel) einen Grauwert zwischen null und 255 annehmen kann, wobei 255 einem weißen und null einem schwarzen Pixel entspricht. In Bildformaten wie DICOM oder TIFF liegen die Pixeldaten in unkomprimierter Form vor. Dies ist von Bedeutung, da Studien gezeigt haben, dass durch die Kompression in das datenmäßig kleinere JPEG-Format der Kontrast der Röntgenbilder erhöht wird und sich signifikante Änderungen bei Messungen des mittleren Grauwertes ergeben (Yasar et al. 2012). Der mittlere Grauwert eines gesamten Röntgenbildes, oder eines Bereiches innerhalb des Bildes ergibt sich aus dem Mittelwert der addierten einzelnen Pixelwerte und stellt ein Maß für die Absorption von Röntgenstrahlung eines Körpers im gemessenen Bereich zwischen Strahlenquelle und Röntgensensor dar. Mittlere Grauwerte wurden in der Vergangenheit häufiger für die Verlaufskontrollen nach Kieferchirurgischen Operationen benutzt, stellen aber keinen absoluten Parameter dar, da sie unter anderem Abhängig von den Röntgenparametern wie Belichtungszeit und Strahlendosis sind. Daher ist ein stabiler Referenzparameter notwendig um Veränderungen zwischen zwei Röntgenbildern darstellen zu können (Chiapasco et al. 2000). Die „Messung der relativen Knochendichte“ von Ihan Hren und Miljavec (2008) beruht auf einer Messung des mittleren Grauwertes der postoperativen Defektregion und des umliegenden ortsständigen Knochens, der nicht durch angrenzende anatomische Strukturen überlagert wird. Aus beiden Messwerten wird ein Quotient gebildet:

$$
\text { Relative Knochendichte }=\frac{\text { mittlerer Grauwert des Defektes }}{\text { mittlerer Grauwert des ortsständigen Knochens }}
$$

Ein Wert von eins bedeutet, dass die untersuchte Region eine gleiche mittlere Strahlenabsorption aufweist wie der umliegende ortsständige Knochen. Diese wird unter anderem durch die Dicke des Knochens, die Dichte der spongiösen Knochenbälkchen, sowie das Vorhandensein kortikaler Knochenwände beeinflusst. Durch die Benennung des ortsständigen Knochens als Referenzparameter, der als optimales Ergebnis eines Heilungs- 
prozesses anzusehen ist, ermöglicht dieses Verfahren einen Vergleich verschiedener Röntgenbilder derselben Region, welche im zeitlichen Verlauf einer Behandlung angefertigt wurden. Durch Vergleichen des Dichtewertes der Verlaufskontrolle mit dem Wert des postoperativen Röntgenbildes können Rückschlüsse auf die Heilung der knöchernen Strukturen geschlossen werden. Durch die Bildung des Quotienten mit dem ortsständigen Knochen verringert sich die Fehlerquelle, die durch Benutzung unterschiedliche Röntgenbildparameter entsteht (Ihan Hren und Miljavec 2008). Die Messung des mittleren Grauwertes ist eine Funktion, die zahlreiche Computerprogramme anbieten. Im Bereich der biologischen und medizinischen Forschung hat sich unter anderem das kostenfreie Programm ImageJ (Wayne Rasband, National Institute of Health, USA) etabliert, welches neben der einfachen Grauwertmessung noch über viele weitere automatisierte Messfunktionen verfügt (Abràmoff et al. 2004, Schneider et al. 2012). 


\section{Zielsetzung und Fragestellung}

Augmentationen und Defektauffüllungen mit Knochenersatzmaterialien stellen ein Einbringen eines Fremdkörpers in den menschlichen Knochen dar, welches einer gründlichen postoperativen Überwachung und weiterer wissenschaftlicher Nachuntersuchung der Heilungsprozesse bedarf. Bislang gibt es kein praxistaugliches nichtinvasives Verfahren, dass dem Operateur erlaubt, die knöchernen Regenerationsprozesse zu beurteilen. Es wurden schon vereinzelt Erkenntnisse über die Heilung von Knochendefekten, die im Bereich der MundKiefer-Gesichtschirurgie mit Ostim® aufgefüllt wurden, publiziert. Bislang fehlen jedoch Untersuchungen zu verschiedenen Indikationsbereichen bei einem größeren Patientenkollektiv, die sich sowohl mit den knöchernen Heilungsprozessen als auch den postoperativen klinischen Verläufen befasst haben.

In der vorliegenden retrospektiven Studie gilt es zunächst zu prüfen, ob die relative Knochendichtemessung mittels ImageJ ein geeignetes Auswertungsverfahren für radiologische Untersuchungen darstellt. Hierfür muss zunächst ein standardisiertes Messprotokoll erarbeitet und dieses hinsichtlich der intra- und interindividuellen Variabilität evaluiert werden. Nach Evaluation des Messverfahrens soll es zur radiologischen Verlaufskontrolle nach Defektauffüllungen mit Ostim® im Zusammenhang mit oralchirurgischen Eingriffen eingesetzt werden, um Erkenntnisse über die Veränderung der relativen Röntgendichte zu erlangen. Parallel hierzu wird eine Untersuchung der postoperativen klinischen Verläufe und typischer Komplikationen durchgeführt.

Hierbei stehen folgende Fragestellungen im Vordergrund:

1. Ist das von Ihan Hren und Miljavec publizierte Verfahren der relativen Knochendichtemessung ein Verfahren, welches reproduzierbare Messergebnisse für klinische und wissenschaftliche Auswertungen liefert?

2. Welche relativen Knochendichten sind bei Patienten, bei denen Defektauffüllungen mit Ostim ${ }^{\circledR}$ nach oralchirurgischen Eingriffen durchgeführt wurden, postoperativ und nach einem Heilungsintervall messbar?

3. Zeigt sich eine Entwicklung der relativen Knochendichtewerte, die auf einen Heilungs- und Umbauprozess schließen lässt?

4. Erreichen die Werte der Knochendichte des Defektes die Werte des ortsständigen Knochens?

5. Haben individuelle Faktoren wie Geschlecht, Alter und Lokalisation des Eingriffs einen Einfluss auf die Knochendichtewerte und deren Entwicklung?

6. Treten nach Defektauffüllungen mit Ostim® Komplikationen auf und haben Geschlecht und Alter des Patienten sowie Begleitmedikation einen Einfluss darauf? 
7. Können Korrelationen zwischen Fällen mit Komplikationen und der Entwicklung der Knochendichtemessung festgestellt werden? 


\section{Material und Methoden}

Bei dieser Studie handelt es sich um eine retrospektive klinische Studie, die aus drei Untersuchungsteilen besteht. Den ersten Teil stell die Voruntersuchung des radiologischen Bildanalyseverfahrens dar. Den zweiten Teil bildet die radiologische Untersuchung klinisch angefertigter Röntgenbilder hinsichtlich des Heilungsprozesses von Knochendefekten im Mund-Kiefer-Gesichtsbereich die mit dem Knochenersatzmaterial Ostim® versorgt worden sind. Der dritte Teil beschäftigt sich mit den klinischen postoperativen Verläufen der Patienten.

\subsection{Bildanalyseverfahren und Voruntersuchung hinsichtlich der Repro- duzierbarkeit}

Die Messung der relativen Knochendichte eignet sich im Besonderen für eine retrospektive Studie, in der kein Einfluss auf die vorliegenden Röntgenbilder genommen werden kann und in der die zugrundeliegenden Umstände, unter denen die Bilder entstanden sind, nicht bekannt sind. Im weiteren Verlauf wird in dieser Arbeit nicht von relativer Knochendichte, sondern von relativer Röntgendichte gesprochen, da einerseits in dem vorliegenden Studiendesign ein Fremdkörper in den Knochen eingebracht wird, der sich schwach radioopak verhält, und man somit im engen Sinne nicht von Knochen sprechen kann, und andererseits keine histologische Untersuchung nach Abheilung der Defekte durchgeführt werden konnte, um die Bildung von Knochen histologisch zu verifizieren. Eine Veränderung der relativen Röntgendichte in Richtung des ortsständigen Knochens kann somit nur als Hinweis auf eine mögliche und in Anbetracht der histologischen Untersuchungen anderer Autoren auch wahrscheinliche Knochenbildung im Defekt dienen.

\subsubsection{Bildanalysesoftware}

Zur Messung der mittleren Grauwerte der verschiedenen Defekt- und Kontrollbereiche wurde in dieser Studie ImageJ 1.44p (Wayne Rasband, National Institute of Health, USA) verwendet. Um Messregionen auszuwählen, stehen in der Software prinzipiell geometrisch vorgeformte Messwerkzeuge, die elliptische, rechteckige oder polygonale Messregionen erstellen, sowie die Freihandauswahl und eine automatische Messregionserkennung. Nach Erstellen der Messregion kann diese durch Hinzufügen und Entfernen einzelner Teile sowie Ergänzung durch räumlich unabhängige Teile des Bildes vor Durchführung der Messung noch modifiziert werden. Es ist ebenso möglich die erstellten Messregionen zu speichern und auf ein anderes Bild - zum Beispiel ein Kontrollbild - zu übertragen und anschließend an eventuell veränderte Projektionsflächen anzupassen. Für die Erfassung von Defekten im mund-kiefer-gesichtschirurgischen Bereich ist ein Umfahren der Defekte per Freihandauswahl notwendig, um die komplexen geometrischen Formen zu erfassen. 


\subsubsection{Standard Operating Procedure}

Die Auswahl der Messregionen per Freihandauswahl ist eine potentielle Fehlerquelle die bislang noch nicht auf ihre Auswirkung auf das Messergebnis untersucht wurde. Zur Evaluation der Reproduzierbarkeit der Messergebnisse wurde eine Voruntersuchung zur Bestimmung der intra- und interindividuellen Variabilität durchgeführt. Nach ersten Probemessungen wurde aufgrund der zugrundeliegenden Anatomie, sowie den Empfehlungen von Ihan Hren und Miljavec ein standard operation procedure (SOP) erstellt, die Regeln zur Festlegung der Messregionen zusammenfasst (Geiger et al. 2016):

- In ImageJ werden die Messparameter für die mittlere Grauwertmessung eingestellt (analyze $\rightarrow$ set measurements -> Häkchen setzen bei area und mean gray value).

- Die zu analysierende Bilddatei wird per drag and drop (oder file -> open) in dem Programm geöffnet.

- Bei Bedarf kann mithilfe der Lupenfunktion oder mit den Tasten „+“ und ",“ der Defektbereich vergrößert werden.

- Pro Knochendefekt wird eine Messregion für den Defekt und eine für den ortsständigen Knochen per Freihandauswahl (freehand selection) nach den folgenden Regeln erstellt:

1. Die Defektregion soll den gesamten Bereich des röntgenologisch sichtbaren Defektes erfassen, dabei aber einen Mindestabstand von einer Pixelbreite zum Rand und eventuell vorhandener kortikaler Strukturen (z.B. Lamina cribriformis nach Extraktionen) einhalten.

2. Die Vergleichsregion die den ortsständigen Knochen darstellt, sollte - wenn möglich - zirkulär in einer gleichmäßigen Schichtstärke um den Defekt angeordnet sein, dabei aber die Abbilder folgender anatomische Strukturen explizit aussparen:

- Canalis nervus mandibularis

- Kortikalis der Maxilla oder Mandibula

- Überlagerungen des Sinus Maxillaris (Ausnahme: Sinuslift)

- Benachbarte Zähne oder Implantate

- Die Mundhöhle einschließlich der

- Überlagerung des Gaumendaches

3. Die Vergleichsregion darf die Größe der Defektregion nicht um $10 \%$ über- oder unterschreiten. 
4. Bei Überlagerungen der Defektregion von Weichteilschatten, Artefakten oder anderen Strukturen, wird das Verhältnis der überlagerten, zu nicht überlagerten Bereichen ermittelt und die Vergleichsregion in einem entsprechenden Verhältnis ausgewählt.

5. Sollte eine dieser Regeln nicht angewendet werden können, ist das Bild aus der Auswertung auszuschließen.

- Nach Anlegen einer Messregion wird die Messfunktion ausgeführt (analyze -> measure).

- Die Ausgegebenen Messwerte können direkt in statistische Datenerfassungstabellen wie Excel übernommen werden.

\subsubsection{Untersuchung der Reproduzierbarkeit}

Nach Festlegung der SOP Parameter führten drei Mitarbeiter der Arbeitsgruppe auf zehn Orthopantomogrammen (OPG), darunter sechs postoperative Bilder und vier Kontrollbilder, Probemessungen durch. Tabelle 3 zeigt die jeweils durchgeführten Operationen der in der Voruntersuchung benutzten Bilddateien (Geiger et al. 2016).

Tabelle 3: Indikationen der in der Voruntersuchung benutzten Bilddateien

\begin{tabular}{|l|l|}
\hline Bild & Indikation \\
\hline $\mathbf{1}$ & Zustand nach Wurzelspitzenresektion und Defektauffüllung 15 \\
\hline $\mathbf{2}$ & Zustand nach einzeitigem Sinuslift im 2. Quadrant und Implantation Regio 026 027 \\
\hline $\mathbf{3}$ & Zustand nach Extraktion und socket preservation 37 \\
\hline $\mathbf{4}$ & Zustand nach Wurzelspitzenresektion und Zystektomie mit Defektauffüllung 35 \\
\hline $\mathbf{5}$ & Zustand nach Osteotomie von verlagertem Zahn 38 und Defektauffüllung \\
\hline $\mathbf{6}$ & Zustand nach Extraktion und socket preservation 37 \\
\hline $\mathbf{7}$ & Kontrollaufnahme 6 Monate postoperativ von Bild Nr. 3 \\
\hline $\mathbf{8}$ & Kontrollaufnahme 5 Monate postoperativ von Bild Nr. 2 \\
\hline $\mathbf{9}$ & Kontrollaufnahme 3 Monate postoperativ von Bild Nr. 4 \\
\hline $\mathbf{1 0}$ & Kontrollaufnahme 6 Monate postoperativ von Bild Nr. 5 \\
\hline
\end{tabular}

Dazu wurde jeweils der Defekt und der umliegende Knochen umfahren und mit Hilfe von ImageJ der mittlere Grauwert der umfahrenen Regionen gemessen. Zum Vergleich der Größe der Region wurde ebenfalls die Anzahl der in die Messung einbezogenen Pixel bestimmt. Diese Messungen wurden unabhängig voneinander durchgeführt und im Abstand von jeweils einem Tag fünfmal wiederholt. Abbildung 1 zeigt exemplarisch eine Probemessung und die ausgewählten Untersuchungsregionen. 


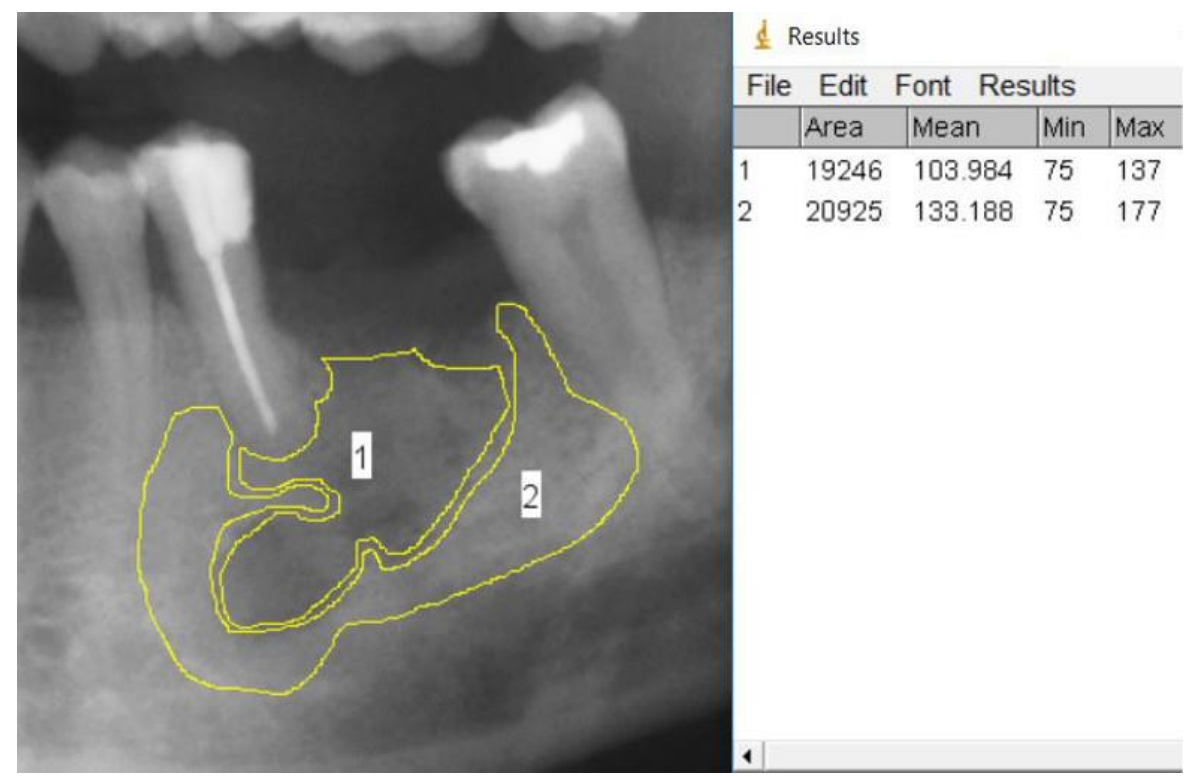

Abbildung 1: Selektion der Messregionen und Probemessung von Bild 4 der Voruntersuchung

Die Messergebnisse wurden für die statistische Auswertung in einer Auswertungstabelle zusammengefasst.

\subsection{Patientenstammdaten und Gruppeneinteilung}

Für diese retrospektive Untersuchung wurde die elektronische Patientenkartei von Patienten der MGK-Klinik Kassel [Praxissoftware Evident, Evident GmbH, Bad Kreuznach] verwandt, bei denen Ostim® im Zusammenhang mit Defektauffüllungen und Augmentationen im Zeitraum Januar 2006 bis Dezember 2012 im Mund-Kiefer-Gesichtsbereich eingesetzt worden war. Es wurden fünf verschiedene Indikationsgruppen unterschieden:

I socket preservation (vgl. Abbildung 2)

II Zystektomien, auch im Zusammenhang mit Wurzelspitzenresektionen

III Sinuslift und andere Augmentationen im Zusammenhang mit dentalen Implantationen

IV Defektauffüllung nach umfangreichen Osteotomien verlagerter Weisheitszähne

V Auffüllung parodontaler Knochendefekte

Die Patientenstammdaten wurden psyeudonymisiert erhoben und in einer Datenerfassungstabelle [Microsoft Office Excel 2007, Microsoft Corp.] aufgenommen. Jedem Patienten wurde eine Nummer zugewiesen, die auf einer in der Klinik hinterlegten Liste den Patientennummern der Klinik-EDV zugeordnet wurden. Für jeden Patienten wurde Geschlecht und Geburtsdatum erhoben. Das jeweilige Operationsdatum wurde aufgenommen und das Alter des Patienten zum Zeitpunkt der Operation bestimmt. Diese Stammdaten wurden für beide nachfolgenden Untersuchungen genutzt, um Rückschlüsse zwischen den beiden Untersuchungsteilen zu ermöglichen. 


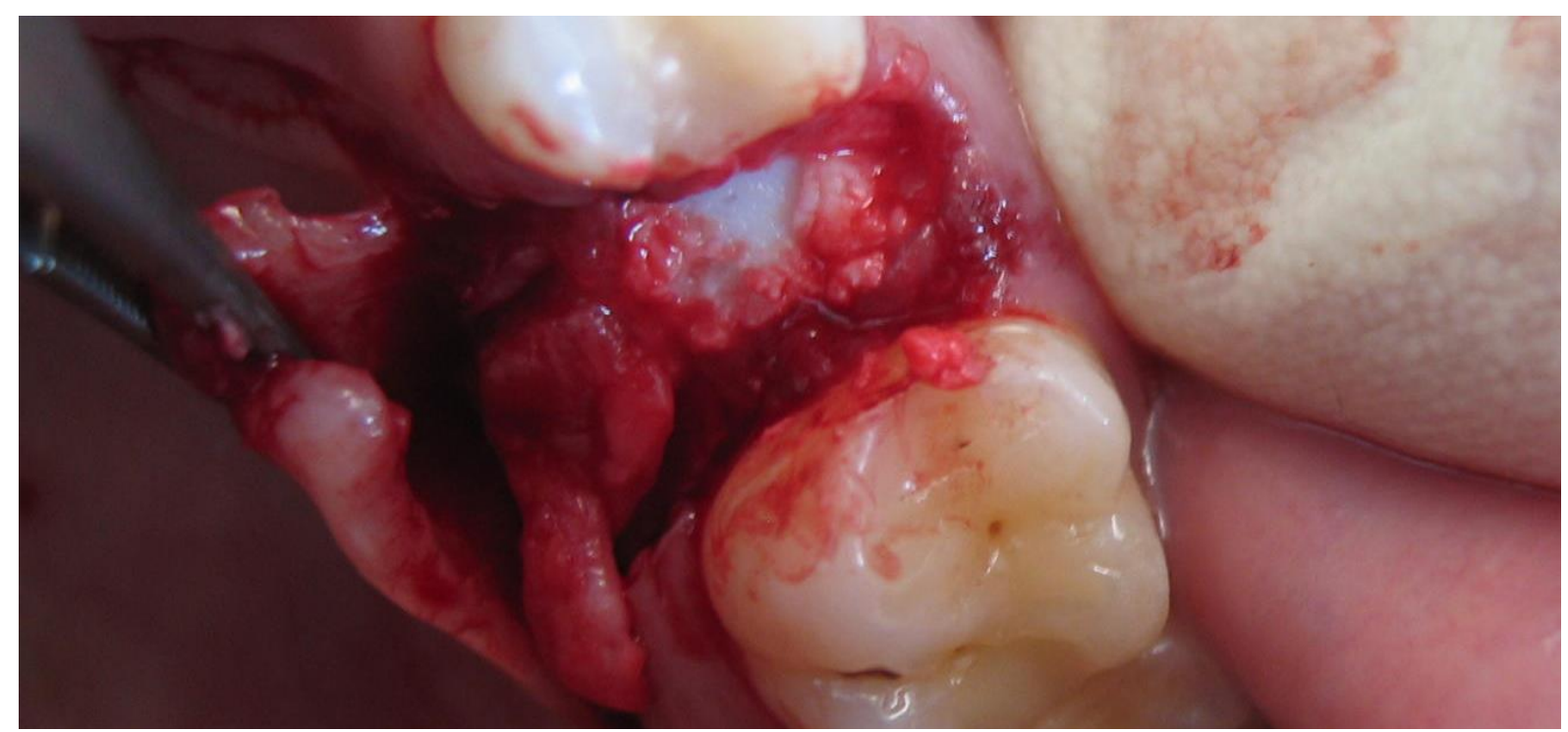

Abbildung 2: Klinisches Bild zur Durchführung einer socket preservation. Zustand nach Zahnentfernung und Auffüllung der Extraktionsalveole mit Ostim® und vorbereiteter Schnittführung für Wundverschluss mit palatinalem bindegewebigen Verschiebelappen.

Die Studie wurde durch die Ethikkommission der Medizinischen Fakultät der Universitätsmedizin Göttingen [Antragsnummer DOK_75_2013] genehmigt. Die Information der Patienten über die wissenschaftliche Auswertung der Patientendaten erfolgte durch Aushang der allgemeinen Geschäftsbedingungen der Klinik.

\subsection{Radiologischer Untersuchungsteil}

Die zeitliche Entwicklung der relativen Röntgendichte der entstandenen Knochendefekte wurde anhand vorhandener Röntgenbilder mit dem in der Voruntersuchung evaluierten Verfahren untersucht. Hierfür wurde die Röntgendatenbank der Klinik [Dexis 7, Sirona Dental Systems, Bensheim] nach vorliegenden digitalen Röntgenbildern durchsucht, die eine Verlaufskontrolle ermöglichen. Routinemäßig wird in dieser Klinik postoperativ das Operationsergebnis nach Augmentation, Implantation, Entfernung retinierter Zähne oder durchgeführter Wurzelspitzenresektion röntgenologisch kontrolliert, wie es in der Stellungnahme der DGZMK von 2/93 gefordert wird (Sitzmann 1993). Je nach Umfang und Lokalisation des Operationsgebietes und erforderlicher Detailauflösung werden entweder digitale OPGs [Kodak 8000c; Carestream Health, Inc. NY USA] oder digitale Zahnfilme [Kodak 2000; Carestream Health, Inc.; NY; USA] mittels Sensortechnik angefertigt (vgl. Abbildung 3). 


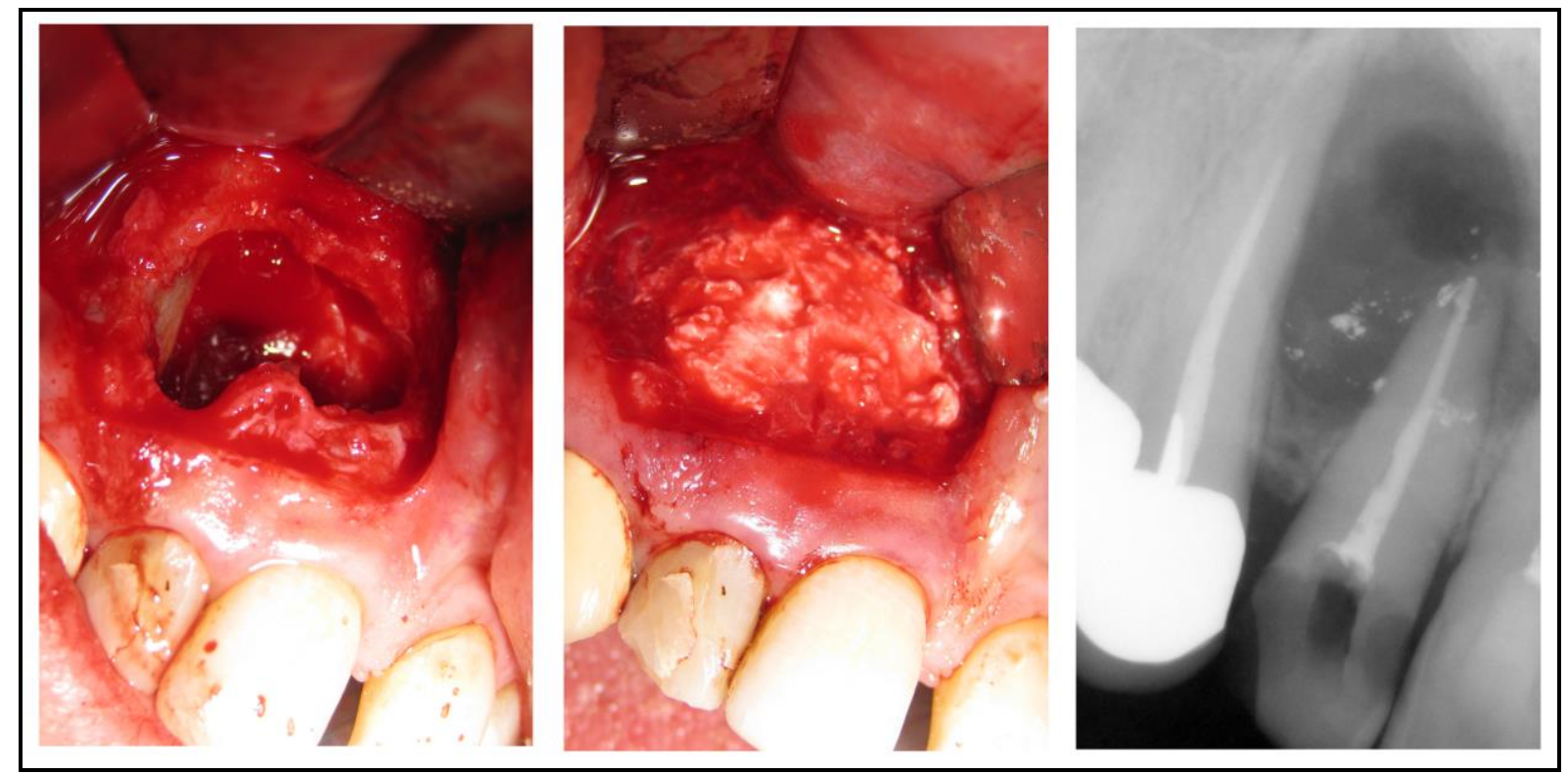

Abbildung 3: Klinische Bilder nach Wurzelspitzenresektion und Zystektomie Zahn 12 und Defektauffüllung mit Ostim® und die dazugehörige postoperative Röntgenaufnahme

Diese Röntgenbilder dienten im Folgenden der Darstellung des postoperativen Zustandes der Defektregion. Zur Kontrolle des Augmentationsergebnisses, zum Ausschluss von Zystenrezidiven oder im Verlauf der Weiterbehandlung ist in den Qualitätsmanagementrichtlinien der Klinik eine routinemäßige Röntgenkontrolle 3 - 6 Monate nach Operation vorgesehen. Da es sich bei der Klinik um eine Überweiserklinik handelt, nehmen nicht alle Patienten diese Termine auch wahr oder lassen die Röntgenbilder bei ihrem Hauszahnarzt anfertigen. Im Rahmen des Qualitätsmanagements der Klinik werden deshalb die Hauszahnärzte aller Patienten, die nicht zu den vereinbarten Kontrolluntersuchungen erschienen sind, angeschrieben mit der Bitte um Übersendung aussagekräftiger Röntgenaufnahmen der betreffenden Region. Diese werden, wenn es sich um digitale Röntgenbilder handelt, in die Klinik-EDV eingepflegt. Konventienelle Röntgenfilme wurden von den Praxismitarbeiten auf einem Röntgenbildbetrachter per Digitalkamera [Canon Ixus 920; Tokio; Japan] abfotografiert und dann in der Klinik-EDV hinterlegt. Alle vorhandenen Röntgenbilder, insbesondere die abfotografierten konventionellen Aufnahmen, wurden hinsichtlich der Aussagekraft, Vergleichbarkeit und Qualität überprüft. Um das gesammelte Bildmaterial hinsichtlich der Heilungsprozesse der Defekte untersuchen zu können, musste es aus der digitalen Röntgenkartei der Praxis exportiert werden. Die im DICOM-Format auf dem Server der Praxis abgespeicherten Röntgenbilder enthalten unter anderem Patientendaten und wurden zum Zwecke der Pseudonymisierung in ein TIFF-Format exportiert. Die postoperativen Röntgenbilder (RöPostOp) und die Kontrollröntgenbilder (RöKntr) wurden dem jeweiligen Fall zugeordnet, indem die Patientennummer der Datenerfassungsliste als Dateiname ausgewählt wurde. Für den ersten Fall ergibt sich also der Dateiname 1_p.tif für 
RöPostOp und 1_k.tif für RöKntr. Es wurde eine Datenerfassungstabelle [Microsoft Excel 2007] für die radiologische Untersuchung mit den patientenbezogenen Stammdaten erstellt und für jeden einzelnen Defekt, für den ein RöPostOP und ein aussagekräftiges RöKntr vorlagen, ein Fall angelegt. Die Defekte wurden nun in die vorher definierten Gruppen unterteilt und festgehalten, ob der Defekt im Ober- oder Unterkiefer lokalisiert gewesen ist. Dazu wurde das Datum der Röntgenkontrolle dokumentiert und rechnerisch der Beobachtungszeitraum zwischen Operation und Röntgenkontrolle bestimmt. Es entstand keine zusätzliche studienbedingte Strahlenbelastung.

\subsubsection{Grauwertmessungen und Bestimmung der relativen Röntgendichten}

Nach Beendigung der Voruntersuchung wurden die vorhandenen Röntgenbilder der Studie auf Anwendbarkeit der SOP untersucht. Der mittlere Grauwert wurde für jeden Defekt und jede Kontrollregion sowohl postoperativ, als auch auf dem Kontrollröntgenbild bestimmt. Hierfür wurde jede Messung fünfmal wiederholt, ein Mittelwert gebildet und daraus die relative Röntgendichte postoperativ und zum Kontrollzeitpunkt errechnet. Beide Werte wurden in die Auswertungstabelle übernommen. Um die Veränderung zwischen den beiden Werten darzustellen wurde eine Differenz gebildet:

$$
\text { Delta = Röntgendichte RöKntr - Röntgendichte RöPostOP }
$$

Dieser Wert wurde ebenfalls für jeden Fall in der Auswertungstabelle erfasst.

\subsection{Erfassung der Klinischen Verläufe}

Für die Auswertung der klinischen Verläufe wurde definiert, dass alle an einem Tag, bei einem Patienten durchgeführten indikationsgleichen chirurgischen Eingriffe als ein Fall zu werten sind, auch wenn sie in mehreren Operationsregionen durchgeführt wurden. Gleichzeitige, aber in ihrer Indikation unterschiedliche Operationen, wurden getrennt betrachtet, um die auftretenden Komplikationsraten indikationsspezifisch untersuchen zu können. Eine Auswertungstabelle wurde erstellt und zusätzlich zu den Patientenstammdaten die zu untersuchenden Daten aufgenommen. Für jeden Fall wurde die Anzahl der versorgten Knochendefekte aus der Kartei entnommen und 3 Kontrollintervalle festgelegt die den postoperativen Kontroll- und Nachsorgeterminen entsprechen:

- $\mathrm{T} 1 \stackrel{\wedge}{=}$. - 4. Tag postoperativ; Routinemäßig durchgeführte Kontrolle der Wundsituation

- $\quad \mathrm{T} 2 \bumpeq 5 .-14$. Tag postoperativ; Entfernung eventuell vorhandener Schleimhautnähte und Kontrolle der Wundheilung

- $\mathrm{T} 3 \bumpeq$ ab 15. Tag postoperativ; Verlaufskontrollen und eventuell benötigte Weiterbehandlungen

Die Patientenkartei wurde für jeden Patienten ausgewertet und ermittelt, ob der Patient in dem definierten Beobachtungsintervall in der Klinik erschienen ist und ob es Eintragungen in 
der Kartei gibt, die Komplikationen im Heilungsverlauf zu dem jeweiligen Zeitraum dokumentieren. Zusätzlich wurde erhoben ob die Patienten eine perioperative Antibiotikaund Schwellungsprophylaxe erhalten haben. Diese Daten wurden zahlenkodiert in der Auswertungstabelle erfasst. Tabelle 4 zeigt die verwendete Zahlencodierung, der in den Akten vermerkten und in der Auswertung erfassten klinischen Verläufe. Die Zahlen wurden nach dem zeitlichen Auftreten während der Datenerhebung vergeben und sind nicht gewichtet.

Tabelle 4: Zahlencodierung zur Auswertung der klinischen Verläufe

\begin{tabular}{|l|l|}
\hline Code & Bedeutung \\
\hline $\mathbf{0}$ & Klinisch unauffällig \\
\hline $\mathbf{1}$ & Nachblutung \\
\hline $\mathbf{2}$ & Wunddehiszenz \\
\hline $\mathbf{3}$ & Starke Schwellung \\
\hline $\mathbf{4}$ & Abszess \\
\hline $\mathbf{5}$ & Zahn- oder Implantatverlust \\
\hline $\mathbf{6}$ & Hämatom \\
\hline $\mathbf{7}$ & Nachresektion erforderlich \\
\hline $\mathbf{8}$ & Implantation nach socket preservation \\
\hline $\mathbf{9}$ & Fraktur / Osteoradionekrose \\
\hline $\mathbf{1 0}$ & Hypästhesie \\
\hline $\mathbf{1 1}$ & Starke Schmerzen \\
\hline $\mathbf{1 2}$ & Periimplantitis \\
\hline $\mathbf{1 3}$ & Fibrombildung \\
\hline $\mathbf{9 9}$ & Im Kontrollintervall nicht zur Untersuchung erschienen \\
\hline
\end{tabular}

\subsection{Statistische Datenauswertung}

Die Messergebnisse der Voruntersuchung hinsichtlich der Reproduzierbarkeit wurden nach Datenerfassung deskriptiv statistisch ausgewertet. Weiterhin wurden die Ergebnisse hinsichtlich der interindividuellen Abweichungen in einer Varianzanalyse untersucht. Hierzu wurde unter Mitarbeit des Institutes für medizinische Statistik der Universität Göttingen eine repeated measures ANOVA mit der Statistiksoftware SAS 9.3 [SAS Institute Inc., Cary, NC, USA] durchgeführt (Chesher 2008) in der die verschiedenen Parameter und deren Einfluss auf das Messergebnis vergleichend statistisch beurteilt wurde.

Die statistische Auswertung des radiologischen Untersuchungsteils und der klinischen Verläufe erfolgte durch die Zentrale Serviceeinheit der Abteilung für Medizinische Biometrie und Statistische Bioinformatik der Universitätsmedizin Göttingen. Die relativen Röntgendichten wurden für Männer, Frauen, Ober- und Unterkiefer durch Mittelwert +/- Standardabweichung beschrieben und der Einfluss von Geschlecht und Kieferposition auf jede Knochendichte-Variable einzeln in einem univariaten Regressionsmodell für Messwiederholungen bestimmt. „Pearsons Korrelationskoeffizient“ wurde für metrische Variablen 
und Röntgendichten angegeben. Zudem wurde der Effekt aller Parameter auf die Röntgendichte-Variablen in einem multivariaten Regressionsmodell mit Berücksichtigung von Messwiederholungen analysiert.

Die Verteilung der Variablen der klinischen Verläufe wurde in jeder Gruppe beschrieben, für metrische Variablen wurde Mittelwert +/- Standardabweichung angegeben und für nominale Variablen absolute und relative Häufigkeit. Des Weiteren wurde die Verteilung der Parameter zwischen Komplikationsgruppe "Nein“ (Code 0 und 8) und Komplikationsgruppe „Ja“ (Code 1 - 7 und 9 - 13) beschrieben und der Effekt der Parameter auf Komplikation sowohl in einem univariaten als auch multivariaten logistischen Regressionsmodell für Messwiederholungen untersucht. Die Röntgendichte-Variablen wurden für die Komplikationsgruppen „Ja“ und „Nein“ deskriptiv beschrieben und der Einfluss der Komplikationen in einem generalisierten linearen Modell untersucht. Das Signifikanzniveau war bei allen statistischen Tests auf alpha $=5 \%$ festgelegt. Alle Analysen wurden mit der statistischen Software $\mathrm{R}$ (Version 3.0.2, www.r-project.org) durchgeführt und für die Analysen mit Messwiederholungen wurde das R-Paket 'geepack' verwendet. 


\section{Ergebnisse}

\subsection{Ergebnisse der Voruntersuchung der Reproduzierbarkeit von Mes- sungen mittels ImageJ}

Auf alle Bilder der Voruntersuchung ließen sich das SOP und die Untersuchungsmethode anwenden. Für jeden Defekt und jede Kontrollregion des ortsständigen Knochens konnten Messregionen angelegt und analysiert werden. Die Varianzkoeffizienten lagen intraindividuell im Mittelwert bei $1,5 \% \pm 1,0$ und variierten zwischen $0,2 \%$ und $4,4 \%$. Dabei zeigten die Messungen der Knochendefekte höhere Konstanz (Varianzkoeffizient mittelwertig 1,1\% \pm 0,8, maximal 3,4\%) als die Messungen des ortsständigen Knochens (Varianzkoeffizient mittelwertig 1,8\% $\pm 1,1$, maximal 4,4\%). Interindividuell lagen die Varianzkoeffizienten mittelwertig bei $3,0 \% \pm 2,4$ und schwankten zwischen $0,6 \%$ und $9,8 \%$. Auch hier ergaben sich konstantere Messergebnisse der Defektregion (Varianzkoeffizient mittelwertig 2,3 \% $\pm 1,9$, maximal 7,2\%) als bei den Messungen der Kontrollregionen (Varianzkoeffizient mittelwertig $3,7 \% \pm 2,6$, maximal 9,5\%). Abbildung 4 zeigt einen vergrößerten Ausschnitt von Bild 1 mit umfahrenen und markierten Messregionen, die unter Anwendung der SOP entstanden sind.

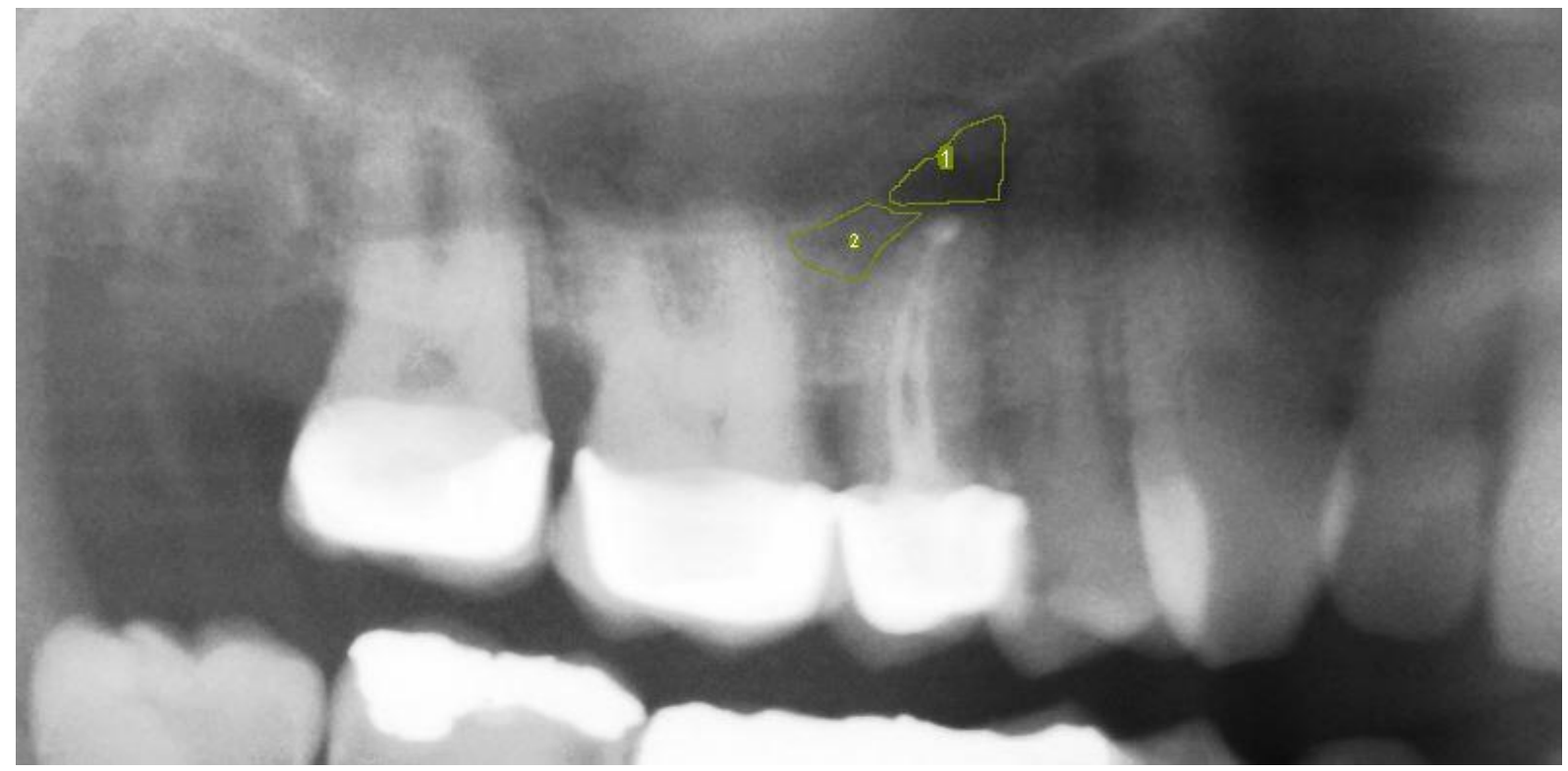

Abbildung 4: Vergrößerter Ausschnitt von Bild 1: Messregion 1: Teile des Defektes, die nicht von der Projektion der Kieferhöhle überlagert sind. Messregion 2: Projektion von spongiösem Knochen, die in unmittelbarer Nachbarschaft zum Defekt nicht von anderen Strukturen überlagert ist.

Die Ergebnisse der Grauwertmessungen der Voruntersuchung und die statistischen Parameter zur Beurteilung der intra- und interindividuellen Variabilität ergaben Unterschiede in der Höhe der Varianzkoeffizienten bei den einzelnen Bildern (vgl. Tabelle 5). 
Tabelle 5: Ergebnisse der Grauwertmessungen der Voruntersuchung

\begin{tabular}{|c|c|c|c|c|c|}
\hline Bild & Messstelle & Untersucher 1 & Untersucher 2 & Untersucher 3 & Alle Untersucher \\
\hline \multirow[t]{4}{*}{1} & Defekt & $61,584 \pm 1,022$ & $64,132 \pm 2,178$ & $54,852 \pm 1,035$ & $60,189 \pm 4,287$ \\
\hline & & $1,660 \%$ & $3,396 \%$ & $1,887 \%$ & $7,123 \%$ \\
\hline & ortsständi- & $89,458 \pm 1,113$ & $93,078 \pm 4,098$ & $109,230 \pm 4,4664$ & $97,255 \pm 9,514$ \\
\hline & ger Knochen & $1,244 \%$ & $4,402 \%$ & $4,271 \%$ & $9,783 \%$ \\
\hline \multirow[t]{4}{*}{2} & Defekt & $126.364 \pm 0.717$ & $123,584 \pm 1,008$ & $123,534 \pm 1,076$ & $124,494 \pm 1,625$ \\
\hline & & $0.567 \%$ & $0,816 \%$ & $0,871 \%$ & $1,306 \%$ \\
\hline & ortsständi- & $147,466 \pm 1,541$ & $132,132 \pm 2,496$ & $143,568 \pm 3,487$ & $141,055 \pm 7,161$ \\
\hline & ger Knochen & $\begin{array}{c}1,027 \% \\
\end{array}$ & $1,889 \%$ & $2,429 \%$ & $\mathbf{5 , 0 7 7 \%}$ \\
\hline \multirow[t]{4}{*}{3} & Defekt & $117,026 \pm 0,773$ & $117,280 \pm 0,377$ & $115,807 \pm 0,970$ & $116,704 \pm 0,961$ \\
\hline & & $0,661 \%$ & $0,321 \%$ & $0,837 \%$ & $\mathbf{0 , 8 2 3 \%}$ \\
\hline & ortsständi- & $115,294 \pm 3,070$ & $117,900 \pm 2,122$ & $111,206 \pm 3,390$ & $114,800, \pm 3,924$ \\
\hline & ger Knochen & $2,662 \%$ & $1,800 \%$ & $3,049 \%$ & $3,418 \%$ \\
\hline \multirow[t]{4}{*}{4} & Defekt & $106,122 \pm 0,508$ & $107,754 \pm 0,959$ & $105,784 \pm 1,173$ & $106,553 \pm 1,234$ \\
\hline & & $0,479 \%$ & $0,890 \%$ & $1,109 \%$ & $1,158 \%$ \\
\hline & ortsständi- & $138,654 \pm 1,807$ & $133,940 \pm 3,408$ & $139,659 \pm 2,191$ & $137,418 \pm 3,505$ \\
\hline & ger Knochen & $\begin{array}{c}1,303 \% \\
\end{array}$ & $2,545 \%$ & $\begin{array}{c}1,569 \% \\
\end{array}$ & $2, \mathbf{5 5 0} \%$ \\
\hline \multirow[t]{4}{*}{5} & Defekt & $112,894 \pm 0,694$ & $115,066 \pm 0,663$ & $112,104 \pm 2,037$ & $113,355, \pm 1,769$ \\
\hline & & $0,615 \%$ & $0,576 \%$ & $\begin{array}{c}1,817, \% \\
\end{array}$ & $1,560 \%$ \\
\hline & ortsständi- & $131,108 \pm 1,342$ & $134,158 \pm 1,418$ & $127,814 \pm 3,652$ & $131,027 \pm 3,477$ \\
\hline & ger Knochen & $1,023 \%$ & $1,057 \%$ & $2,858 \%$ & $2,654 \%$ \\
\hline \multirow[t]{4}{*}{6} & Defekt & $144,692 \pm 4,783$ & $135,972 \pm 1,019$ & $133,705 \pm 1,610$ & $138,123 \pm 5,622$ \\
\hline & & $3,306, \%$ & $\begin{array}{c}0,750 \% \\
\end{array}$ & $\begin{array}{c}1,204 \% \\
\end{array}$ & $\mathbf{4 , 0 7 0} \%$ \\
\hline & ortsständi- & $154,106 \pm 3,090$ & $151,888 \pm 1,868$ & $152,681 \pm 0,977$ & $152,892 \pm 2,213$ \\
\hline & ger Knochen & $2,005 \%$ & $\begin{array}{c}1,230 \% \\
\end{array}$ & $\begin{array}{l}0,640 \% \\
\end{array}$ & $1,448 \%$ \\
\hline \multirow[t]{4}{*}{7} & Defekt & $111,654 \pm 0,606$ & $114,272 \pm 1,316$ & $110,228 \pm 1,730$ & $112,051 \pm 2,112$ \\
\hline & & $0,543 \%$ & $\begin{array}{c}1,151 \% \\
\end{array}$ & $1,570 \%$ & $1, \mathbf{8 8 5} \%$ \\
\hline & ortsständi- & $124,950 \pm 0,531$ & $123,930 \pm 0,325$ & $123,729 \pm 0,506$ & $124,203 \pm 0,700$ \\
\hline & ger Knochen & $0,425 \%$ & $\begin{array}{c}0,263 \% \\
\end{array}$ & $0,409 \%$ & $0,564 \%$ \\
\hline \multirow[t]{4}{*}{8} & Defekt & $106,264 \pm 0,661$ & $102,918 \pm 1,140$ & $104,936 \pm 1,920$ & $104,706 \pm 1,891$ \\
\hline & & $0,622 \%$ & $\begin{array}{c}1,108 \% \\
\end{array}$ & $1,830 \%$ & $1, \mathbf{8 0 6} \%$ \\
\hline & ortsständi- & $92,644 \pm 2,928$ & $98,364 \pm 2,677$ & $87,317 \pm 2,044$ & $92,775 \pm 5,243$ \\
\hline & ger Knochen & $3,160 \%$ & $2,721 \%$ & $2,341 \%$ & $5,651 \%$ \\
\hline \multirow[t]{4}{*}{9} & Defekt & $124,376 \pm 0,643$ & $125,964 \pm 0,510$ & $122,112 \pm 0,666$ & $124,151 \pm 1,731$ \\
\hline & & $0,517 \%$ & $0,405 \%$ & $0,546 \%$ & $1,394 \%$ \\
\hline & ortsständi- & $151,230 \pm 2,321$ & $146,898 \pm 2,601$ & $147,851 \pm 4,096$ & $148,660 \pm 3,459$ \\
\hline & ger Knochen & $1,535 \%$ & $1,771 \%$ & $2,770 \%$ & $2,327 \%$ \\
\hline \multirow[t]{4}{*}{10} & Defekt & $160,038 \pm 1,652$ & $157,222 \pm 1,439$ & $157,350 \pm 2,426$ & $158,203 \pm 2,204$ \\
\hline & & $1,032 \%$ & $\begin{array}{c}0,915 \% \\
\end{array}$ & $1,542 \%$ & $1,393 \%$ \\
\hline & ortsständi- & $157,296 \pm 1,117$ & $145,268 \pm 1,550$ & $150,558 \pm 0,292$ & $151,040 \pm 5,199$ \\
\hline & ger Knochen & $0,710 \%$ & $\begin{array}{c}1,067 \% \\
\end{array}$ & $0,194 \%$ & $3,442 \%$ \\
\hline \multirow[t]{3}{*}{ MW } & Defekt & $1,000 \% \pm 0,886$ & $1,033 \% \pm 0,874$ & $1,321 \% \pm 0,475$ & $2,252 \% \pm 1,928$ \\
\hline & Umgebung & $1,509 \% \pm 0,863$ & $1,875 \% \pm 1,150$ & $2,053 \% \pm 1,320$ & $3,691 \% \pm 2,626$ \\
\hline & Insgesamt & $1,255 \% \pm 0,890$ & $1,454 \% \pm 1,084$ & $1,687 \% \pm 1,036$ & $2,972 \% \pm 2,361$ \\
\hline
\end{tabular}
Zeilen 1 - 10: Ergebnisse der Voruntersuchung $\frac{\text { Mittelwerte der Grauwertmessungen } \pm \text { Standardabweichung }}{\text { Varianzkoeffizient }}$

Zeile MW: Mittelwerte der Varianzkoeffizienten der einzelnen und aller Untersucher

Die höchste intraindividuelle Konstanz wurde von Untersucher 3 bei der Messung des ortsständigen Knochens bei Bild 10 erreicht mit 0,2\%. Die größte Abweichung zeigte Untersucher 2 beim ortsständigen Knochen von Bild 1. Die niedrigste interindividuelle Variabilität wurde in Bild 7 erreicht $(0,6 \%)$ während die größten Varianzkoeffizienten bei Bild 1 auftraten $(9,8 \%)$. Die Varainzkoeffizienten waren im Oberkiefer mit mittelwertig 4,1\% signifikant größer als im Unterkiefer mit mittelwertig 2,2\%. 
Abbildung 5 zeigt exemplarisch die übereinander gelegten Messregionen jeweils einer Messung der drei Untersucher von Fall zwei. Das postoperative Röntgenbild nach Implantation und Sinuslift zeigt die Schwierigkeit beim Auswählen der Kontrollregion, während die Defektregion von allen drei Untersuchern relativ konstant ausgewählt wurde.

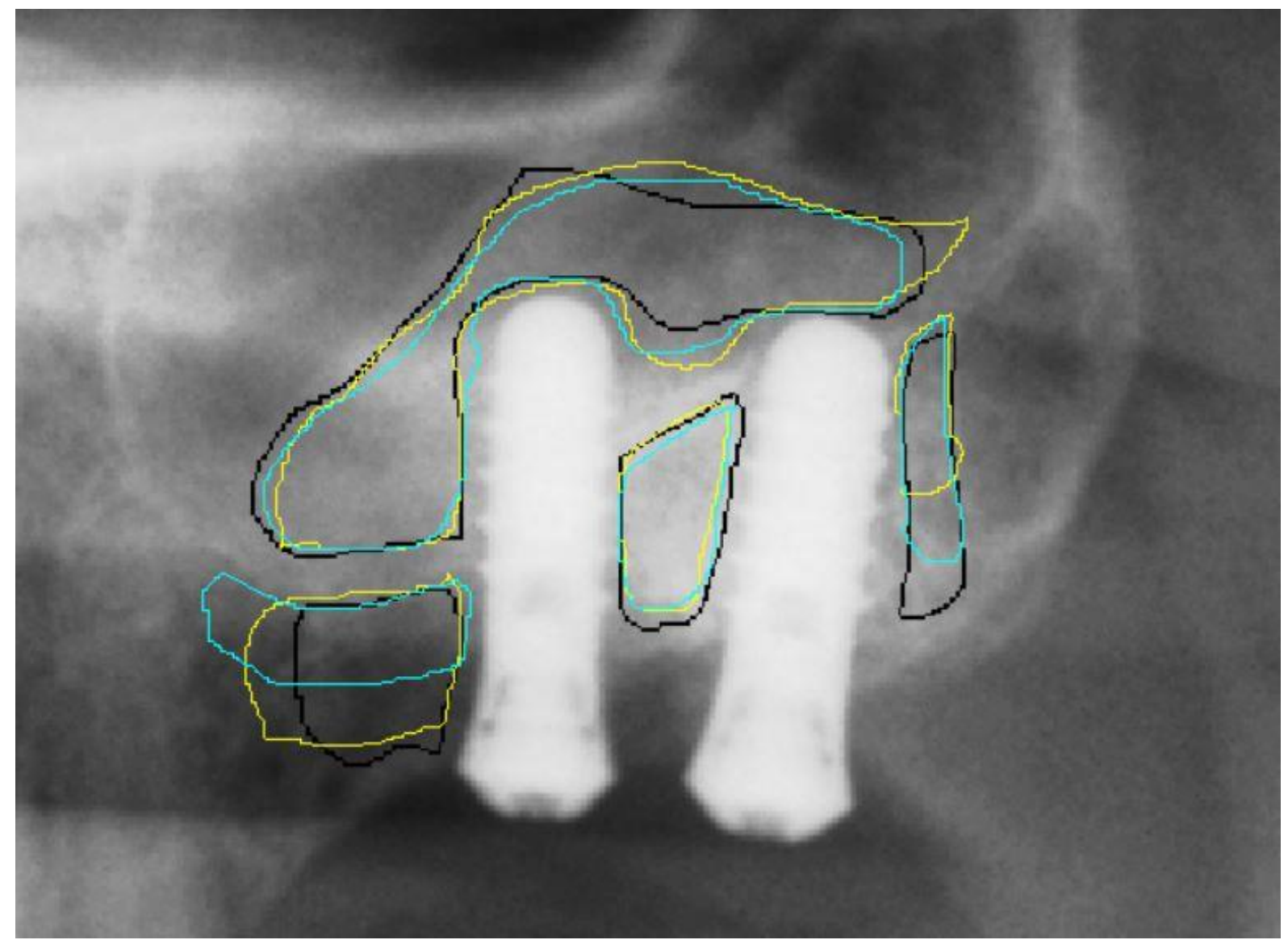

Abbildung 5: Vergrößerter Ausschnitt des OPGs von Fall 2 mit den umfahrenen Untersuchungsregionen von den verschiedenen Untersuchern (Untersucher $1=$ gelb, Untersucher 2 = schwarz, Untersucher 3 = blau). Varianzkoeffizenten interindividuell Defektregion $=1,306 \%$; Kontrollregion $=5,077 \%$ )

Insgesamt zeigte sich, dass der Einfluss des Untersuchers auf die gemessenen Grauwerte nicht signifikant war $(\mathrm{Pr}>\mathrm{F}=0,9462)$. Betrachtet man die Kombination aus Untersucher und Messregion ergibt sich auch hier keine Signifikanz $(\operatorname{Pr}>\mathrm{F}=0,9648)$. Die Grauwerte der Defekte hatten hingegen signifikant unterschiedliche Werte im Vergleich zu den des ortsständigen Knochens ( $\mathrm{Pr}>\mathrm{F}=0,0323)$ (vgl. Tabelle 6).

Tabelle 6: Ergebnisse der Varianzanalye (Type 3 Tests of Fixed Effects)

\begin{tabular}{|l|l|l|}
\hline & F Wert & Pr > F \\
\hline Untersucher & 0,06 & 0,9462 \\
\hline Messregion & 4,83 & 0,0323 \\
\hline Untersucher * Messregion & 0,04 & 0,9648 \\
\hline
\end{tabular}




\subsection{Ergebnisse der radiologischen Verläufe}

\subsubsection{Patientenkollektiv}

Von Januar 2006 bis Dezember 2012 wurden 238 Patienten an 545 entstandenen Knochendefekten durch eine Defektfüllung oder Augmentation mit Ostim® versorgt. Es lagen für 309 Knochendefekte postoperative Röntgenbilder und Kontrollbilder vor. Davon konnten die Bilder von 233 Knochendefekten in die Grauwertanalyse eingeschlossen werden. Bei 74 der ausgeschlossenen Fälle handelte es sich um kleinvolumige oder laterale Augmentationen der Kieferkämme bei denen keine radiologische Projektion der augmentierten Bereiche erkennbar war. Die Abbildung 7 zeigt exemplarisch die klinischen und radiologischen Bilder eines Behandlungsfalles, der aufgrund dessen nicht analysiert werden konnte.

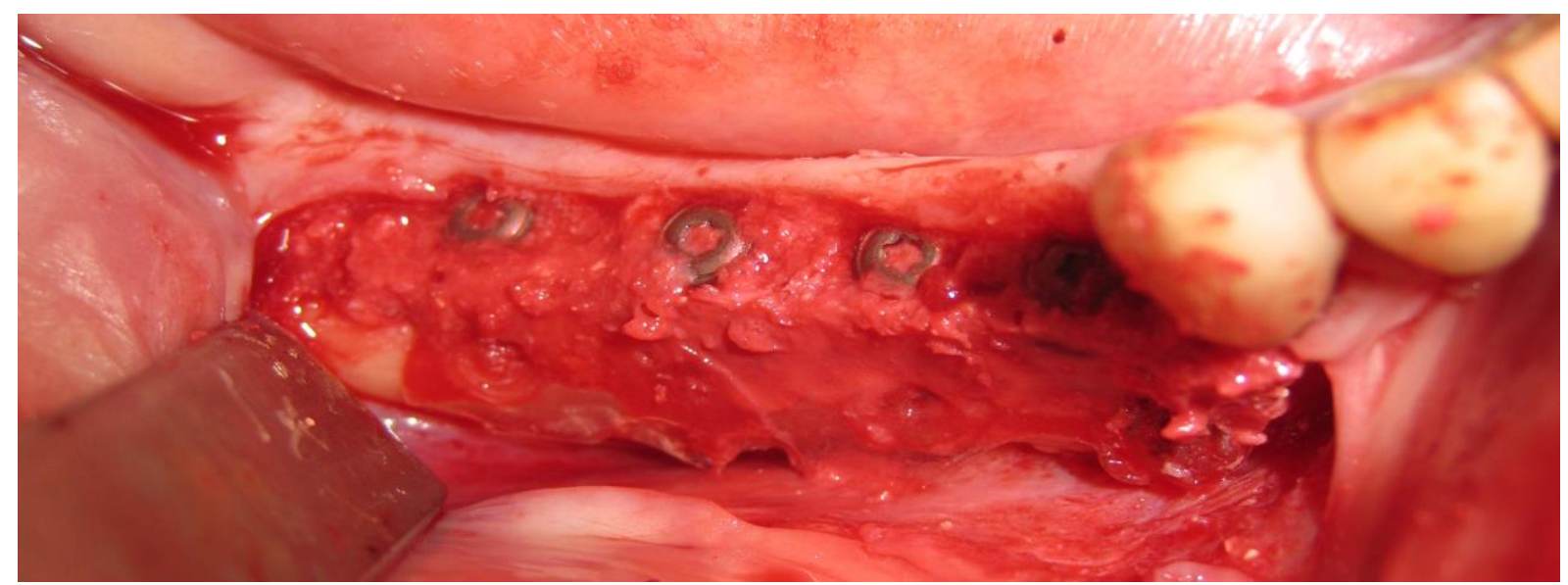

Abbildung 6: Klinisches Bild nach Implantatinsertion und lateraler Augmentation mit Ostim® und Membrantechnik vor Wundverschluss.

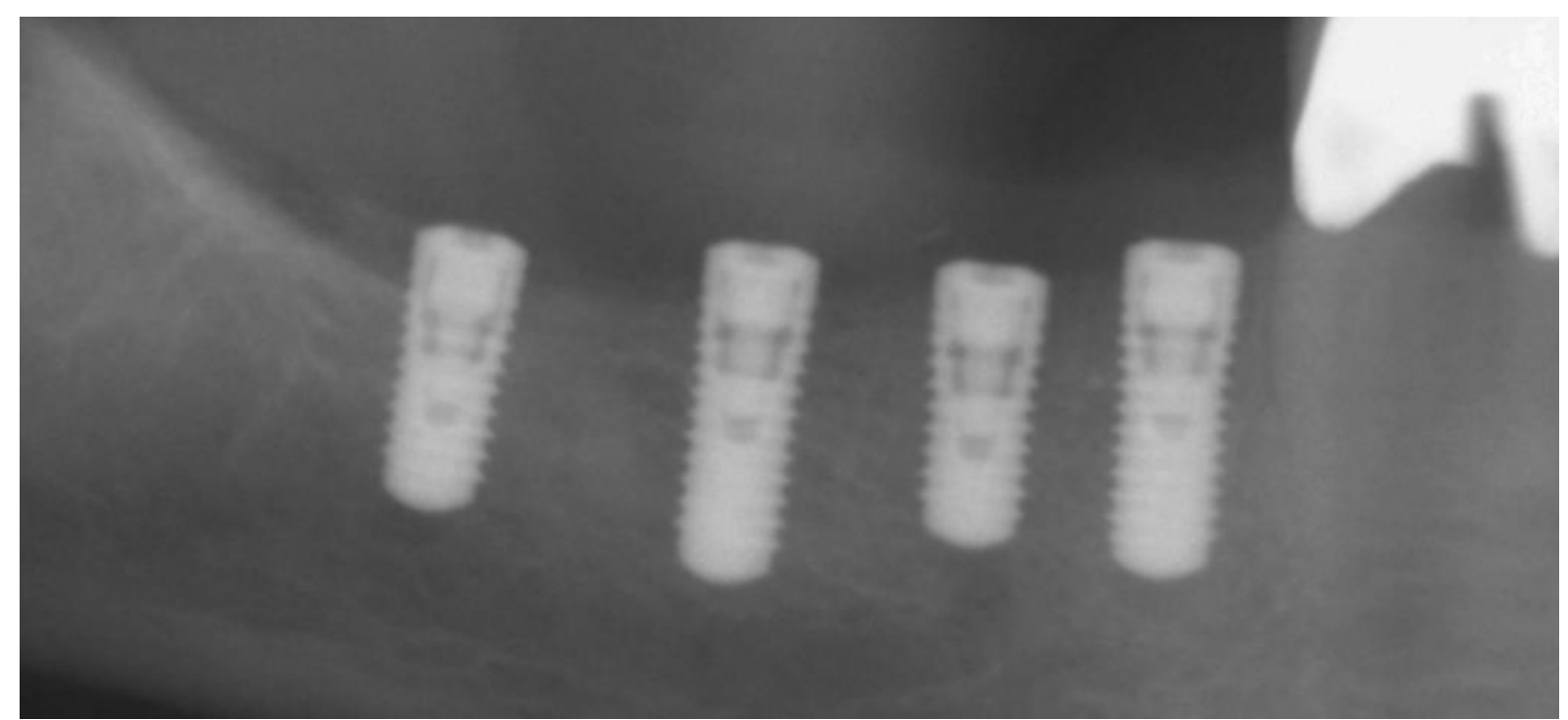

Abbildung 7: Vergrößerter Ausschnitt des postoperativen OPGs desselben Falles wie Abbildung 6 nach Implantatinsertion und lateraler Augmentation im Unterkieferfrontzahnbereich. Die Lokalisation des Augmentats ist auf dem Röntgenbild nicht eindeutig bestimmbar und eine Bestimmung der relativen Röntgendichte daher nicht möglich. 
Zwei weitere Fälle mussten aufgrund Nichtanwendbarkeit des SOP aus der Analyse ausgeschlossen werden. In einem Fall wurde zunächst im Unterkiefer implantiert und augmentiert, dann das postoperative Röntgenbild erstellt und anschließend ein Zahn extrahiert und eine socket preservation durchgeführt. Dadurch lag für die socket preservation kein aussagekräftiges postoperatives Bild vor. In dem anderen Fall handelte es sich um die Entfernung einer Nasopalatinalzyste, deren Defektlumen sich auf der postoperativen Panoramaaufnahm nicht erkennbar projizierte (vgl. Abbildung 8).

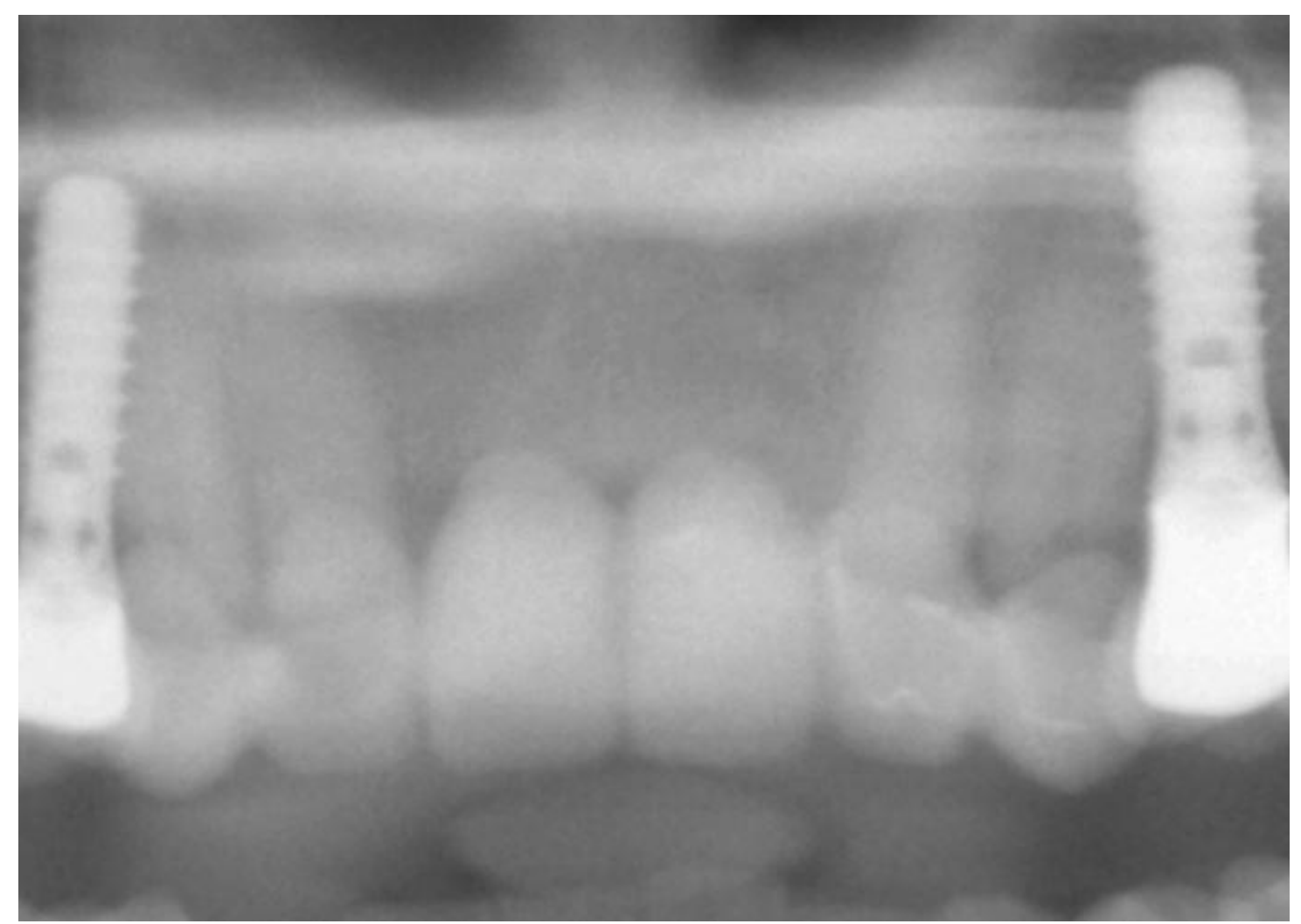

Abbildung 8: Vergrößerter Ausschnitt eines postoperativen OPGs nach Zystektomie und Defektauffüllung einer Nasopalatinalzyste. Das ehemalige Zystenlumen ist auf der Röngenaufnahme nicht auszumachen und daher eine Bestimmung der relativen Röntgendichte nicht möglich.

Der mittlere Beobachtungszeitraum der analysierten Defekte betrug $199 \pm 200$ Tage bei einem durchschnittlichen Alter zum Zeitpunkt der OP von $51 \pm 17$ Jahren. 107 Defekte von männlichen Patienten und 126 von weiblichen wurden analysiert. Davon befanden sich 137 im Oberkiefer und 96 im Unterkiefer (vgl. Tabelle 7). 
Tabelle 7: Gesamtkollektiv der röntgenologisch untersuchten Defekte

\begin{tabular}{|l|l|l|}
\hline Parameter & Wert & Gesamtkollektiv \\
\hline Defekte Gesamt & & $\mathrm{n}=309$ \\
\hline Untersuchte Defekte & & $\mathrm{n}=233$ \\
\hline Mittleres Alter zum OP-Zeitpunkt in Jahren & & $51,0 \pm 17,0$ \\
\hline Mittlerer Beobachtungszeitraum in Tagen & & $199,0 \pm 200,0$ \\
\hline Geschlecht & $\mathrm{m}$ & $107(45,9 \%)$ \\
\cline { 2 - 3 } & w & $126(54,1 \%)$ \\
\hline \multirow{2}{*}{ Lokalisation } & OK & $137(58,8 \%)$ \\
\cline { 2 - 3 } & UK & $96(41,2 \%)$ \\
\hline
\end{tabular}

Prozentuale Angaben und statistische Analysen beziehen sich auf die Anzahl n der untersuchten Defekte.

Tabelle 8 zeigt die Verteilung der Defekte innerhalb der Gruppen sowie Geschlecht und Alter der Patienten zum Zeitpunkt der OP, Beobachtungszeitraum zwischen den Röntgenbildern und die Lokalisation der Knochendefekte. Für Gruppe $V$ wurde aufgrund der geringen Fallzahl auf eine statistische Analyse verzichtet. Eine kurze deskriptive Darstellung der Ergebnisse erfolgt im Rahmen der Betrachtung der einzelnen Gruppenergebnisse.

Tabelle 8: Verteilung der röntgenologisch untersuchten Defekte innerhalb der Gruppen

\begin{tabular}{|c|c|c|c|c|c|c|}
\hline Parameter & Wert & $\begin{array}{l}\text { Gruppe I } \\
\text { socket } \\
\text { preserva- } \\
\text { tion }\end{array}$ & $\begin{array}{l}\text { Gruppe II } \\
\text { WSR und } \\
\text { Zystekto- } \\
\text { mien }\end{array}$ & $\begin{array}{l}\text { Gruppe III } \\
\text { Augmen- } \\
\text { tationen }\end{array}$ & $\begin{array}{l}\text { Gruppe IV } \\
\text { Weisheits- } \\
\text { zahnoste- } \\
\text { otomien }\end{array}$ & $\begin{array}{l}\text { Gruppe V } \\
\text { Paro- } \\
\text { dontale } \\
\text { Defekte }\end{array}$ \\
\hline $\begin{array}{l}\text { Defekte } \\
\text { Gesamt }\end{array}$ & & $n=121$ & $\mathrm{n}=48$ & $\mathrm{n}=91$ & $n=46$ & $n=3$ \\
\hline $\begin{array}{l}\text { Untersuchte } \\
\text { Defekte }\end{array}$ & & $n=120$ & $\mathrm{n}=47$ & $\mathrm{n}=17$ & $n=46$ & $n=3$ \\
\hline $\begin{array}{l}\text { Mittleres Alter } \\
\text { OP-Zeitpunkt } \\
\text { in Jahren }\end{array}$ & & $55,1 \pm 16,2$ & $49,6 \pm 16,2$ & $49,0 \pm 17,9$ & $44,5 \pm 16,5$ & $55,7 \pm 5,1$ \\
\hline $\begin{array}{l}\text { Mittlerer Be- } \\
\text { obachtungs- } \\
\text { zeitraum in } \\
\text { Tagen }\end{array}$ & & $\begin{array}{l}153,3 \\
\pm 86,1\end{array}$ & $\begin{array}{l}218,9 \\
\pm 170,1\end{array}$ & $\begin{array}{l}169,0 \\
\pm 66,7\end{array}$ & $\begin{array}{l}311,1 \\
\pm 369,9\end{array}$ & $\begin{array}{l}112,3 \\
\pm 36,1\end{array}$ \\
\hline \multirow[t]{2}{*}{ Geschlecht } & $\mathrm{m}$ & $42(35 \%)$ & $29(61,7 \%)$ & $12(70,6 \%)$ & $24(52,2 \%)$ & $0(0 \%)$ \\
\hline & w & $78(65 \%)$ & $18(38,3 \%)$ & $5(29,4 \%)$ & $22(47,8 \%)$ & $3(100 \%)$ \\
\hline \multirow[t]{2}{*}{ Lokalisation } & $\mathrm{OK}$ & $64(53,3 \%)$ & $32(68,1 \%)$ & $15(88,2 \%)$ & $24(52,2 \%)$ & $2(66,7 \%)$ \\
\hline & UK & $56(46,7 \%)$ & $15(31,9 \%)$ & $2(11,8 \%)$ & $22(47,8 \%)$ & $1(33,3 \%)$ \\
\hline
\end{tabular}

Prozentuale Angaben und statistische Analysen beziehen sich auf die Anzahl $n$ der untersuchten Defekte. 


\subsubsection{Messungen der relativen Röntgendichte}

Postoperativ betrug die relative Röntgendichte der Knochendefekte im Gesamtkollektiv mittelwertig 0,88 \pm 0,09 mit einem minimalen Wert von 0,52 und einem maximalen Wert von 1,01. Ein signifikanter Effekt der Kieferposition auf die postoperative Röntgendichte konnte festgestellt werden. Defekte im Oberkiefer wiesen kleinere Werte auf $(0,87 \pm 0,1)$ als Defekte die im Unterkiefer lokalisiert waren $(0,9 \pm 0,07)$. Tabelle 9 zeigt die Ergebnisse des univariaten Regressionsmodells sowie der multivariaten linearen Regression für Röntgendichte postoperativ.

Tabelle 9: Ergebnisse der uni- und multivariaten linearen Regressionsmodelle für Röntgendichte.postOP

\begin{tabular}{|l|l|l|l|}
\hline Parameter & Wert & Röntgendichte.Postop & $\mathbf{p}$ \\
\hline \multirow{2}{*}{ Lokalisation } & OK & $0,87 \pm 0,10$ & 0,0158 \\
\cline { 2 - 4 } & UK & $0,90 \pm 0,07$ & \\
\hline Parameter & Reg.koeffizient & Std.fehler & $\mathbf{p}$ \\
\hline Lokalisation UK & 0,024 & 0,011 & 0,0363 \\
\hline
\end{tabular}

Die relative Röntgendichte der ehemaligen Defektregionen auf den Kontrollbildern betrug mittelwertig 0,98 $\pm 0,07$ mit einem minimalen Wert von 0,745 und einem maximalen von 1,282. Abbildung 9 zeigt die Ergebnisse der relativen Röngendichtemessungen im Gesamtkollektiv.

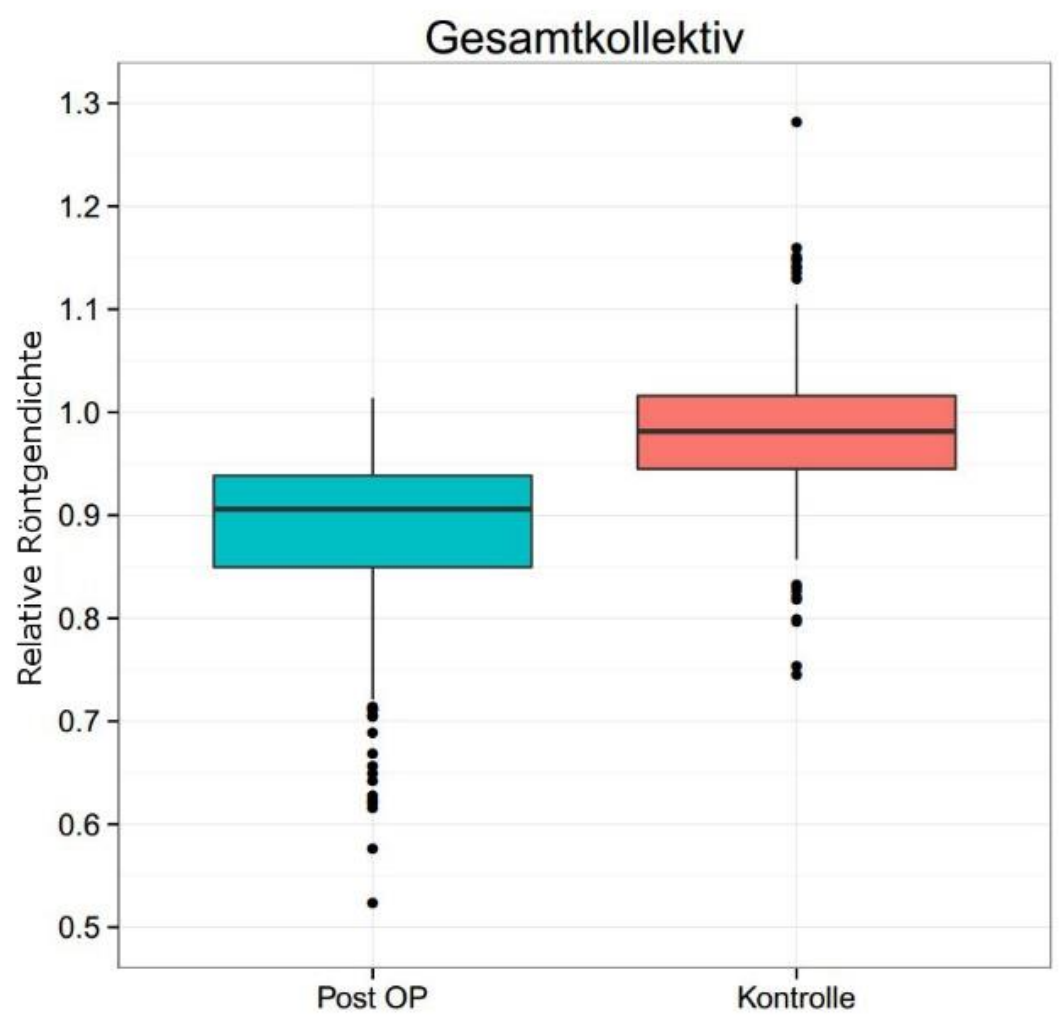

Abbildung 9: Boxplotdarstellung der Ergebnisse der relativen Röntgendichtemessung postoperativ ( $\mathrm{MW}=0,88 \pm 0,09$ ) und zum Kontrollzeitpunkt ( $\mathrm{MW}=0,98 \pm 0,07$ ). 
Es zeigte sich ein signifikanter Zusammenhang von postoperativer Röntgendichte zu der Röntgendichte zum Kontrollzeitpunkt $(p<0,001)$. Eine größere postoperative Röntgendichte korrelierte demnach mit einer größeren Röntgendichte zum Kontrollzeitpunkt (Abbildung 10).

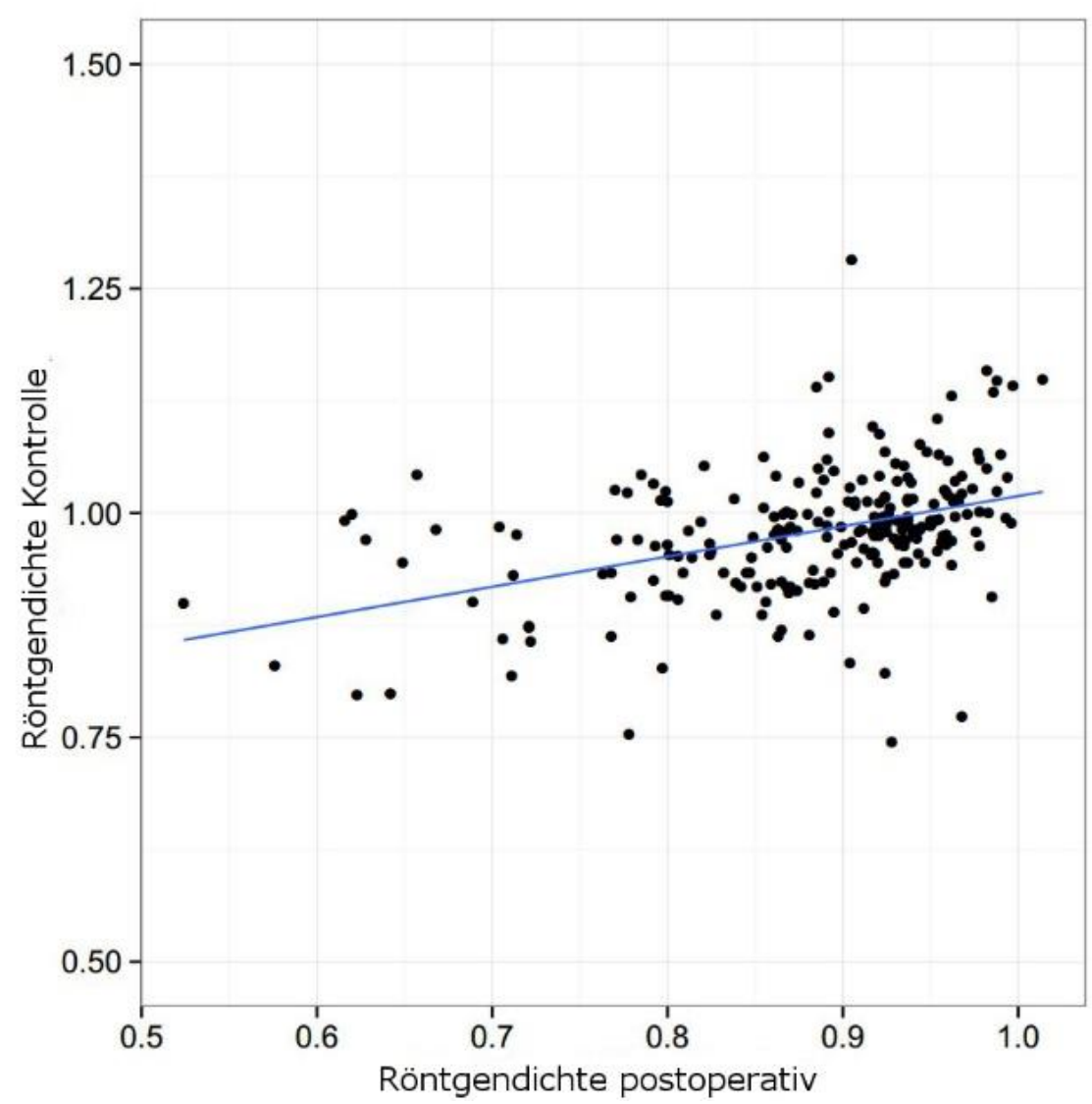

Abbildung 10: Scatterplotdarstellung der Korrelation zwischen Röntgendichte zum Kontrollzeitpunkt und Röntgendichte postoperativ

(Pearsons Korrelationskoeffizient $=0,412$; Regressionskoeffizient $=0,348$ ). 
Die Veränderung der relativen Röntgendichte im Beobachtungszeitraum (Delta) betrug mittelwertig 0,097 $\pm 0,087$ mit einem minimalen Wert von $-0,195$ und einem maximalen Wert von 0,386. Bei 218 von 233 analysierten Defekten ergab sich eine Zunahme der relativen Röntgendichte - dargestellt durch einen positiven Delta-Wert - bei zwei Defekten blieb der Wert konstant und in 13 Fällen war eine Abnahme zu verzeichnen. Ein signifikanter Einfluss des Alters auf Delta konnte in der multivariaten Regression festgestellt werden $(p=0,020)$. Dies lässt sich auf eine schwache negative Korrelation zwischen dem Alter zum Operationszeitpunkt und Delta zurückzuführen (Abbildung 11). Mit zunehmendem Alter wurden die Delta-Werte kleiner, die relative Röntgendichte stieg im Beobachtungszeitraum weniger an als bei jüngeren Patienten.

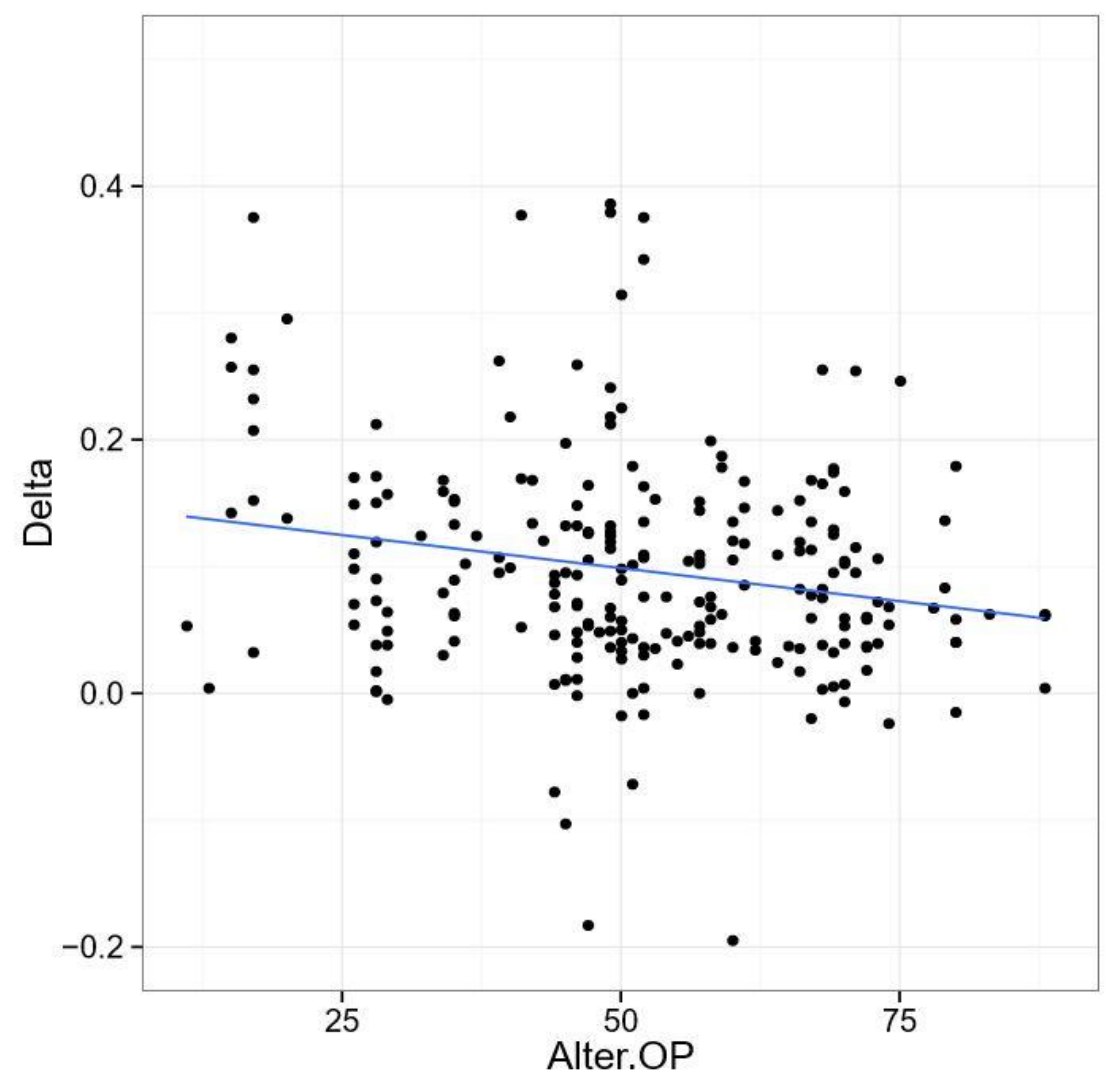

Abbildung 11: Scatterplotdarstellung der Korrelation zwischen Delta (Veränderung der relativen Röntgendichte im Kontrollzeitraum) und Alter zum Operationszeitpunkt (Pearsons Korrelationskoeffizient $=-0,2005$; Regressionskoeffizient $=-0,00097$ ). 
Wie Abbildung 12 zeigt, ergibt sich kein signifikanter Zusammenhang zwischen Delta und dem Beobachtungszeitraum. Ein längerer Beobachtungszeitraum führte nicht zu einem stärkeren Anstieg der relativen Röntgendichte.

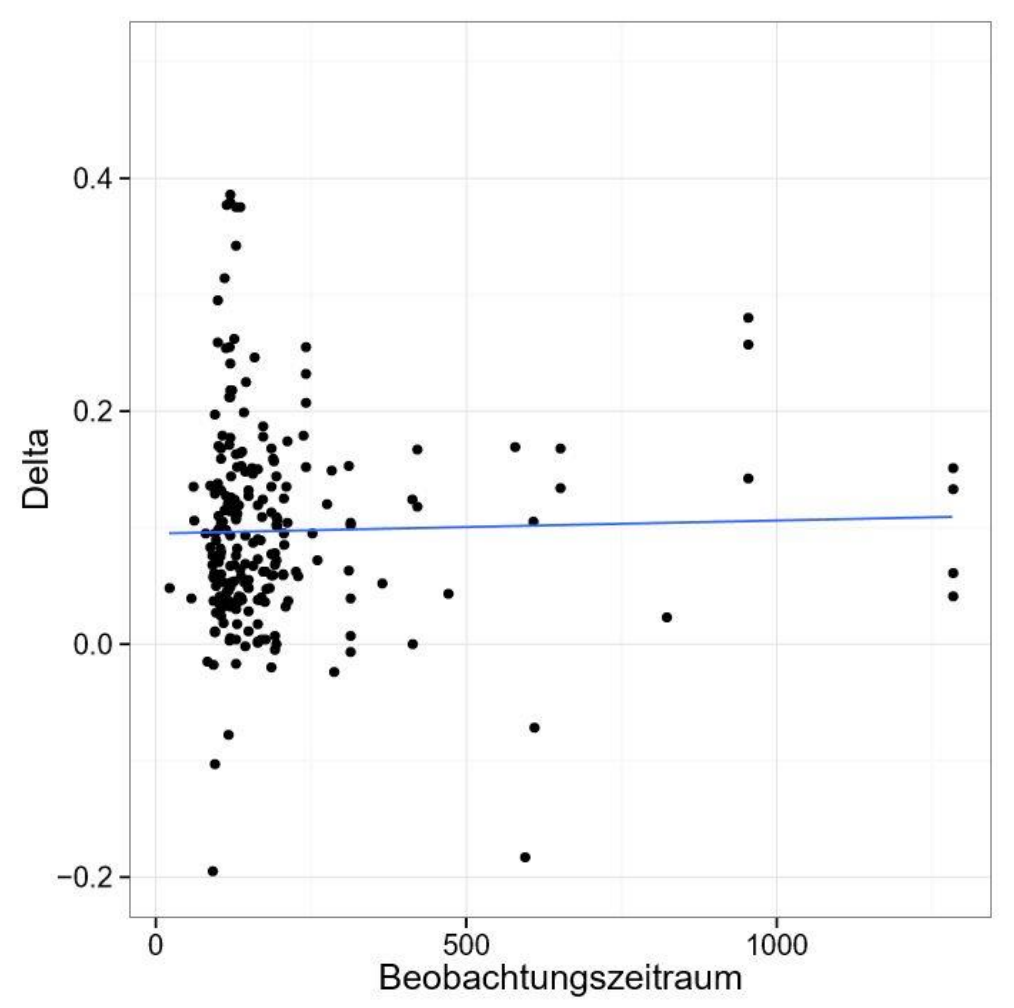

Abbildung 12: Scatterplotdarstellung der Korrelation zwischen Delta (Veränderung der relativen Röntgendichte im Beobachtungszeitraum) und dem Beobachtungszeitraum (Pearsons Korrelationskoeffizient = 0,027; Regressionskoeffizient $<-0,005$ ). 


\subsubsection{Messergebnisse der relativen Röntgendichte}

In allen Gruppen zeigte sich mittelwertig eine Zunahme der relativen Röntgendichte. Die höchsten Werte zeigte Gruppe IV sowohl bei der postoperativen Röntgendichte als auch zum Kontrollzeitpunkt und bei Delta (Abbildung 13).

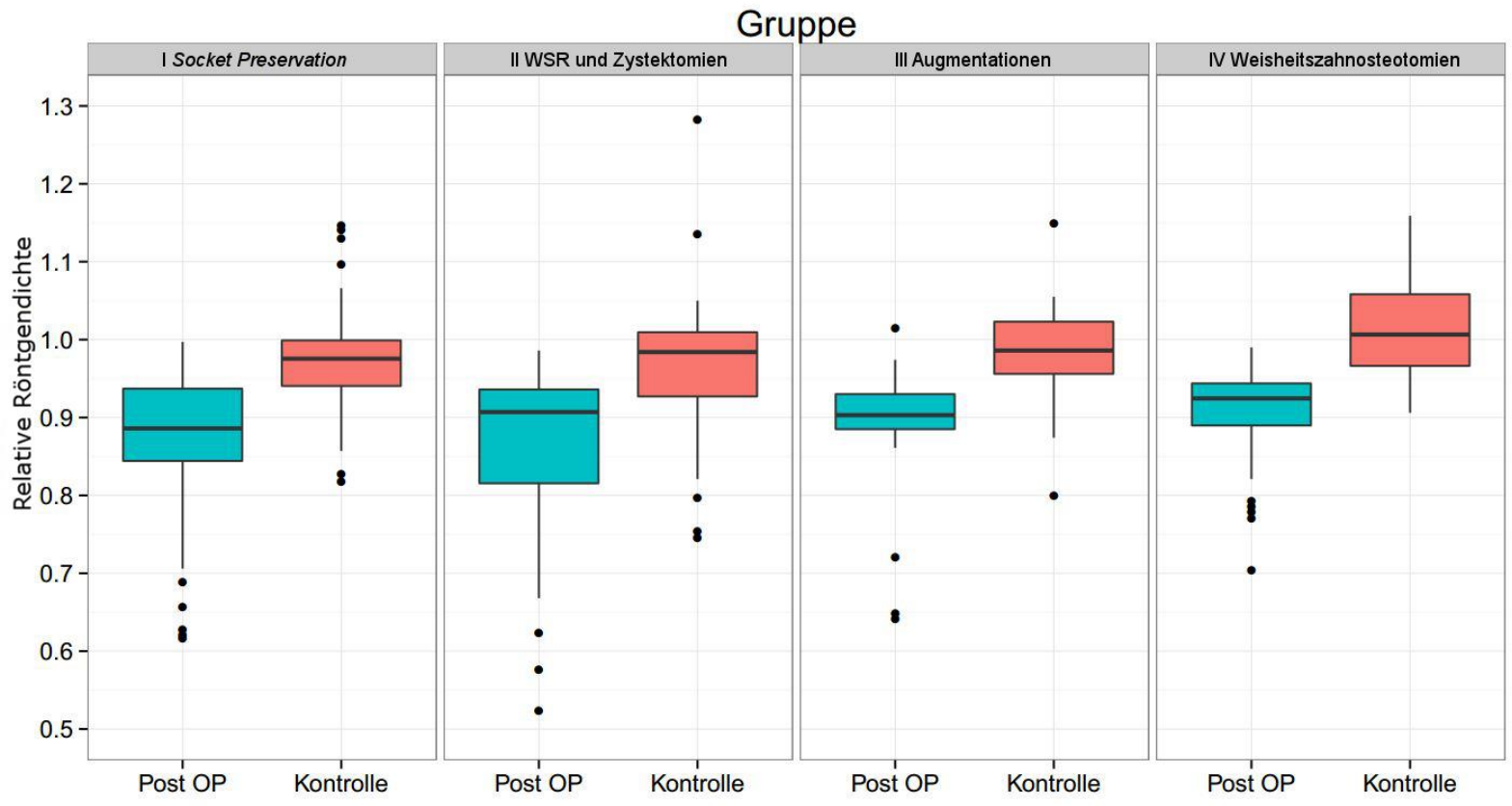

Abbildung 13: Boxplotdarstellung der mittleren relativen Röntgendichte in den einzelnen Gruppen postoperativ und zum Kontrollzeitpunkt. Auf eine graphische Darstellung von Gruppe $\mathrm{V}$ wurde wegen der geringen Fallzahl verzichtet.

In Gruppe I (socket preservation) ergaben sich mittlere relative Röntgendichten von 0,88 \pm 0,08 postoperativ und $0,97 \pm 0,06$ zum Kontrollzeitpunkt. Delta als Maß für die Veränderung der relativen Röntgendichte im Beobachtungszeitraum betrug mittelwertig 0,094 \pm 0,076 mit einem maximalen Wert von 0,386 und einem minimalen Wert von -0,020. Delta war in 116 Fällen positiv und bei 4 Defekten negativ.

Gruppe II (Wurzelspitzenresektionen und Zystektomien) wies mittlere relative Röntgendichten von $0,87 \pm 0,11$ postoperativ und $0,96 \pm 0,09$ bei Kontrolle auf. Delta betrug mittelwertig 0,098 $\pm 0,113$ mit einem Maximum von 0,377 und einem Minimum von -0,183. In 40 Fällen war Delta positiv bei zwei neutralen und fünf negativen Werten.

In Gruppe III (Augmentationen im Zusammenhang mit dentalen Implantationen) ergaben sich mittlere relative Röntgendichten von $0,88 \pm 0,11$ postoperativ und 0,98 $\pm 0,08$ zum Kontrollzeitpunkt. Delta lag mittelwertig bei $0,105 \pm 0,064$ bei einem Höchstwert von 0,295 und einem niedrigsten Wert von $-0,005$. Insgesamt lagen 16 positive und ein negativer DeltaWert vor.

In Gruppe IV (Weisheitszahnosteotomien) betrug die mittlere relative Röntgendichte postoperativ $0,90 \pm 0,06$ und zum Kontrollzeitpunkt bei 1,01 $\pm 0,06$. Es ergab sich ein Mittelwert 
für Delta von 0,110 $\pm 0,077$ bei einem Maximum von 0,280, einem Minimum von $-0,002$ und insgesamt 45 positiven und einem negativen Delta-Wert.

In Gruppe V (Auffüllung parodontaler Knochendefekte) lag die relative Röntgendichte postoperativ mittelwertig bei $0,87 \pm 0,13$ und zum Kontrollzeitpunkt bei $0,85 \pm 0,06$. Delta betrug mittelwertig $-0,021 \pm 0,141$ bei zwei negativen und einem positiven Wert (vgl. Tabelle 10).

Tabelle 10: Übersicht über die Ergebnisse der Röntgendichtemessungen in den einzelnen Gruppen

\begin{tabular}{|l|l|l|l|l|l|}
\hline Parameter & $\begin{array}{l}\text { Gruppe I } \\
\text { socket } \\
\text { preservation }\end{array}$ & $\begin{array}{l}\text { Gruppe II } \\
\text { WSR und } \\
\text { Zystekto- } \\
\text { mien }\end{array}$ & $\begin{array}{l}\text { Gruppe III } \\
\text { Augmenta- } \\
\text { tionen }\end{array}$ & $\begin{array}{l}\text { Gruppe IV } \\
\text { Weisheits- } \\
\text { zahnosteo- } \\
\text { tomien }\end{array}$ & $\begin{array}{l}\text { Gruppe V } \\
\text { Parodontale } \\
\text { Defekte }\end{array}$ \\
\hline $\begin{array}{l}\text { Röntgen- } \\
\text { dichte post- } \\
\text { operativ }\end{array}$ & $0,88 \pm 0,08$ & $0,87 \pm 0,11$ & $0,88 \pm 0,11$ & $0,90 \pm 0,06$ & $0,87 \pm 0,13$ \\
\hline $\begin{array}{l}\text { Röntgen- } \\
\text { dichte } \\
\text { Kontrollbild }\end{array}$ & $0,97 \pm 0,06$ & $0,96 \pm 0,09$ & $0,98 \pm 0,08$ & $1,01 \pm 0,06$ & $0,85 \pm 0,06$ \\
\hline Delta & $\begin{array}{l}0,094 \\
\pm 0,076\end{array}$ & $\begin{array}{l}0,098 \\
\pm 0,113\end{array}$ & $\begin{array}{l}0,105 \\
\pm 0,064\end{array}$ & $\begin{array}{l}0,110 \\
\pm 0,077\end{array}$ & $\pm 0,141$ \\
\hline
\end{tabular}

\subsection{Ergebnisse der klinischen Verläufe}

\subsubsection{Patientenkollektiv}

Bei den 238 von Januar 2006 bis Dezember 2012 operierten Patienten konnten die klinischen Verläufe von 299 Fällen nachverfolgt werden. Tabelle 11 zeigt die erhobenen Patientenstammdaten, das durchschnittliches Alter der Patienten zum Zeitpunkt der OP sowie die Verteilung auf die Geschlechter. Weiterhin aufgeführt sind die angewendeten Maßnahmen zur perioperativen Antibiotika- und medikamentösen Schwellungsprophylaxe. 
Tabelle 11: Gesamtkollektiv der nachverfolgten klinischen Verläufe

\begin{tabular}{|l|l|l|}
\hline Parameter & Wert & Gesamtkollektiv \\
\hline Mnzahl OPs & & $\mathrm{n}=299$ \\
\hline Geschlecht & & 51,0 \\
\hline \multirow{2}{*}{ Antibiotikaprophylaxe } & $\mathrm{m}$ & $156(52,2 \%)$ \\
\cline { 2 - 3 } & $\mathrm{w}$ & $143(47,8 \%)$ \\
\hline \multirow{2}{*}{ Schwellungsprophylaxe } & nein & $40(13,4 \%)$ \\
\cline { 2 - 3 } & ja & $260(87,0 \%)$ \\
\hline
\end{tabular}

Tabelle 12 zeigt die Verteilung der Fälle in den einzelnen Gruppen.

Tabelle 12: Verteilung in Gruppen sowie Durchschnittsalter und Geschlecht

\begin{tabular}{|c|c|c|c|c|c|c|}
\hline Parameter & Wert & $\begin{array}{l}\text { Gruppe I } \\
\text { socket } \\
\text { preserva- } \\
\text { tion }\end{array}$ & $\begin{array}{l}\text { Gruppe II } \\
\text { WSR und } \\
\text { Zystekto- } \\
\text { mien }\end{array}$ & $\begin{array}{l}\text { Gruppe III } \\
\text { Augmenta- } \\
\text { tionen }\end{array}$ & $\begin{array}{l}\text { Gruppe IV } \\
\text { Weisheits- } \\
\text { zahn- } \\
\text { osteotomien }\end{array}$ & $\begin{array}{l}\text { Gruppe V } \\
\text { Parodon- } \\
\text { tale } \\
\text { Defekte }\end{array}$ \\
\hline Anzahl OPs & & 102 & 80 & 49 & 64 & 4 \\
\hline $\begin{array}{l}\text { Mittleres } \\
\text { Alter zum } \\
\text { OP-Zeitpunkt } \\
\text { in Jahren }\end{array}$ & & $56,3 \pm 5,2$ & $50,0 \pm 15,5$ & $56,9 \pm 15,0$ & $38,8 \pm 8,2$ & $55,3 \pm 4,3$ \\
\hline \multirow[t]{2}{*}{ Geschlecht } & $\mathrm{m}$ & $\begin{array}{l}48 \\
(47,1 \%)\end{array}$ & $\begin{array}{l}48 \\
(60 \%)\end{array}$ & $\begin{array}{l}23 \\
(46,9 \%)\end{array}$ & $\begin{array}{l}37 \\
(57,8 \%)\end{array}$ & $\begin{array}{l}0 \\
(0 \%)\end{array}$ \\
\hline & $w$ & $\begin{array}{l}54 \\
(52,9 \%)\end{array}$ & $\begin{array}{l}32 \\
(40 \%)\end{array}$ & $\begin{array}{l}26 \\
(53,1 \%)\end{array}$ & $\begin{array}{l}27 \\
(42,2 \%)\end{array}$ & $\begin{array}{l}4 \\
(100 \%)\end{array}$ \\
\hline \multirow[t]{2}{*}{$\begin{array}{l}\text { Antibiotika- } \\
\text { prophylaxe }\end{array}$} & nein & $\begin{array}{l}17 \\
(16,7 \%)\end{array}$ & $\begin{array}{l}10 \\
(12,5 \%)\end{array}$ & $\begin{array}{l}3 \\
(6,1 \%)\end{array}$ & $\begin{array}{l}10 \\
(15,6 \%)\end{array}$ & $\begin{array}{l}0 \\
(0 \%)\end{array}$ \\
\hline & ja & $\begin{array}{l}85 \\
(83,3 \%)\end{array}$ & $\begin{array}{l}70 \\
(87,5 \%)\end{array}$ & $\begin{array}{l}46 \\
(93,9 \%)\end{array}$ & $\begin{array}{l}54 \\
(84,4 \%)\end{array}$ & $\begin{array}{l}4 \\
(100 \%)\end{array}$ \\
\hline \multirow[t]{2}{*}{$\begin{array}{l}\text { Schwellungs- } \\
\text { prophylaxe }\end{array}$} & nein & $\begin{array}{l}14 \\
(13,7 \%)\end{array}$ & $\begin{array}{l}16 \\
(20 \%)\end{array}$ & $\begin{array}{l}13 \\
(26,5 \%)\end{array}$ & $\begin{array}{l}3 \\
(4,7 \%)\end{array}$ & $\begin{array}{l}1 \\
(25 \%)\end{array}$ \\
\hline & ja & $\begin{array}{l}88 \\
(86,3 \%)\end{array}$ & $\begin{array}{l}64 \\
(80 \%)\end{array}$ & $\begin{array}{l}36 \\
(73,5 \%)\end{array}$ & $\begin{array}{l}61 \\
(95,3 \%)\end{array}$ & $\begin{array}{l}3 \\
(75 \%)\end{array}$ \\
\hline
\end{tabular}


Gruppe V wies mit lediglich 4 Fällen eine zu geringe Fallzahl auf, um statistisch relevante Ergebnisse zu liefern und wird daher nur deskriptiv beschrieben. Auf vergleichende Analyse und graphische Darstellung der Ergebnisse wurde aufgrund mangelnder Relevanz verzichtet.

\subsubsection{Beschreibung der klinischen Verläufe}

\subsubsection{Gesamtkollektiv zu den einzelnen Untersuchungszeiträumen}

In 48 Fällen (16\%) traten zum Zeitraum T1 (1. - 4. Tag postoperativ) verschiedene Komplikationen auf, wobei Nachblutungen und starke Schwellungen mit jeweils 18 Fällen (6\%) am häufigsten auftraten. 13 Patienten (4,3\%) erschienen nicht zu Kontrolluntersuchungen in diesem Intervall. Abbildung 14 zeigt die klinischen Verläufe im Untersuchungszeitraum T1 sowie die Verteilung der aufgetretenen Komplikationen im Gesamtkollektiv.

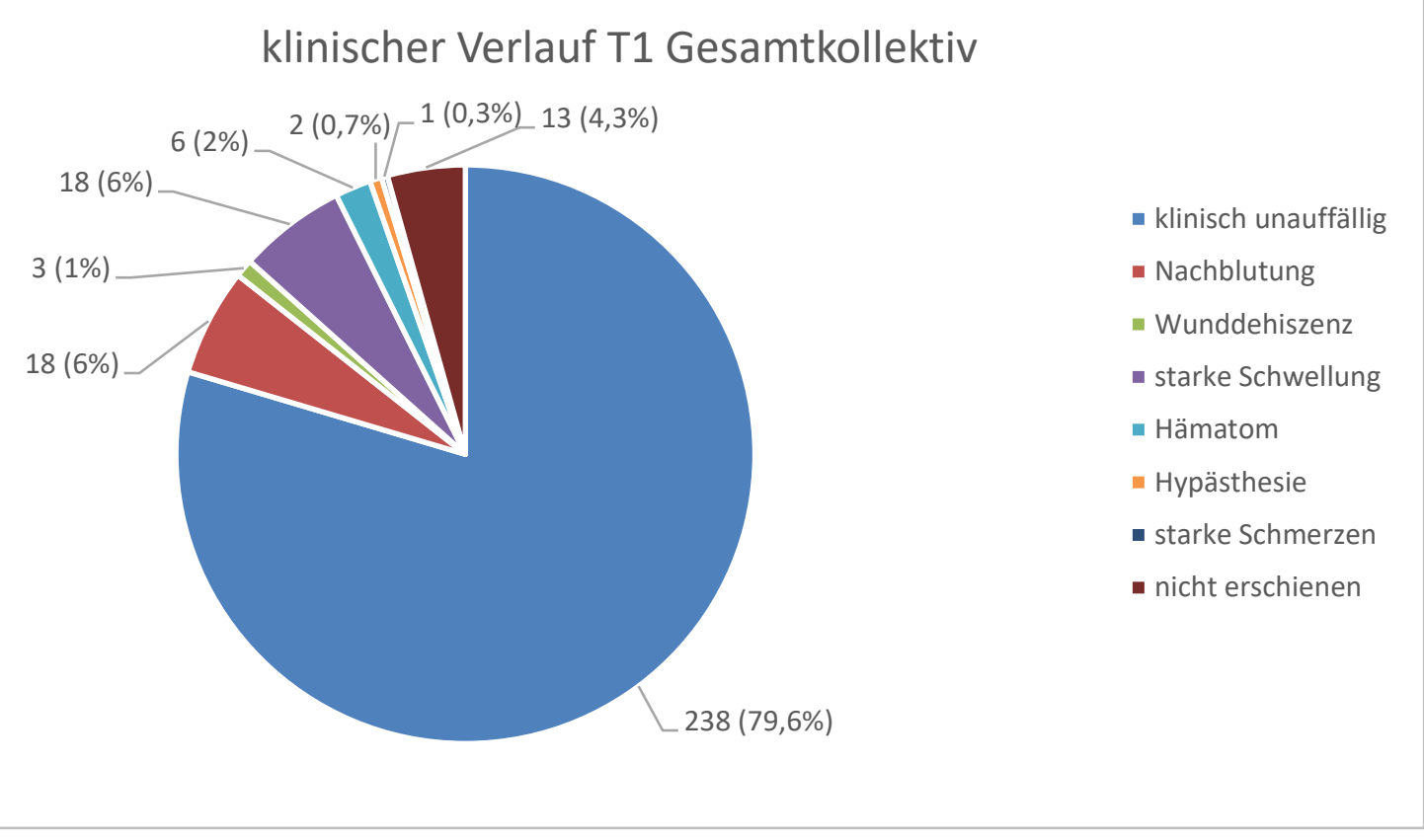

Abbildung 14: Diagramm zur Häufigkeit und prozentualen Verteilung der klinischen Verläufe innerhalb des Gesamtkollektivs im Untersuchungszeitraum T1

Die vergleichende statistische Auswertung ergab einen Einfluss des Geschlechts auf das Auftreten von Komplikationen ( $p=0,0047$ ). Frauen hatten im Vergleich zu Männern ein 2,7fach höheres Risiko eine Komplikation zu erleiden. Tabelle 13 zeigt die Ergebnisse der multivariaten logistischen Regression für alle untersuchten Parameter. 
Tabelle 13: Ergebnisse der multivariaten logistischen Regression für Komplikationen Ja/Nein bei T1.

\begin{tabular}{|l|l|l|l|l|}
\hline Parameter & Regressionskoeffizient & Standardfehler & $\begin{array}{l}\text { odds } \\
\text { ratio }\end{array}$ & $\mathbf{p}$ \\
\hline Antibiotikaprophylaxe & 1,4610 & 0,7478 & 4,31 & 0,0508 \\
\hline $\begin{array}{l}\text { Alter zum OP-Zeitpunkt } \\
\text { in Jahren }\end{array}$ & $-0,0085$ & 0,0100 & 0,99 & 0,3962 \\
\hline weibliches Geschlecht & 0,9951 & 0,3521 & 2,70 & 0,0047 \\
\hline Schwellungsprophylaxe & 0,3646 & 0,4724 & 1,44 & 0,4402 \\
\hline
\end{tabular}

In 35 Fällen (11,6\%) traten im Untersuchungszeitraum T2 (5.-14. Tag postoperativ) verschiedene Komplikationen auf. Am häufigsten traten Wunddehiszenzen mit 13 Fällen $(4,3 \%)$ auf. 12 Personen (4\%) erschienen nicht zu Nachkontrollterminen in diesem Intervall. Zum Zeitraum T2 ergab sich kein signifikanter Einfluss der untersuchten Parameter auf das Auftreten von Komplikationen. Abbildung 15 zeigt die klinischen Verläufe im Untersuchungszeitraum T2 sowie die Verteilung der aufgetretenen Komplikationen im Gesamtkollektiv.

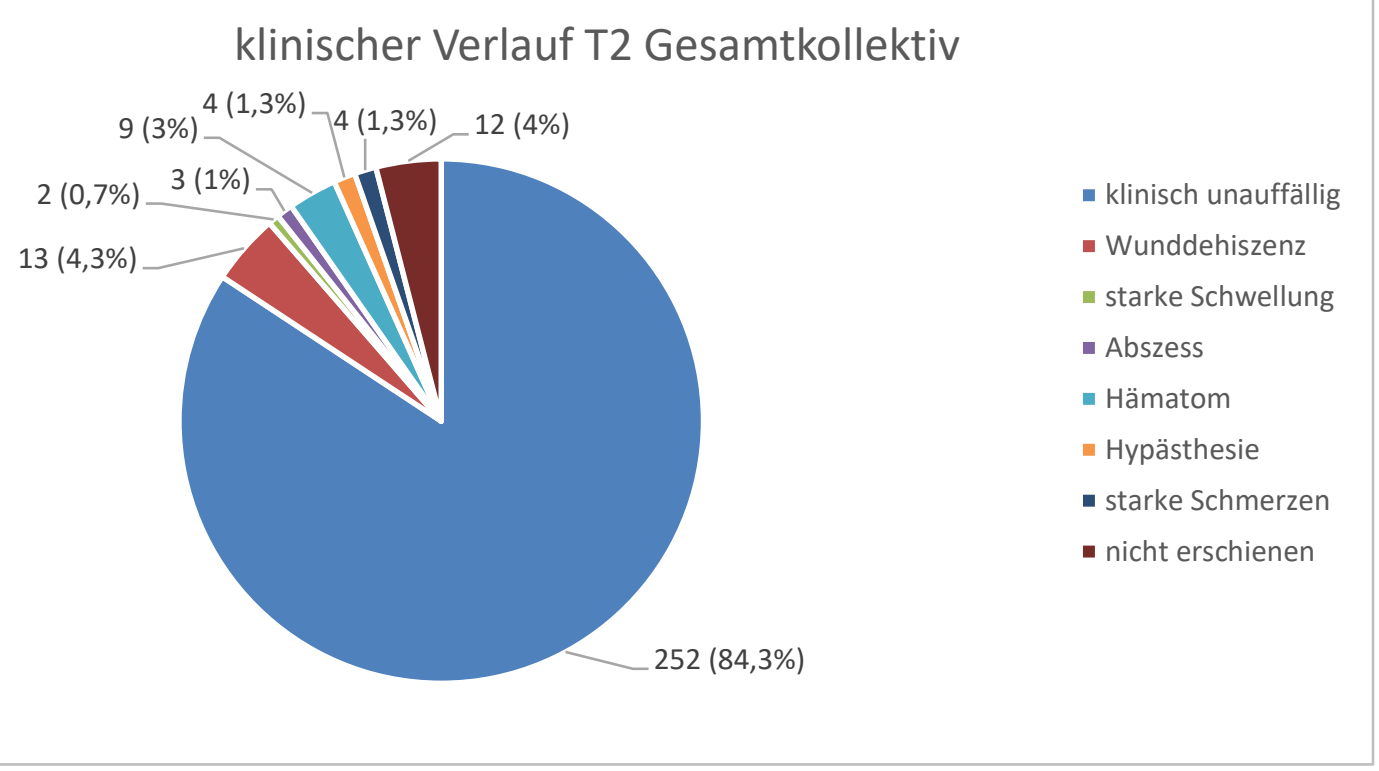

Abbildung 15: Diagramm zur Häufigkeit und prozentualen Verteilung der klinischen Verläufe innerhalb des Gesamtkollektivs im Untersuchungszeitraum T2.

In 24 Fällen (8,1\%) traten im Untersuchungszeitraum T3 (ab 15. Tag postoperativ) Komplikationen auf, wobei Zahn- und Implantatverlust mit 11 Fällen (4,3\%) die häufigste Ursache darstellte. 107 (35,5\%) erschienen nicht zu weiteren Kontrollen in diesem Intervall. In 40 Fällen konnte nach einer socket preservation innerhalb des Beobachtungszeitraums eine Implantation durchgeführt werden (vgl. Abbildung 16). 
Es ergab sich kein signifikanter Einfluss der untersuchten Parameter hinsichtlich des Auftretens von Komplikationen zum Zeitraum T3.
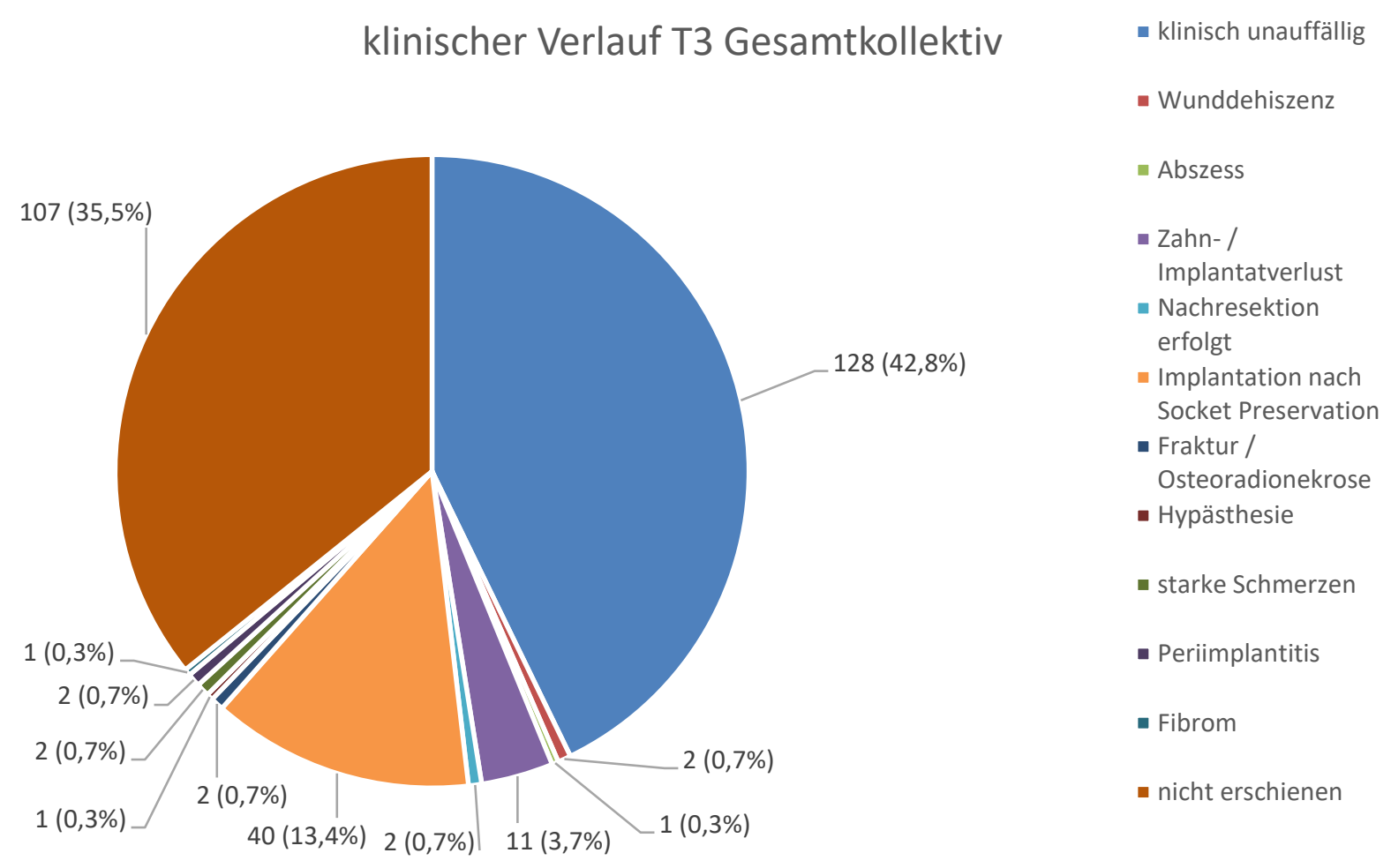

Abbildung 16: Diagramm zur Häufigkeit und prozentualen Verteilung der klinischen Verläufe innerhalb des Gesamtkollektivs im Untersuchungszeitraum T3.

\subsubsection{Betrachtung der Gruppen}

Zu den Zeiträumen T1 und T2 liegt der Anteil, der nachuntersuchten Patienten in allen Gruppen bei über 93\%. Dieser sinkt bei T3 in der Gruppen I auf 69,6\%, in Gruppe II auf 60\% und in Gruppe IV auf 37,5\%. ab. Gruppe III hat, abgesehen von der statistisch nicht relevanten Gruppe V (100\%), mit 91,8\% die höchste Nachuntersuchungsquote zum Zeitraum T3. Tabelle 14 zeigt die Nachuntersuchungsquoten der einzelnen Gruppen zu den jeweiligen Beobachtungszeiträumen.

Tabelle 14: Nachuntersuchungsquote der einzelnen Gruppen zu den jeweiligen Beobachtungszeiträumen

\begin{tabular}{|c|c|c|c|c|c|c|c|c|c|c|c|}
\hline \multicolumn{3}{|c|}{$\begin{array}{c}\text { Gruppe I } \\
\text { socket } \\
\text { preservation }\end{array}$} & \multicolumn{3}{|c|}{$\begin{array}{c}\text { Gruppe II } \\
\text { WSR und } \\
\text { Zystektomien }\end{array}$} & \multicolumn{3}{|c|}{$\begin{array}{c}\text { Gruppe III } \\
\text { Augmentationen }\end{array}$} & \multicolumn{3}{|c|}{$\begin{array}{c}\text { Gruppe IV } \\
\text { Weisheitszahn- } \\
\text { osteotomien }\end{array}$} \\
\hline $\mathrm{T} 1$ & T2 & T3 & T1 & T2 & T3 & $\overline{T 1}$ & T2 & T3 & T1 & T2 & T3 \\
\hline \multicolumn{3}{|c|}{$n=102$} & \multicolumn{3}{|c|}{$n=80$} & \multicolumn{3}{|c|}{$n=49$} & \multicolumn{3}{|c|}{$n=64$} \\
\hline $97,1 \%$ & $98 \%$ & $69,6 \%$ & $93,8 \%$ & $96,2 \%$ & $60 \%$ & $95,9 \%$ & $93,9 \%$ & $91,8 \%$ & $95,3 \%$ & $93,8 \%$ & $37,6 \%$ \\
\hline
\end{tabular}


Von allen nachuntersuchten Patienten wurde für die jeweilige Gruppe zu dem jeweiligen Untersuchungszeitraum die Komplikationsrate errechnet (vgl. Tabelle 15).

Tabelle 15: Komplikationsrate der einzelnen Gruppen zu den jeweiligen Beobachtungszeiträumen

\begin{tabular}{|c|c|c|c|c|c|c|c|c|c|c|c|}
\hline $\begin{array}{c}\text { Gruppe I } \\
\text { socket } \\
\text { preservation }\end{array}$ & \multicolumn{2}{c|}{$\begin{array}{c}\text { Gruppe II } \\
\text { WSR und } \\
\text { Zystektomien }\end{array}$} & \multicolumn{2}{c|}{$\begin{array}{c}\text { Gruppe III } \\
\text { Augmentationen }\end{array}$} & \multicolumn{2}{c|}{$\begin{array}{c}\text { Gruppe IV } \\
\text { Weisheitszahn- } \\
\text { osteotomien }\end{array}$} \\
\hline T1 & T2 & T3 & T1 & T2 & T3 & T1 & T2 & T3 & T1 & T2 & T3 \\
\hline $\mathrm{n}=99$ & $\mathrm{n}=100$ & $\mathrm{n}=71$ & $\mathrm{n}=75$ & $\mathrm{n}=77$ & $\mathrm{n}=48$ & $\mathrm{n}=47$ & $\mathrm{n}=46$ & $\mathrm{n}=45$ & $\mathrm{n}=61$ & $\mathrm{n}=60$ & $\mathrm{n}=24$ \\
\hline $16,2 \%$ & $7 \%$ & $1,4 \%$ & $22,7 \%$ & $16,9 \%$ & $29,2 \%$ & $4,3 \%$ & $13 \%$ & $11,1 \%$ & $21,3 \%$ & $15 \%$ & $12,5 \%$ \\
\hline
\end{tabular}

In Gruppe I und Gruppe IV nahm die Komplikationsrate von T1 zu T3 ab. Den niedrigsten Wert insgesamt zeigte Gruppe I zum Zeitraum T3 (1,4\%). Bei Gruppe II war die Komplikationsrate insgesamt am höchsten und zeigte bei T3 mit 29,2\% den höchsten Wert. Auffällig ist ebenfalls die Entwicklung der Komplikationsrate von Gruppe III, die direkt postoperativ mit 4,3\% den niedrigsten Wert bei T1 zeigt, dann aber als einzige Gruppe zu T2 einen höheren Wert aufweist (Abbildung 17).

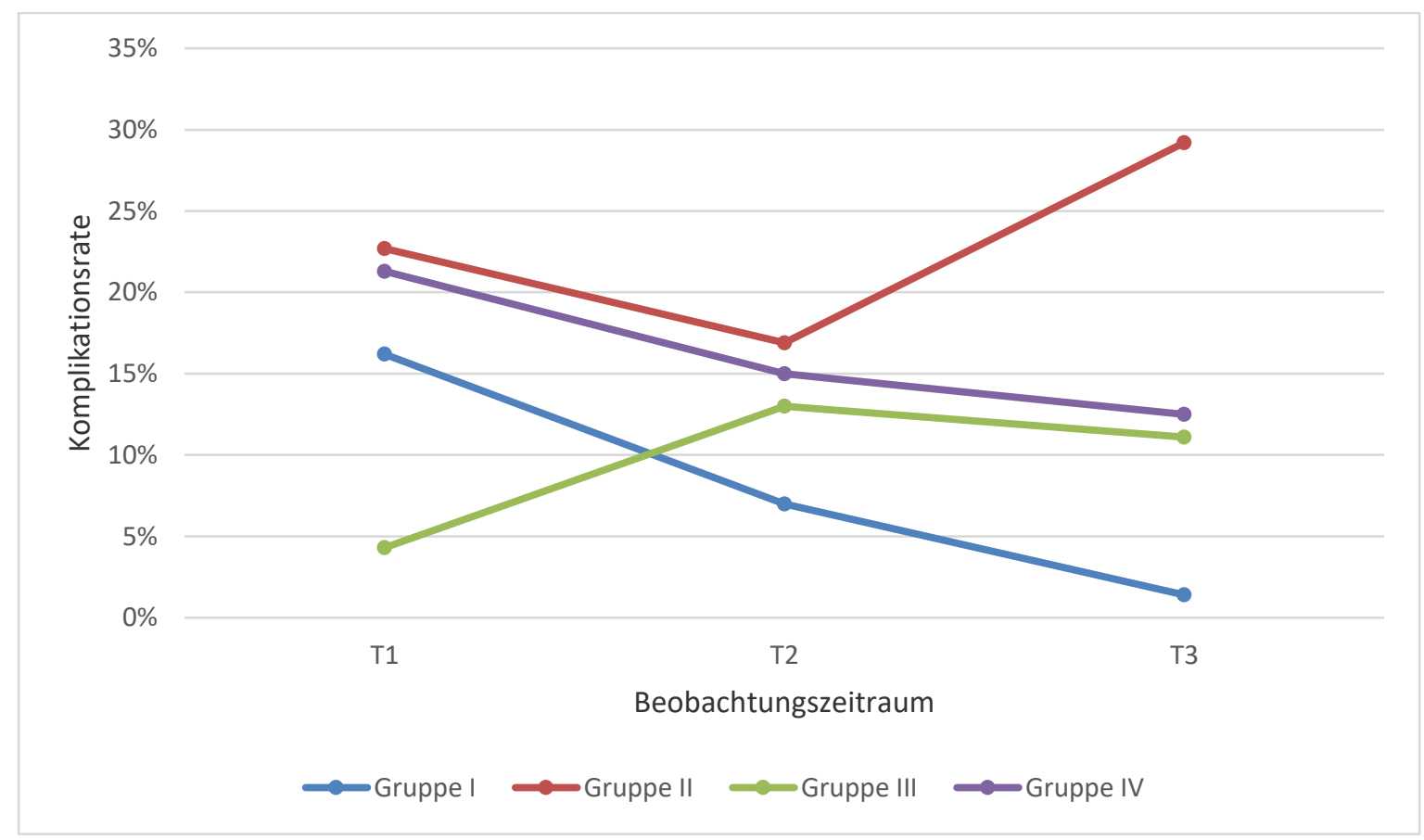

Abbildung 17: Komplikationsraten der einzelnen Gruppen im Vergleich 
Die einzelnen Gruppen zeigten zu den jeweiligen Untersuchungszeiträumen unterschiedliche klinische Verläufe. Tabelle 16 zeigt die Häufigkeiten der aus der Patientenkartei hervorgehenden postoperativen Verläufe in den verschiedenen Gruppen.

Bei Gruppe I lagen zu T1 am häufigsten Nachblutungen (7,8\%) vor während bei T2 Wunddehiszenzen mit 2,9\% am häufigsten Auftraten. In 40 Fällen (39,2\%) erfolgte im Beobachtungszeitraum T3 eine Implantation im versorgten Defektgebiet. Bei einem Patienten trat als Folge einer Bestrahlung und sich daraus entwickelnder Osteoradionekrose eine Fraktur der Mandibula auf, die sich jedoch nicht im ursprünglichen Operationsgebiet befand.

In Gruppe II traten zu T1 am häufigsten Nachblutungen (8,8\%) gefolgt von starken Schwellungen (7,5\%) auf, während bei T2 Wunddehiszenzen und Hämatome mit 7,5\% am häufigsten waren. Im Beobachtungszeitraum T3 mussten die betroffenen Zähne in 8 Fällen (10\%) entfernt und in 2 Fällen (2,5\%) nachreseziert werden.

Gruppe III hatte bei T1 jeweils einen Fall (2\%) von starker Schwellung und Hypästhesie als einzig aufgetretene Auffälligkeiten. Bei T2 lagen Wunddehiszenzen und Hypästhesien bei $4,1 \%$ der Fälle vor. In 2 Fällen (4,1\%) mussten gesetzte Implantate nach Augmentation im Beobachtungszeitraum wieder entfernt werden. Bei 2 Patienten $(4,1 \%)$ bildete sich eine Periimplantitis aus, die eine Weiterbehandlung erforderte.

Während bei Gruppe IV zu T1 starke Schwellungen (10,9\%) und Nachblutungen (4,7\%) am häufigsten waren, zeigten sich bei T2 vor allem Schmerzen (4,7\%). Als Langzeitkomplikationen ergaben sich in jeweils einem Fall eine Hypästhesie, persistierende Schmerzen und Fibrombildung. Diese trat allerdings erst zweieinhalb Jahre nach dem OP-Zeitpunkt auf, ohne räumlichen Zusammenhang zum Operationsgebiet.

In Gruppe V musste einer der behandelten Zähne im Beobachtungszeitraum T3 entfernt werden, ansonsten traten keine auffälligen klinischen Verläufe auf. 
Tabelle 16: Klinische Verläufe zahlencodiert mit prozentualer Häufigkeit nach Gruppen sortiert

\begin{tabular}{|c|c|c|c|c|c|c|c|c|c|c|c|c|c|c|c|}
\hline \multirow{3}{*}{$\begin{array}{l}\text { Klinische } \\
\text { Verläufe }\end{array}$} & \multicolumn{3}{|c|}{$\begin{array}{c}\text { Gruppe I } \\
\text { socket preservation }\end{array}$} & \multicolumn{3}{|c|}{$\begin{array}{c}\text { Gruppe II } \\
\text { WSR und Zystektomien }\end{array}$} & \multicolumn{3}{|c|}{$\begin{array}{c}\text { Gruppe III } \\
\text { Augmentationen }\end{array}$} & \multicolumn{3}{|c|}{$\begin{array}{c}\text { Gruppe IV } \\
\text { Weisheitszahnosteotomien }\end{array}$} & \multicolumn{3}{|c|}{$\begin{array}{c}\text { Gruppe V } \\
\text { Parodontale Defekte }\end{array}$} \\
\hline & \multicolumn{3}{|c|}{$\mathrm{n}=102$} & \multicolumn{3}{|c|}{$\mathrm{n}=80$} & \multicolumn{3}{|c|}{$n=49$} & \multicolumn{3}{|c|}{$\mathrm{n}=64$} & \multicolumn{3}{|c|}{$\mathrm{n}=4$} \\
\hline & $\mathrm{T} 1$ & T2 & T3 & $\mathrm{T1}$ & T2 & T3 & $\mathrm{T} 1$ & T2 & T3 & $\mathrm{T} 1$ & T2 & T3 & $\mathrm{T} 1$ & T2 & T3 \\
\hline 0 & $81,4 \%$ & $91,2 \%$ & $29,4 \%$ & $72,5 \%$ & $80 \%$ & $43,7 \%$ & $91,8 \%$ & $81,6 \%$ & $79,5 \%$ & $75 \%$ & $79,7 \%$ & $32,8 \%$ & $100 \%$ & $100 \%$ & $75 \%$ \\
\hline 1 & $7,8 \%$ & & & $8,8 \%$ & & & & & & $4,7 \%$ & & & & & \\
\hline 2 & $2 \%$ & $2,9 \%$ & & $1,2 \%$ & $7,5 \%$ & $1,2 \%$ & & $4,1 \%$ & $2 \%$ & & $3,1 \%$ & & & & \\
\hline 3 & $3,9 \%$ & $1 \%$ & & $7,5 \%$ & & & $2 \%$ & $2 \%$ & & $10,9 \%$ & & & & & \\
\hline 4 & & & & & $1,2 \%$ & $1,2 \%$ & & & & & $3,1 \%$ & & & & \\
\hline 5 & & & & & & $10 \%$ & & & $4,1 \%$ & & & & & & $25 \%$ \\
\hline 6 & $1 \%$ & $1 \%$ & & $3,8 \%$ & $7,5 \%$ & & & & & $3,1 \%$ & $3,1 \%$ & & & & \\
\hline 7 & & & & & & $2,5 \%$ & & & & & & & & & \\
\hline 8 & & & $39,2 \%$ & & & & & & & & & & & & \\
\hline 9 & & & $1 \%$ & & & & & & $2 \%$ & & & & & & \\
\hline 10 & $1 \%$ & $2 \%$ & & & & & $2 \%$ & $4,1 \%$ & & & & $1,6 \%$ & & & \\
\hline 11 & & & & & & $1,2 \%$ & & $2 \%$ & & $1,6 \%$ & $4,7 \%$ & $1,6 \%$ & & & \\
\hline 12 & & & & & & & & & $4,1 \%$ & & & & & & \\
\hline 13 & & & & & & & & & & & & $1,6 \%$ & & & \\
\hline 99 & $2,9 \%$ & $2 \%$ & $30,4 \%$ & $6,2 \%$ & $3,8 \%$ & $40 \%$ & $4,1 \%$ & $6,1 \%$ & $8,2 \%$ & $4,7 \%$ & $6,2 \%$ & $62,5 \%$ & & & \\
\hline
\end{tabular}

Legende: T1: 1. - 4. Tag postoperativ; T2: 5. - 14. Tag postoperativ; T3: ab 15. Tag postoperativ

\section{Klinische Verläufe:}

0 - Klinisch unauffälliger Verlauf

1 - Nachblutung

2 - Wunddehiszenz

3 - Starke Schwellung

4 - Abszess

5 - Zahn- oder Implantatverlust

6 - Hämatom

8 - Implantation nach socket preservation

9 - Fraktur / Osteoradionekrose

10 - Hypästhesie

11 - Starke Schmerzen

12 - Periimplantitis

13 - Fibrombildung

7 - Nachresektion erforderlich nach WSR

99 - Im Kontrollintervall nicht zur Untersuchung erschienen 


\subsection{Vergleich zwischen relativer Röntgendichte und klinischem Verlauf}

Um festzustellen, ob Korrelationen zwischen den Messungen der relativen Röntgendichte und den klinischen Beobachtungen bestehen, wurden die Fälle, bei denen Daten zum radiologischen und klinischen Verlauf vorlagen, statistisch miteinander verglichen. Die postoperativen Röntgendichten wurden mit dem Auftreten von Komplikationen zum Zeitraum T1, die Röntgendichten der Kontrollbilder und die Deltawerte mit den klinischen Verläufen von T3 verglichen. Fälle mit Komplikationen im Untersuchungszeitraum T3 wiesen zwar kleinere relative Röntgendichten zum Kontrollzeitpunkt auf, es zeigten sich aber keine signifikanten Korrelationen (Tabelle 17).

Tabelle 17: Ergebnisse der statistischen Auswertung von Korrelationen zwischen beiden Teilstudien

\begin{tabular}{|l|l|l|l|l|}
\hline Variable & \multicolumn{2}{|c|}{ Komplikation bei T1 } & p & p.Holm \\
\cline { 2 - 5 } & nein & ja & & \\
\hline \multirow{2}{*}{$\begin{array}{l}\text { Relative Röntgen- } \\
\text { dichte RöPostOP }\end{array}$} & $0,88 \pm 0,08$ & $0,87 \pm 0,1$ & 0,6626 & 1,0000 \\
\hline & \multicolumn{2}{|c|}{ Komplikation bei T3 } & $\mathbf{p}$ & p.Holm \\
\cline { 2 - 5 } & nein & Ja & 0,926 & 1,0000 \\
\hline $\begin{array}{l}\text { Differenz der rela- } \\
\text { tiven Röntgendich- } \\
\text { te (Delta) }\end{array}$ & $0,1 \pm 0,09$ & $0,1 \pm 0,12$ & 0,2574 \\
\hline $\begin{array}{l}\text { Relative Röntgen- } \\
\text { dichte RöKntr }\end{array}$ & $0,98 \pm 0,07$ & $0,95 \pm 0,08$ & 0,0858 & \\
\hline
\end{tabular}

Weiterhin wurde untersucht, ob das Auftreten von Zahn- oder Implantatverlust bei T3 in den Gruppen II und III mit einer niedrigeren Röntgendichte zum Kontrollzeitpunkt vergesellschaftet ist. Sowohl Delta, als auch die Röntgendichte zum Kontrollzeitpunkt zeigten kleinere Werte bei Fällen die die Komplikation Zahn- / Implantatverlust aufwiesen, die aber aufgrund der kleinen Gruppengröße und der dadurch notwendigen Bonferroni-Holm-Adjustierung der p-Werte keine Signifikanz erreichten, wie Tabelle 18 zeigt.

Tabelle 18: Vergleich von Fällen mit Zahn- oder Implantatverlust und klinisch unauffälligen Fällen in Gruppe II und III hinsichtlich Delta und Röntgendichte zum Kontrollzeitpunkt

\begin{tabular}{|l|l|l|l|l|}
\hline \multirow{2}{*}{ Variable } & \multicolumn{2}{|c|}{ Komplikation bei T3 } & p & p.Holm \\
\cline { 2 - 4 } & nein & $\begin{array}{l}\text { Zahn- oder Implan- } \\
\text { tatverlust (Code 5) }\end{array}$ & \\
\hline $\begin{array}{l}\text { Differenz der rela- } \\
\text { tiven Röntgen- } \\
\text { dichte (Delta) }\end{array}$ & $0,11+/-0,1$ & $-0,01+/-0,15$ & 0,0617 & 0,2468 \\
\hline $\begin{array}{l}\text { Relative Rönt- } \\
\text { gendichte RöKntr }\end{array}$ & $0,98+/-0,09$ & $0,88+/-0,11$ & 0,0295 & 0,1475 \\
\hline
\end{tabular}


Von den 15 Fällen, bei denen sich ein Wert für Delta $\leq 0$ ergab, lagen für 14 Fälle klinische Verläufe zum Zeitpunkt T3 vor. Gruppe II war mit sieben Fällen am häufigsten vertreten (vgl. Abbildung 18).

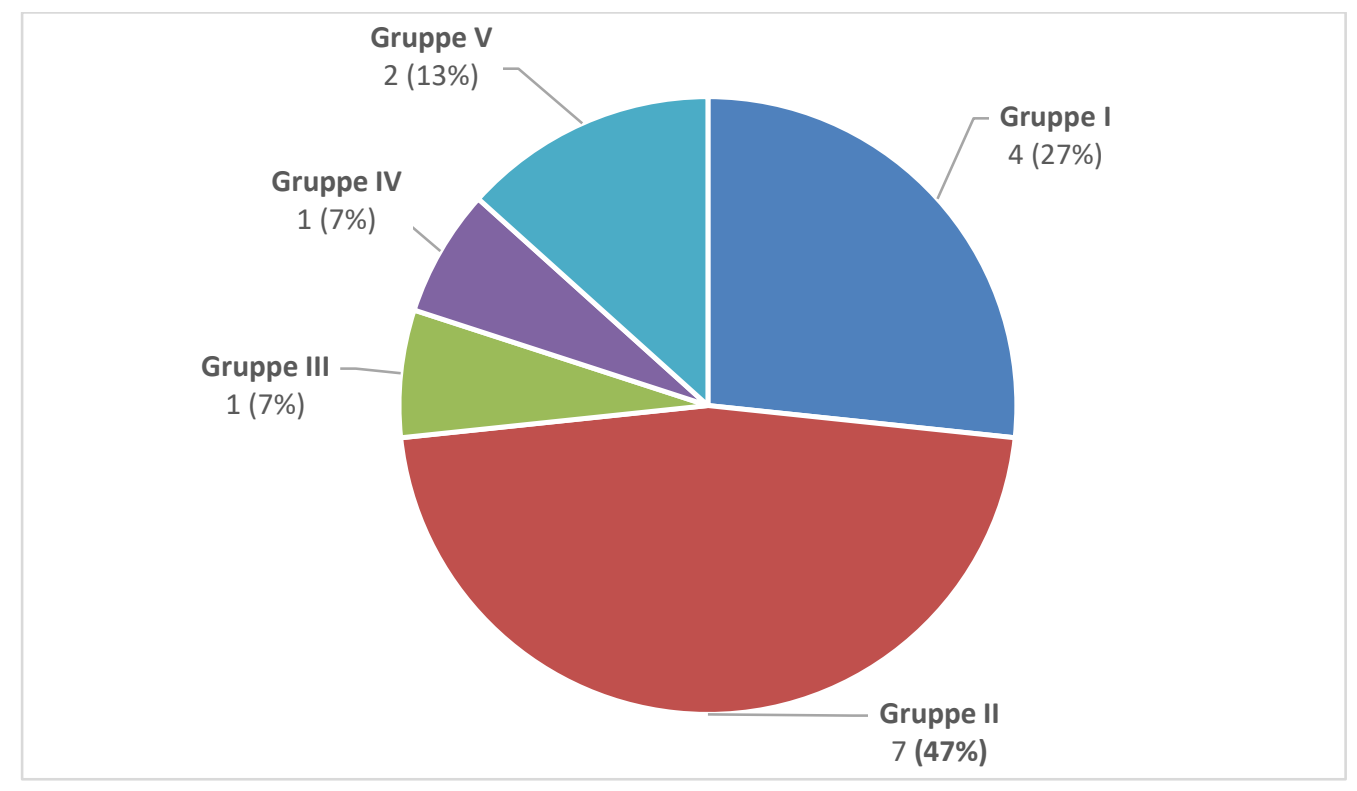

Abbildung 18: Diagramm zur Verteilung der Fälle mit negativem Delta auf die einzelnen Gruppen

In $80 \%$ der Fälle trat keine Komplikation zum Zeitraum T3 auf. Bei zwei Fällen - jeweils aus der Gruppe II - mussten die betreffenden Zähne im Beobachtungszeitraum entfernt werden (vgl. Abbildung 19).

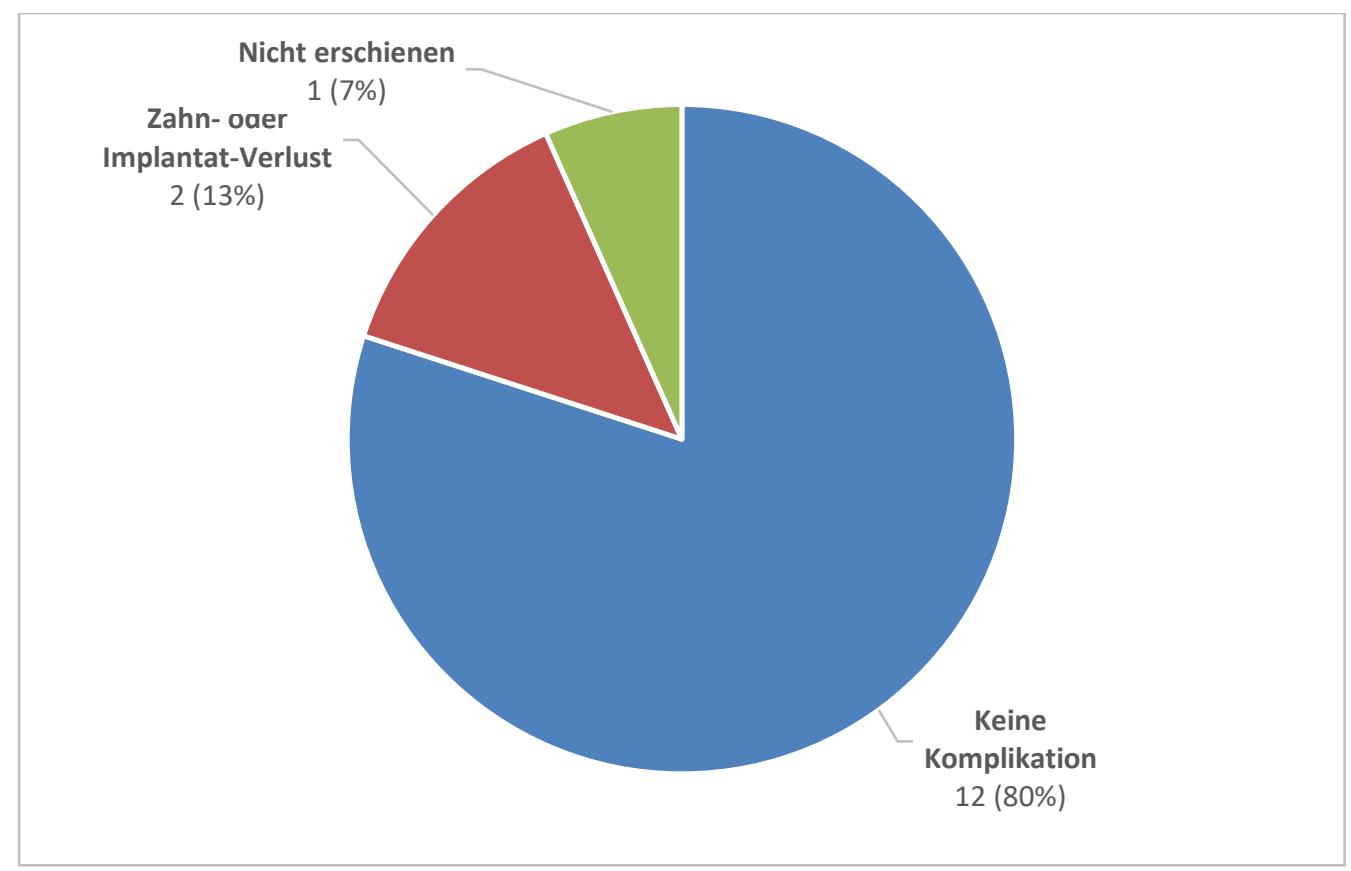

Abbildung 19: Diagramm zu den klinischen Verläufen zum Zeitraum T3 bei Fällen mit negativem Delta 


\section{Diskussion}

In der vorliegenden Studie wurden mehrere Fragestellungen untersucht, zu denen bislang keine publizierten Ergebnisse vorlagen. Weder die Reproduzierbarkeit von Grauwertmessungen digitaler OPGs, noch die Entwicklung der relativen Röntgendichte nach Defektauffüllung mit Ostim® im Mund-Kiefer-Gesichtsbereich, oder die Komplikationsraten nach Einsatz von nanokristallinem Hydroxylapatit wurden bisher wissenschaftlich evaluiert.

Dabei ist die Größe des untersuchten Patientenkollektives mit 238 Patienten, 299 durchgeführten Operationen und insgesamt 545 versorgten Knochendefekten hervorzuheben. Klinische Untersuchungen zu Ostim® waren bisher nur bei Einzelfällen (Smeets et al. 2008), und an kleineren Kollektiven mit bis zu 30 Patienten (Belouka und Strietzel 2016, Canuto et al 2013, Kamboj et al. 2016, Dottore et al. 2014, Huber et al. 2006, Kasaj et al. 2008, Schwarz et al. 2006, Strietzel et al. 2007) durchgeführt und publiziert worden. Durch die Größe des Kollektivs konnten statistisch relevante Datenmengen in vier von fünf Gruppen erhoben und untersucht werden. Lediglich Gruppe V, Auffüllung parodontaler Defekte, war mit vier durchgeführten Operationen nicht aussagekräftig und wurde daher nur deskriptiv beschrieben. Die Aufteilung und gesonderte Betrachtung in Gruppen war aufgrund der verschiedenen Invasivität und der unterschiedlich ablaufenden Heilungsprozesse der untersuchten Operationen angebracht.

\subsection{Voruntersuchung}

Die durchgeführte Evaluation der röntgenologischen Untersuchungsmethode ist ein wichtiger Teil dieser Studie. Das Verfahren der Messung der relativen Röntgendichte wurde bislang noch nicht auf seine Reproduzierbarkeit hin untersucht. Es existierte bisher kein publiziertes SOP für die Messung der relativen Grauwerte, um den Messprozess zu standardisieren. Die Freihandauswahl der Defekte stellt allerdings eine potentielle Fehlerquelle dar. Das in dieser Studie erarbeitete SOP wurde durch die Voruntersuchung hinsichtlich der intra- und interindividuellen Variabilität untersucht.

Insgesamt sprechen die Varianzkoeffizienten der Probemessungen, sowohl intra- als auch interindividuell (MW insgesamt $=2,972 \% \pm 2,361$ ), für einen konstanten Messprozess. Auch die vergleichende statistische Auswertung zeigte keinen Einfluss des Untersuchers auf die Messergebnisse $(\operatorname{Pr}>F=0,9462)$. Um die nicht gänzlich vermeidbaren Messschwankungen zu minimieren wurden alle Messungen in dieser Studie fünfmal durchgeführt und der Mittelwert der Ergebnisse gebildet. Insgesamt erscheint das Verfahren als geeignet, um unter den gegebenen Bedingungen einer retrospektiven Studie die mittleren Grauwerte von Knochendefekten und ortsständigem Knochen zu erheben und daraus die relative Röntgendichte zu berechnen. 
Die deutlich höheren Varianzkoeffizienten bei Messungen des umliegenden Knochens (MW interindividuell $=3,691 \% \pm 2,626$ im Vergleich zu 2,252 \% $\pm 1,928$ ) spiegeln die Tatsache wider, dass es sich bei der Auswahl der Defektregionen um eine einfache optische Selektion handelt, die sich am meist gut erkennbaren Defektrand orientiert. Bei der Auswahl der Messregion des ortsständigen Knochens ist in den meisten Fällen eine Interpretation der vorhandenen anatomischen Region unter Berücksichtigung der Regeln des vorher festgelegten SOP notwendig. Dadurch können sich Abweichungen in der Auswahl der Messregion ergeben, die - je nachdem um welche Indikation, Lokalisation und Defektausdehnung es sich handelt - zu einer Inkonsistenz der Messergebnisse führen können. Bei strikter Einhaltung des SOP halten sich diese jedoch in Grenzen.

Besonders hohe Inkonsistenz ergab sich bei der Auswertung von Bild 1. Dieser Fall demonstriert einige Schwierigkeiten die bei der Festlegung der Messregionen auftreten können. Aufgrund der anatomischen Lokalisierung in unmittelbarer Kieferhöhlennähe und nur in geringem Ausmaß vorhandenen spongiösen Kieferknochens kam es zu verschiedenen Interpretationen der zu umfahrenden Messregionen. Die radiologische Projektion der Kieferhöhle sollte bei der Grauwertanalyse grundsätzlich ausgeschlossen werden, es sei denn es handelt sich um die Analyse eines durchgeführten Sinuslifts. Durch Beschränkungen auf die Anteile des Os maxillaris und Aussparen des Sinus maxillaris können in diesem Bild konstante Messergebnisse erreicht werden, die die knöchernen Verhältnisse besser widerspiegeln.

Fraglich ist, ob zur Beurteilung des SOPs und der Reproduzierbarkeit der Messergebnisse die hier benutzte Anzahl an Messungen durch drei Untersucher als ausreichend anzusehen ist und eine noch größere Anzahl an Messungen - auch durch ungeschultes Personal - wäre sicherlich wünschenswert gewesen. Dies war unter den gegebenen Umständen jedoch nicht durchführbar. Die hier durchgeführte erste Evaluierung konnte aber zeigen, dass bei Untersuchern, die mit dem Messverfahren vertraut sind, konstante Messergebnisse produziert werden. Vor einer Implementierung in den klinischen Altag sind Untersuchungen mit mehr Probanden und mehr Bildern denkbar.

Um eine einfachere und schnellere Messmethodik zu testen, wurden zusätzlich alle Probemessungen von einem Untersucher der Arbeitsgruppe noch einmal mit standardisierten Messregionen der Größe 20 × 20 Pixel durchgeführt. Es erwies sich allerdings bei größeren, inhomogenen Defekten als ungenaues Verfahren, mit zum Teil signifikant von den vorherigen Messergebnissen abweichenden Werten. Aufgrund dessen wurden in dieser Studie alle Messregionen per Freihandauswahl festgelegt. Durch die Entwicklung eines SOP und die Untersuchung der intra- und interindividuellen Abweichung konnte ein evaluiertes Verfahren gefunden werden, dass praxisnah, einfach anzuwenden und kostengünstig 
durchzuführen ist. Eine Anwendung ist somit auch bei anderen Nachuntersuchungen und im klinischen Alltag denkbar.

\subsection{Radiologische Verläufe}

Die radiologische Bildanalyse legt als Hauptteil der Arbeit den Fokus auf die Evaluierung der Heilungsprozesse im augmentierten Kieferknochen. Von 545 dokumentierten Knochendefekten konnte der Heilungsverlauf von 233 Knochendefekten nachuntersucht und dargestellt werden, was ein großes Kollektiv an Patienten und Defekten darstellt. Durch das retrospektive Studiendesign ergaben sich einige Nachteile gegenüber einer prospektiven Studie. So konnte kein festes Kontrollintervall für die radiologische Nachkontrolle vereinbart werden, wodurch kein einheitlicher Beobachtungszeitraum für die Röntgenbilder existierte. Weiterhin hätte man in einer prospektiven Studie mehrere Röntgenkontrollen im Zeitraum der Knochenregeneration durchführen können, um den Prozess noch besser zu beobachten. Die klinisch relevante Kontrolle bezieht sich jedoch meistens auf den abgeschlossenen Heilungsprozess. Zwar wurden allen Patienten radiologische Nachuntersuchungen zur Kontrolle der Heilung der Knochendefekte nach drei bis sechs Monaten angeraten, doch nur bei 309 Knochendefekten lagen radiologische Kontrollaufnahmen vor, von denen 233 zur Analyse der relativen Röntgendichte geeignet waren, was aber trotzdem eine hohe Anzahl darstellt. Der Grund hierfür ist in der Praxisstruktur als Überweiserpraxis zu suchen. Nachkontrollen werden von den Patienten häufig nicht wahrgenommen oder beim Hauszahnarzt durchgeführt. Obwohl die Überweiser im Rahmen des Qualitätsmanagements regelmäßig angeschrieben werden, um Röntgenbilder von Augmentationsfällen anzufordern, lagen nur wenige Röntgenbilder aus Fremdpraxen vor, die in die Untersuchung hätten eingeschlossen werden können. Positiv anzumerken ist, dass keine studienbedingte Strahlenbelastung entstanden ist.

Es zeigte sich im Allgemeinen ein signifikanter Anstieg der relativen Röntgendichte zwischen postoperativem Röntgenbild ( $\mathrm{MW}=0,88 \pm 0,09)$ und Kontrollbild ( $\mathrm{MW}=0,98 \pm 0,07$ ), also eine Veränderung der Röntgenabsorption im Defektgebiet. In Anbetracht der vorliegenden Literatur ist es wahrscheinlich, dass diese Veränderung durch eine partielle Resorption von Ostim® und eine gleichzeitig erfolgte osteokonduktive Knochenneubildung hervorgerufen wird. Dies kann jedoch durch das durchgeführte Untersuchungsverfahren nicht bewiesen werden. Durch die Messung der relativen Röntgendichte kann zwar eine Veränderung der Mineralisation der Defektregion gezeigt werden, sie erbringt aber keinen Nachweis, ob diese Veränderung durch Aufbau von neuem Knochen, Resorption des Knochenersatzmaterials, einer Kombination beider Prozesse oder andere - eventuell pathologische - Prozesse ausgelöst wurde. Wünschenswert wäre die Durchführung von histologischen Probeentnahmen gewesen, was sich aufgrund der retrospektiven Struktur der Studie und dem sehr großen operativen Aufwand nicht realisieren ließ. Mit dem angewandten Verfahren konnten 
ebenfalls keine Nachuntersuchungen von lateralen Augmentationen im Rahmen von Implantationen erfolgen, da sich häufig keine oder nur unklare Projektionen des Augmentationsvolumens radiologisch darstellen ließen. Dadurch konnten in Gruppe III nur 17 der 91 Fälle untersucht werden, bei denen zumeist ein Sinuslift vorlag.

Die auf den Kontrollbildern mittelwertig erreichten relativen Röntgendichten lassen insgesamt einen im physiologischen Rahmen abgeschlossenen Heilungsprozess vermuten, der in der Mehrheit der Fälle im Bereich der Röntgenabsorption des ortsständigen Knochens lag. Dass die Veränderung der relativen Röntgendichte im Beobachtungszeitraum (Delta) in 218 von 233 Fällen positiv ( $M W=0,097 \pm 0,087$ ) war, könnte ebenso als Hinweis für eine Knochenneubildung im Defekt bei der Mehrzahl der durchgeführten Defektfüllungen angesehen werden.

Es kann keine Aussage über die Resorption von Ostim® getroffen werden. Auffällig ist allerdings, dass bei Defekten mit größerem Defektvolumen - wie bei Weisheitszahnosteotomien - häufiger relative Röntgendichten über eins auftreten, was für ein vermehrtes Vorliegen von knöchern inkorporierten Ostim®-Partikeln sprechen könnte.

Der Vergleich der radiologischen Daten mit anderen Studien ist nur bedingt möglich. In allen Studien, in denen radiologische Nachbetrachtungen nach dem Einsatz von Ostim® Anwendung fanden, wurden keine Messverfahren zur Bestimmung der Knochenheilung durchgeführt. Gerlach und Niehues (2007) untersuchten die Heilung nach Zystektomie und Defektfüllung in 44 Fällen. In den Röntgenbildern zeigten sich bei größeren Defektvolumina ähnlich wie bei der vorliegenden Studie wolkige Verschattungen im Defektinneren, die auf nicht resorbierbares Knochenersatzmaterial schließen lassen. Dies deckt sich auch mit Beobachtungen von Strietzel et al. (2007), nach denen lagerferne Bereiche des Augmentats weniger Resorption zeigten als lagernahe Bereiche. Es finden sich keine Studien, die anhand der relativen Röntgendichte die Heilungsprozesse nach Zahnextraktionen und Weisheitszahnosteotomien, mit oder ohne anschließende Defektauffüllung, oder den Verlauf von Augmentationen untersucht haben. Einzig die Studie von Ihan Hren und Miljavec (2008) untersuchte die Heilung von 33 großen Zysten in der Mandibula mithilfe von Grauwertmessungen an digitalisierten OPGs. Die postoperativen Röntgendichten lagen mit $0,49-0,60$ deutlich niedriger als die Werte in dieser Studie $(0,87 \pm 0,11)$. Nach zwölf Monaten zeigte sich bei Ihan Hren und Miljavec (2008) eine mittlere relative Knochendichte von 0,87 im Vergleich zu 0,98 \pm 0,07 nach mittelwertig sechs Monaten Beobachtungszeitraum in der vorliegenden Studie. Sowohl der Unterschied in der postoperativen relativen Röntgendichte als auch die geringer ausgefallene Ausheilung der Defekte könnte durch die Tatsache erklärt werden, dass in der vorliegenden Studie vor allem kleinere radikuläre Zysten im Zusammenhang mit Wurzelspitzenresektionen, bei Ihan Hren und Miljavec (2008) vornehmlich größere Zysten, darunter auch Keratozysten, residuale oder follikuläre Zysten 
untersucht wurden. Ebenso könnte das eingebrachte Knochenersatzmaterial die postoperative Röntgendichte beeinflussen und zu höheren postoperativen Werten führen.

Bei Fällen mit der Spätkomplikation „Zahn- oder Implantatverlust“ (Code 5), die lediglich bei Gruppe II und III und V möglich gewesen ist, zeigten sich mittelwertig niedrigere relative Röntgendichten in den Kontrollbildern $(0,88 \pm 0,11)$ und niedrigere Deltawerte $(-0,01 \pm 0,12)$ als bei den Fällen aus Gruppe II, III und V ohne Spätkomplikationen (RöKo = 0,97 \pm 0,07; Delta $=0,1 \pm 0,09)$. Da dieser Unterschied allerdings nicht statistisch signifikant ausfiel (p.Holm RöKo = 0,1475; p.Holm Delta = 0,2468) und die Gruppe bei denen sowohl klinische Verläufe mit Zahn- oder Implantatverlust auftraten und gleichzeitig röntgenologische Daten vorlagen nur 8 Fälle beinhaltete, kann hier lediglich von einer Tendenz gesprochen werden. Auch hier wäre ein längerer, konstanter Beobachtungszeitraum und größere Fallzahlen wünschenswert gewesen um zu beobachten ob diese Tendenz bestätigt werden kann.

Signifikante Unterschiede fanden sich zwischen den postoperativen Röntgendichten der Defekte in Ober- und Unterkiefer. Defekte im Oberkiefer zeigten niedrigere postoperative Röntgendichten $(0,87 \pm 0,10)$ als Defekte im Unterkiefer $(0,90 \pm 0,07)$, was sich auf die Unterschiede in der Anatomie von Maxilla und Mandibula hinsichtlich der Dichte der Spongiosa und der Dicke der Kortikalis zurückführen lässt. Im Oberkiefer sind bei Extraktionen und anderen oralchirurgischen Eingriffen häufiger die kortikalen Strukturen kompromittiert was dann zu einem deutlichen Abfall des mittleren Grauwertes des Defektes und damit der relativen Röntgendichte führt.

Die Korrelation zwischen postoperativer Röntgendichte und den Werten zum Kontrollzeitpunkt könnte durch verschiedene Faktoren hervorgerufen werden. In einem idealen Modell sollte sich kein Einfluss der postoperativen Röntgendichte auf die Röntgendichte zum Kontrollzeitpunkt ergeben, da für alle Defekte der Wert eins als optimales Heilungsergebnis anzusehen ist. Man muss allerdings davon ausgehen, dass radiologische Faktoren wie Überlagerungen einen Einfluss auf die Messergebnisse haben, welcher trotz sorgfältiger Arbeitsweise nicht gänzlich verhindert werden kann. Dieser Zusammenhang könnte auch durch noch nicht abgeschlossene Heilungsprozesse, noch nicht erfolgtes bone remodeling, oder inkorporiertes Knochenersatzmaterial erklärt werden.

In Übereinstimmung mit Ihan Hren und Miljavec zeigte sich eine schwache negative Korrelation von Delta und dem Patientenalter (Ihan Hren und Miljavec 2008). Bei höherem Patientenalter fielen die Deltawerte kleiner aus. Dies lässt sich durch die im Alter verminderten Regenerationsprozesse im Knochen erklären. Daraus lässt sich die Empfehlung ableiten, dass auch bei Knochendefektfüllungen in höherem Alter ein verlängerter Zeitraum für die Heilungsprozesse im Kieferknochen eingeräumt werden muss. Es konnte kein Zusammenhang zwischen den Delta-Werten und dem Beobachtungszeitraum festgestellt werden. Dies liegt vermutlich daran, dass die Heilungsprozesse schon 
vor dem Erstellen des Kontrollröntgenbildes soweit abgeschlossen waren, dass ein längerer Beobachtungszeitraum nicht mehr zu Änderungen der Defektmineralisation führte.

Der Beobachtungszeitraum, der sich durch eingehaltene Kontrolluntersuchungen oder der nächsten Weiterbehandlung mit radiologischer Kontrolle ergab, lag mittelwertig bei $185 \pm$ 177 Tagen, was in etwa einem halben Jahr entspricht. Lediglich sechs Defekte hatten einen kürzeren Beobachtungszeitraum als 90 Tage (Delta mittelwertig 0,09) und zwei Defekte weniger als 60 Tage (Delta mittelwertig 0,043). Spekulativ könnte man vermuten, dass der Heilungsprozess im Mittel zwischen dem 60. und 90. Tag zum Abschluss gekommen ist und deshalb kein signifikanter Anstieg von Delta mehr zu beobachten war. Diese Vermutung stimmt mit der vorliegende Literatur über Heilungsprozesse von Knochendefekten, die im Tierversuch mit Ostim® versorgt wurden, über ein. Thorwarth et al. (2005) und Spies et al. (2008) berichteten von sechs bis zwölf Wochen bis zur Verknöcherung von CSD, was Beobachtungszeiträumen von 42 bis 84 Tagen entspricht. Anhand der Studienergebnisse ist es schwierig, eine Aussage zu treffen, ob der Heilungsprozess bei den in dieser Studie augmentierten Defekten beschleunigt oder verlangsamt im Vergleich zu konventionell versorgten Operationswunden abläuft, da das Kontrollröntgenbild in den meisten Fällen vermutlich erst nach Abschluss des Heilungsprozess angefertigt wurde. Amler (1969) zeigte bei seinen Untersuchungen allerdings, dass bereits nach 35 Tagen etwa zwei Drittel der Extraktionsalveole mit Geflechtknochen aufgefüllt war.

\subsection{Klinische Verläufe}

Durch die große Anzahl von 299 klinischen Verläufen ist die vorliegende Studie zu den großen klinischen Nachuntersuchungen einzuordnen. Es existieren zwar größere klinsiche Nachuntersuchungen wie die von Rud et al (1972) mit 1000 Fällen zu Wurzelspitzenresektionen und ähnlich große Studien wie die von Chaparro-Avedano (2005) mit 390 entfernten Weisheitszähnen bei 173 Patienten aber zum Einsatz von nanokristallinem Hydroxylapatit zur Behandlung von Knochendefekten gab es bislang lediglich Einzelfalldarstellungen (Smeets et al 2008) und kleinere Patientenkollektive mit bis zu bis zu 49 Fällen (Bezrukov et al 1998, Gerlach und Niehues 2007). Die Nachuntersuchung der klinischen Verläufe der Operationen ist als Ergänzung zu der röntgenologischen Betrachtung wichtig um zu überprüfen ob die radiologischen Werte Rückschlüsse auf den klinischen Verlauf zulassen. Als retrospektive Untersuchung ergaben sich auch in diesem Teil grundsätzliche Nachteile gegenüber prospektiven Studien. So konnten in der vorliegenden Studie keine standardisierten Untersuchungsparameter für die Nachuntersuchungen festgelegt oder feste Nachkontrolltermine vereinbart werden. Es musste auf die jeweiligen Einträge in der elektronischen Patientenakte zurückgegriffen werden, um daraus die klinischen Verläufe zu den untersuchten Zeiträumen zu bestimmen. Dabei konnte auf ein vergleichsweise

gleichförmiges Untersuchungsmuster zu den Untersuchungszeiträumen T1 und T2 
zurückgegriffen werden, das sich am standardisierten postoperativen Ablauf nach oralchirurgischen Operationen orientierte. Im weiteren Verlauf konnten nur Patienten erfasst werden, die routinemäßig oder durch weitere Behandlungen wieder in der Praxis erschienen. Die Daten zu T1 und T2 sind durch die hohen Nachuntersuchungsquoten (95,7\% und 96\%) als vergleichsweise aussagekräftig anzusehen. Spekulativ ist anzunehmen, dass die Komplikationsrate bei $\mathrm{T} 1$ höher anzusetzen ist, da Schwellungen und andere nicht schwerwiegende Komplikationen vom untersuchenden Behandler eventuell nicht im Behandlungsblatt vermerkt worden sind. Die Daten von T3 sind nur unter Vorbehalt zu interpretieren (Nachuntersuchungsquote 64,5\%). Behandelte Zähne und Implantate könnten im weiteren Verlauf verloren gegangen, nicht nachuntersuchte Patienten bei ihren Hauszahnärzten weiterbehandelt worden oder in der Folge komplikationslos geblieben sein. Für eine Beurteilung des Langzeiterfolgs sollte eine weitere Nachuntersuchung der behandelten Knochendefekte nach jeweils fünf und zehn Jahren erfolgen. Auch wenn für einzelne Fälle ein Beobachtungszeitraum von fünf Jahren erreicht worden ist, sind andere Fälle nur in kürzeren Intervallen nachuntersucht worden. Die Daten bieten aber einen ersten Einblick auf die zu erwartenden Verläufe.

Die Komplikationen innerhalb des Gesamtkollektivs unterschieden sich zwischen typischen Frühkomplikationen wie Schwellungen, Nachblutungen, Hämatomen, Wunddehiszenzen und Schmerzen bei T1 und T2, während bei T3 typische Spätkomplikationen wie Zahn- und Implantatverlust, erforderliche Nachbehandlungen und persistierende Hypästhesien oder Schmerzen auftraten. In den Review-Artikeln von ten Heggeler et al. (2011) und Vittorini Oregas et al. (2013) sind wenige klinische Komplikationen nach socket preservation beschrieben, darunter Wunddehiszenzen, welche in einigen Fällen auftraten. In dieser Studie kam es in Gruppe I zum Zeitraum T1 bei 2\% und zu T2 bei 2,9\% der Operationen zu Wunddehiszenzen an augmentierten Extraktionsalveolen, die jedoch zu keinen Komplikationen im weiteren klinischen Verlauf bei T3 führten. Dies deckt sich mit den Beobachtungen von Canuto et al. (2013) zur socket preservation mit Ostim®, die ohne Lappenbildung durchgeführt wurde und keine Komplikationen im Heilungsverlauf zeigte. Allerdings ergaben sich bei Canuto et al. (2013) leicht erhöhte Beschwerden (6,92 auf Schmerzskala im Vergleich zu 5,22 bei konservativem Vorgehen) der Patienten am zweiten postoperativen Tag, was mit den in dieser Studie beobachteten starken Schwellungen (3,9\% bei T1 in Gruppe 1) im Zusammenhang stehen könnte. Diese mit am häufigsten aufgetretene Frühkomplikation (6\% Gesamtkollektiv) könnte auf den hohen Wassergehalt von Ostim® zurückzuführen sein, welches in die umliegenden Gewebe diffundieren und dadurch zur Gewebeschwellung führen könnte. Dabei zeigen die vorliegenden klinischen Verläufe ähnliche Komplikationen wie in der Studie von Strietzel et al. (2007), bei der nach lateralen Augmentationen des Unterkiefers mit Ostim ${ }^{\circledR}$ ebenfalls starke Schwellungen und Wunddehiszenzen auftraten. 
Die Häufigkeit fiel in dieser Studie mit jeweils $2 \%$ deutlich geringer aus als bei Strietzel et al. (2007) (starke Schwellungen 21,4\%, Wunddeshiszenz 7,1\%), was eventuell auf die in 84,3\% der Fälle durchgeführte Schwellungsprophylaxe zurückzuführen ist. Abweichend davon konnten bei Bezrukov et al. (1998) verringerte postoperative Komplikationsraten nach Defektfüllungen von Unterkieferzysten mit Ostim® beobachtet werden.

Die höheren Komplikationsraten von Gruppe II und IV gegenüber Gruppe I und III lassen sich mit der höheren Invasivität durch Entfernung kortikaler Knochenanteile und größeren ossären Wundflächen erklären. Ebenso könnte ein vergrößertes Augmentationsvolumen unterhalb der Schleimhaut zu größeren Komplikationsraten führen. Chaparro-Avedano et al. (2005) untersuchten die Komplikationen nach Osteotomien von Weisheitszähnen von jugendlichen Patienten. Es zeigten sich postoperative Komplikationen wie Schwellungen und persistierende Schmerzen und Hämatome in 15,6\% der Fälle. In der vorliegenden Studie traten zum Zeitraum T1 in 21,3\% der Fälle ähnliche Komplikationen auf. Vor allem Schwellungen und Schmerzen traten mit 12,5\% häufiger auf als bei der Studie von Chaparro-Avedano et al. (2005) (8,9\%). Es zeigte sich wie auch in der vorliegenden Studie (odds ratio 2,7) ein höheres Risiko für Komplikationen bei weiblichen Patienten unmittelbar nach der OP (18\% im Vergleich zu 9,8\% bei männlichen Patienten) (Chaparro-Avendano et al. 2005). Dieser Unterschied könnte durch die Systematik der Datenerhebung bedingt sein, die nicht auf vorher festgelegten Parametern, sondern auf der Interpretation und Dokumentation der behandelnden und nachuntersuchenden Zahnärzte und der Darstellung der Beschwerden durch die Patienten beruht. Spekulativ ist auch eine höhere Anfälligkeit des weiblichen Bindegewebes gegenüber Wassereinlagerungen und dadurch größeren Einfluss von Ostim® auf das Auftreten von starken Schwellungen zu diskutieren.

Zum Zeitraum T3 traten insgesamt keine Komplikationen auf, die eindeutig auf die Defektfüllungsmaßnahmen zurückzuführen waren. Gruppe I zeigte kaum Spätkomplikationen und in 39,2\% der Fälle wurde nach socket preservation eine Implantation im behandelten Gebiet durchgeführt, was letztendlich der Hauptgrund für die Durchführung einer socket preservation darstellt. Trotz durchgeführter socket preservation sind in einigen Fällen Augmentationen bei der nachfolgenden Implantation notwendig gewesen. In welchem Umfang und bei wie vielen Patienten dies der Fall gewesen ist, konnte in dieser Studie nicht ermittelt werden. Anhand der Daten kann auch keine Aussage getroffen werden, ob sich durch die durchgeführte Defektfüllung ein Vorteil gegenüber konservativem Vorgehen ergibt. Gruppe II hatte die höchste Komplikationsrate bei T3. Wurzelspitzenresektionen stellen einen Erhaltungsversuch nach einer fehlgeschlagenen endodontischen Versorgung dar, dessen Erfolg von vielen Faktoren beeinflusst wird. Rud et al. (1972) untersuchten die Erfolgsraten von konventionellen Wurzelspitzenresektionen. Nach einem Jahr Beobachtungszeit waren 19\% der Zähne in der Kategorie „unsicher“ oder „unbefriedigend“ 
einzuordnen, während im weiteren Verlauf diese Werte auf 10\% sanken. In der vorliegenden Untersuchung mussten im Beobachtungszeitraum T3 10\% der Zähne nach Wurzelspitzenresektion und Zystektomie entfernt werden. Auch die weiteren aufgetretenen Komplikationen sind als Misserfolg anzusehen, was eine Erfolgsquote von 72,9\% der nachuntersuchten Fälle bei T3 ergibt und in etwa den Ergebnissen von Rud et al. (1972) entspricht.

Hinsichtlich der Spätkomplikationen nach Augmentation und dentaler Implantation zeigten sich ähnliche Verläufe wie bei Smeets et al. (2008) und Dottore et al. (2014), bei denen Implantatverlust nach Sinuslift und postoperative Wunddehiszenzen auftraten. In dieser Studie konnten beide Komplikationen in seltenen Fällen beobachtet werden (Implantatverlust 4,1\%, Wunddehiszenzen 2\%). Inwieweit die Defektfüllung einen Einfluss auf die Erfolgsquote nach Implantation hat, ist aus den Daten der klinischen Verläufe nicht abzuleiten.

\subsection{Schlussfolgerung und Ausblick}

Die Messung der relativen Röntgendichte führt mithilfe des in dieser Studie erarbeiteten SOP zu reproduzierbaren Ergebnissen, die einen Rückschluss auf Remineralisierungsprozesse von Knochendefekten im Mund-Kiefer-Gesichstsbereich zulassen. Histologische Untersuchungen können durch dieses Verfahren im Hinblick auf Knochenneubildung nicht ersetzt, aber sinnvoll ergänzt werden. Eine systematische Anwendung in wissenschaftlichen Nachuntersuchungen klinischer Röntgenbilder und im klinischen Alltag ist denkbar. Hierzu sollte noch weitere wissenschaftliche Erfahrung mit dem Messverfahren gewonnen werden.

Nach der Anwendung von Ostim ${ }^{\circledR}$ bei Operationen im Bereich der Mund-KieferGesichtschirurgie ist mit einem Anstieg der relativen Röntgendichte zu rechnen, die nach 60 bis 90 Tagen Werte im Bereich des ortsständigen Knochens erreicht. Der Anstieg ist abhängig vom Patientenalter, weshalb bei älteren Patienten ein verlängerter Heilungszeitraum eingeräumt und häufiger mit inkompletter Heilung gerechnet werden muss. Ein Abnehmen der relativen Röntgendichte im Beobachtungszeitraum kann hingegen ein Hinweis auf einen Misserfolg und klinische Komplikationen sein, die zu Zahn- oder Implantatverlust führen kann. Eine histologische Verifizierung dieser Ergebnisse in einer prospektiv angelegten klinischen Studie wäre sinnvoll, um die Aussagekraft der hier vorgelegten Ergebnisse hinsichtlich einer osteokonduktiven Knochenneubildung zu untermauern. Weiterhin wären Vergleichsstudien im split-mouth-design mit Knochenersatzmaterialien und konserverativ versorgten Knochendefekten denkbar, die bezüglich der Entwicklung der relativen Röntgendichte während des Heilungsprozesses untersucht werden.

Hinsichtlich der Frühkomplikationen ist bei dem Einsatz von Ostim® mit einem gehäuften Auftreten von starken postoperativen Schwellungen zu rechnen, die sich trotz durchgeführter Schwellungsprophylaxe zeigte. Ansonsten sind typische indikationsspezifische Komplikationen nach Operationen im Mund-Kiefer-Gesichtsbereich ohne signifikanten Einfluss von Ostim® auf die Komplikationsrate zu erwarten. Auch hier sollten die in dieser 
Studie ermittelten Ergebnisse mithilfe einer prospektiv angelegten Studie mit fest vorgeschriebenen Untersuchungsparametern über einen langen Beobachtungszeitraum überprüft werden.

Bei dentalen Implantationen mit Sinuslift könnte Ostim® eine Alternative zu autologem Knochen darstellen, wenn dieser nicht in ausreichendem Maße zur Verfügung steht oder das Heben eines Knochentransplantats vermieden werden soll.

In einer Folgestudie sollte die Betrachtung der klinischen Verläufe bis auf 10 Jahre Beobachtungszeit ausgeweitet werden um einen Langzeitvergleich mit Ergebnissen der Literatur zu ermöglichen. 


\section{Zusammenfassung}

Ziel der vorliegenden Arbeit war es, zum einen den Einsatz des nanokristallinen Hydroxylapatits Ostim® bei Operationen in der Mund-Kiefer-Gesichtschirurgie hinsichtlich der Heilung der Knochendefekte und der Komplikationsrate in einer retrospektiven Studie zu untersuchen. Zum anderen sollte das Verfahren der relativen Röntgendichtemessung mittels ImageJ evaluiert werden.

Nach Erstellung einer SOP wurde die Messung der mittleren Grauwerte hinsichtlich der Reproduzierbarkeit erfolgreich getestet. Anschließend wurden Patienten der MGK Klinik Kassel ermittelt, die im Zeitraum von Januar 2006 bis Dezember 2012 eine Defektauffüllung mit Ostim® erhalten hatten. Die Patienten wurden in fünf Untersuchungsgruppen unterteilt:

I socket preservation

II Zystektomien, auch im Zusammenhang mit Wurzelspitzenresektionen

III Sinuslift und andere Augmentationen im Zusammenhang mit dentalen Implantationen

IV Defektauffüllung nach umfangreichen Osteotomien verlagerter Weisheitszähne

V Auffüllung parodontaler Knochendefekte

Für diese Patienten wurden die postoperativen Röntgenbilder und Bilder, die als Verlaufskontrolle geeignet waren, verwendet und die jeweiligen relativen Röntgendichten der Defekte postoperativ und zum Kontrollzeitpunkt bestimmt. Zusätzlich wurden zu drei postoperativen Zeiträumen (T1 1. - 4. Tag; T2 = 5. - 14. Tag; $T 3=a b 15$. Tag postoperativ) die klinischen Verläufe und die vermerkten Komplikationen aus den Patientenakten aufgenommen. Alle Ergebnisse wurden deskriptiv und vergleichend statistisch ausgewertet.

Die Evaluation des Messverfahrens zeigte, dass es reproduzierbare Ergebnisse liefert (mittlerer Varianzkoeffizient intraindividuell $=1,5 \% \pm 1,0$; interindividuell $=3,0 \% \pm 2,4$ ). Es konnte kein Einfluss des Untersuchers auf die Ergebnisse der Grauwertmessung festgestellt werden.

Bei 238 Patienten wurden an 545 Knochendefekten Defektauffüllungen ausgeführt. Von diesen 545 Defekten konnten für 309 Fälle geeignete postoperative sowie Kontrollröntgenbilder gefunden werden. In 233 Fällen konnte auf beiden Röntgenbildern die relative Röntgendichte bestimmt werden. Die vorliegende Studie stellt somit von der Anzahl der Patienten und Defekte eine der größten Studien dar. Bei 93,5\% der Fälle konnte ein Anstieg der relativen Röntgendichte (RöpostOP $=0,88 \pm 0,09$; RöKntr $=0,98 \pm 0,07$ ) im Beobachtungszeitraum festgestellt werden. Dies galt sowohl im Gesamtkollektiv als auch in den einzelnen Gruppen. Eine Annäherung des mittleren Grauwertes an den des ortsständigen Knochens war nach 60 - 90 Tagen in einem Großteil der Fälle zu beobachten. Bei älteren Patienten fiel dieser Prozess langsamer und häufiger unvollständig aus als bei jüngeren. 
Es konnten die klinischen Verläufe für 299 Operationen nachverfolgt werden. Dabei zeigten sich typische indikationsspezifische Komplikationen in den einzelnen Gruppen. Am häufigsten traten zu T1 Nachblutungen und starke Schwellungen (je 6\%), zu T2 Wunddehiszenzen (4,3\%) und zu T3 Zahn- oder Implantatverlust (3,7\%) auf.

Mithilfe einer einfachen und schnell durchführbaren Untersuchungsmethode konnten in dieser Studie Hinweise auf stattfindende Heilungsprozesse der Kieferknochen nach Defektfüllungen mit Ostim ${ }^{\circledR}$ im Bereich der Mund-Kiefer-Gesichtschirurgie gewonnen werden, welche in histologischen Nachuntersuchungen verifiziert werden sollten. Hinsichtlich der klinischen Verläufe befinden sich die Komplikationsraten in vergleichbaren Bereichen zu konventionellem Vorgehen. 


\section{Literaturverzeichnis}

Abràmoff M, Magalhães PJ, Ram SJ (2004): Image Processing with ImageJ. Biophotonics Int $11,36-42$

Albee FH (1921): Certain fundamental laws underlying the surgical use of the bone graft. Ann Surg $\underline{74}, 196-205$

Albrektsson T (1980a): In vivo studies of bone grafts. The possibility of vascular anastomoses in healing bone. Acta Orthop Scand $\underline{51}, 9-17$

Albrektsson T (1980b): The healing of autologous bone grafts after varying degrees of surgical trauma. A microscopic and histochemical study in the rabbit. J Bone Joint Surg $\mathrm{Br}$ $\underline{62}, 403-410$

Albrektsson T, Albrektsson B (1978): Microcirculation in grafted bone. A chamber technique for vital microscopy of rabbit bone transplants. Acta Orthop Scand $\underline{49}, 1-7$

Albrektsson T, Johansson C (2001): Osteoinduction, osteoconduction and osseointegration. Europ Spine J 10, 96-101

Amler MH (1969): The time sequence of tissue regeneration in human extraction wounds. Oral Surg Oral Med Oral Pathol 27, 309-318

Andreasen JO, Rud J (1972): Modes of healing histologically after endodontic surgery in 70 cases. Int J Oral Surg 1 (3), 148-160

Araujo MG, Lindhe J (2005): Dimensional ridge alterations following tooth extraction. An experimental study in the dog. J Clin Periodontol $\underline{32}, 212-218$

Axhausen G. (1908): Histologische Untersuchungen über Knochentransplantation am Menschen. Dtsch Z Chir $\underline{91}$, 388-428

(BÄK 2001): Bundesärztekammer (Hrsg.): Richtlinien zum Führen einer Knochenbank. Dt Ärztebl $\underline{98}, 1011-1016$

Barth A (1893): Ueber histologische Befunde nach Knochenimplantationen. Langenbecks Arch Surg $\underline{46}, 409-417$

Battmann A, Brink A, Fölsch C, Schulz A: Biokompatibilität von Knochenersatzmaterialien - In-vitro-Untersuchungen zum Einfluß des Wachstumsfaktors bFGF. In: Schnettler R, Markgraf E (Hrsg.): Knochenersatzmaterialien und Wachstumsfaktoren. Thieme, Stuttgart, New York 1997, 100-104 
Belouka SM, Strietzel FP (2016): Sinus Floor Elevation and Augmentation Using Synthetic Nanocrystalline and Nanoporous Hydroxyapatite Bone Substitute Materials: Preliminary Histologic Results. Int J Oral Maxillofac Implants $\underline{31}$ (6), 1281-1291

Bezrukov VM, Grigor'iants LA, Zuev VP, Pankratov AS (1998): The surgical treatment of jaw cysts using hydroxyapatite with an ultrahigh degree of dispersity. Stomatologiia (Mosk) 구, 31-35

Bilhan H, Arat S, Geckili O (2012): How precise is dental volumetric tomography in the prediction of bone density? Int J Dent online [https://www.hindawi.com/journals/ijd/2012/348908/]; Zugriff am 21.09.2017

Blake GM, Fogelman I (2007): Role of dual-energy X-ray absorptiometry in the diagnosis and treatment of osteoporosis. J Clin Densitom $\underline{10}$ (1), 102-110

Bobyn JD, Pilliar RM, Cameron HU, Weatherly GC (1980): The optimum pore size for the fixation of porous-surfaced metal implants by the ingrowth of bone. Clin Orthop Relat Res 150, 263-270

Brooks RA (1977): A Quantitative Theory of the Hounsfield Unit and Its Application to Dual Energy Scanning. J Comput Assist Tomogr 1 (4), 487-493

Cann CE, Genant HK (1980): Precise Measurement of Vertebral Mineral Content Using Computed Tomography. J Comput Assist Tomogr $\underline{4}$ (4), 493-500

Canuto RA, Pol R, Martinasso G, Muzio G, Gallesio G, Mozzati M (2013): Hydroxyapatite paste Ostim®, without elevation of full-thickness flaps, improves alveolar healing stimulating BMP- and VEGF-mediated signal pathways: an experimental study in humans. Clin Oral Implant Res $\underline{24}, 42-48$

Carmagnola D, Abati S, Celestino S, Chiapasco M, Bosshardt D, Lang NP (2008): Oral implants placed in bone defects treated with Bio-Oss $₫$ Ostim $\AA$-Paste or PerioGlas: an experimental study in the rabbit tibiae. Clin Oral Implant Res $\underline{19}$, 1246-1253

Chaparro-Avendano AV, Perez-Garcia S, Valmaseda-Castellon E, Berini-Aytes L, Gay-

Escoda C (2005): Morbidity of third molar extraction in patients between 12 and 18 years of age. Med Oral Patol Oral Cir Bucal 10, 422-431

Chesher D (2008): Evaluating Assay Precision. Clin Biochem Rev 29, 23-26

Chiapasco M, Rossi A, Motta JJ, Crescentini M (2000): Spontaneous bone regeneration after enucleation of large mandibular cysts: A radiographic computed analysis of 27 consecutive cases. J Oral Maxillifac Surg $\underline{58}, 942-948$ 
Chitsazi M, Shirmohammadi A, Faramarzie M, Pourabbas R, Rostamzadeh A (2013): A clinical comparison of nano-crystalline hydroxyapatite (Ostim $\AA$ ) and autogenous bone graft in the treatment of periodontal intrabony defects. Med Oral Patol Oral Cir Bucal, $\underline{16}$ (3), 448-453

Chris Arts J, Verdonschot N, Schreurs BW, Buma P (2006): The use of a bioresorbable nano-crystalline hydroxyapatite paste in acetabular bone impaction grafting. Biomaterials $\underline{27}, 1110-1118$

Devlin H, Horner K, Ledgerton D (1998): A Comparison of Maxillary and Mandibular Bone Mineral Densities. J Prosthet Dent $\underline{79}$ (3), 323-327

Dottore AM, Kawakami PY, Bechara K, Rodrigues JA, Cassoni A, Figueiredo LC, Piat-

telli A, Shibli JA (2014): Stability of Implants Placed in Augmented Posterior Mandible after Alveolar Osteotomy Using Resorbable Nonceramic Hydroxyapatite or Intraoral Autogenous Bone: 12-Month Follow-Up. Clin Implant Dent Relat Res 16 (3), 330-336

Esposito M, Grusovin MG, Coulthard P, Worthington HV (2006): The efficacy of various bone augmentation procedures for dental implants: a Cochrane systematic review of randomized controlled clinical trials. Int J Oral Maxillofac Implants 21, 696-710

(EU 2004): Europäisches Parlament und Rat der Europäischen Union: zur Festlegung von Qualitäts- und Sicherheitsstandards für die Spende, Beschaffung, Testung, Verarbeitung, Konservierung, Lagerung und Verteilung von menschlichen Geweben und Zellen: Richtlinie 2004/23/EG 2004

(EU 2006): Europäisches Parlament und Rat der Europäischen Union: zur Durchführung der Richtlinie 2004/23/EG des Europäischen Parlaments und des Rates hinsichtlich technischer Vorschriften für die Spende, Beschaffung und Testung von menschlichen Geweben und Zellen: Richtlinie 2006/17/EG 2006

Frost HM (1987): Bone "mass" and the "mechanostat": A proposal. Anat Rec $\underline{219}, 1-9$

Frost HM (2003): Bone's mechanostat: A 2003 update. Anat Rec $\underline{275}, 1081-1101$

Geiger M, Blem G, Ludwig A (2016): Evaluation of ImageJ for Relative Bone Density Measurement and Clinical Application. J Oral Health Craniofac Sci 1, 12-21

Gerlach KL, Niehues D (2007): Die Behandlung der Kieferzysten mit einem neuartigen nanopartikulären Hydroxylapatit. Mund Kiefer GesichtsChir 11, 131-137

Giannoudis PV, Einhorn TA, Marsh D (2007): Fracture healing: the diamond concept. Injury $\underline{38}(4), 3-6$ 
Goldman HM, Cohen DW (1958): The Infrabony Pocket: Classification and Treatment. J Periodontol $\underline{29}, 272-291$

Goulet JA, Senunas LE, DeSilva GL, Greenfield ML (1997): Autogenous iliac crest bone graft. Complications and functional assessment. Clin Orthop Relat Res $\underline{339}, 76-81$

Gruber R, Weich H, Dullin C, Schliephake H (2009): Ectopic bone formation after implantation of a slow release system of polylactid acid and rhBMP-2. Clin Oral Implant Res $\underline{20}$, 24-30

Gruber RM, Ludwig A, Merten H, Achilles M, Poehling S, Schliephake H (2008): Sinus floor augmentation with recombinant human growth and differentiation factor-5 (rhGDF5): a histological and histomorphometric study in the Goettingen miniature pig. Clin Oral Implant Res $\underline{19}$, 522-529

Günther KP, Scharf H, Pesch H, Puhl W (1998): Osteointegration of different bone substitute materials in an experimental model. Orthopäde 27, 105-117

Gürtler L: Übertragbarkeit von Infektionserregern über allogene Knochentransplantate. In: Schnettler R, Markgraf E (Hrsg.): Knochenersatzmaterialien und Wachstumsfaktoren. Thieme, Stuttgart, New York 1997, 8-11

Hammerle CHF, Araujo MG, Simion M (2012): Evidence-based knowledge on the biology and treatment of extraction sockets. Clin Oral Implant Res $\underline{23}$ (5), 80-82

Herr G, Schmid U, Holz G, Reutter K, Schnettler R: Einfluß verschiedener Desinfektionsund Sterilisationsverfahren auf die biologische Aktivität und Struktur von Knochengewebe. In: Schnettler R, Markgraf E (Hrsg.): Knochenersatzmaterialien und Wachstumsfaktoren. Thieme, Stuttgart, New York 1997, 78-84

Herten M, Rothamel D, Schwarz F, Friesen K, Koegler G, Becker J (2009): Surface- and nonsurface-dependent in vitro effects of bone substitutes on cell viability. Clin Oral Invest $\underline{13}, 149-155$

Hidalgo DA (1989): Titanium miniplate fixation in free flap mandible reconstruction. Ann Plast Surg $\underline{23}, 498-507$

Hollinger JO, Kleinschmidt JC (1990): The Critical Size Defect as an Experimental Model to Test Bone Repair Materials. J Craniofac Surg 1, 60-68

Horvath A, Mardas N, Mezzomo LA, Needleman IG, Donos N (2013): Alveolar ridge preservation. A systematic review. Clin Oral Investig 17 (2), 341-363

Huber F, Belyaev O, Hillmeier J, Kock H, Huber C, Meeder P, Berger I (2006): First histological observations on the incorporation of a novel nanocrystalline hydroxyapatite paste OSTIM® in human cancellous bone. BMC Musculoskelet Disord $\underline{7}, 1-14$ 
Hulbert SF, Young FA, Mathews RS, Klawitter JJ, Talbert CD, Stelling FH (1970): Potential of ceramic materials as permanently implantable skeletal prostheses. J Biomed Mater Res $\underline{4}, 433-456$

Hulbert SF, Morrison SJ, Klawitter JJ (1972): Tissue reaction to three ceramics of porous and non-porous structures. J Biomed Mater Res $\underline{6}, 347-374$

Ihan Hren N, Miljavec M (2008): Spontaneous bone healing of the large bone defects in the mandible. Int J Oral Maxillofac Surg 37, 1111-1116

Jacobson AG (1966): Inductive processes in embryonic development. Science $\underline{152}, 25-34$

Jäger M, Westhoff B, Wild A, Krauspe R (2005): Knochenspanentnahme am Becken. Techniken und Probleme. Orthopäde 34, 976-994

Kamboj M, Aroa R, Gupta H (2016): Comparative evaluation of the efficacy of synthetic nanocrystalline hydroxyapatite bone graft $(\mathrm{Ostim} \circledast)$ and synthetic microcrystalline hydroxyapatite bone graft (Osteogen $\circledast$ ) in the treatment of human periodontal intrabony defects: A clinical and denta scan study. J Indian Soc Periodontol 20, 423-428

Kappe T, Cakir B, Mattes T, Reichel H, Floren M (2010): Infections after bone allograft surgery: a prospective study by a hospital bone bank using frozen femoral heads from living donors. Cell Tissue Bank 11, 253-259

Karageorgiou V, Kaplan D (2005): Porosity of 3D biomaterial scaffolds and osteogenesis. Biomaterials $\underline{26}$ (27), 5474-5491

Kasaj A, Röhrig B, Zafiropoulos G, Willershausen B (2008a): Clinical Evaluation of Nanocrystalline Hydroxyapatite Paste in the Treatment of Human Periodontal Bony Defects A Randomized Controlled Clinical Trial: 6-Month Results. J Periodontol 79, 394-400

Kasaj A, Willershausen B, Reichert C, Röhrig B, Smeets R, Schmidt M (2008b): Ability of nanocrystalline hydroxylapatite paste to promote human periodontal ligament cell proliferation. J Oral Sci $\underline{50}, 279-285$

Khardori N, Yassien M (1995): Biofilms in device-related infections. J Ind Microbiol 15, 141147

Kilian O, Wenisch S, Karnati S, Baumgart-Vogt E, Hild A, Fuhrmann R, Jonuleit T, Dingeldein E, Schnettler R, Franke R (2008): Observations on the microvasculature of bone defects filled with biodegradable nanoparticulate hydroxyapatite. Biomaterials $\underline{29}$, 3429-3437

Kim H, Sung SO, Kim SJ, Kim S, Park I, Jo KW (2013): Analysis of the factors affecting graft infection after cranioplasty. Acta Neurochir (Wien) 155, 2171-2176 
Kübler N (1997): Osteoinduktion und- reparation. Mund Kiefer GesichtsChir 1, 2-25

Lane JM, Betts F, Posner AS, Yue DW (1984): Mineral parameters in early fracture repair. J Bone Joint Surg Am $\underline{66}$ (8), 1289-1293

Laschke MW, Witt K, Pohlemann T, Menger MD (2007): Injectable nanocrystalline hydroxyapatite paste for bone substitution:In vivo analysis of biocompatibility and vasculariza-

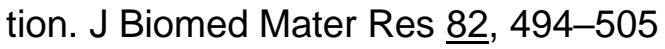

Lexer E (1914): Free Transplantation. Ann Surg $\underline{60}$ (2), 166-194

Lu JX, Flautre B, Anselme K, Hardouin P, Gallur A, Descamps M, Thierry B (1999): Role of interconnections in porous bioceramics on bone recolonization in vitro and in vivo. $J$ Mater Sci Mater Med 10, 111-120

Margolis IB, Smith RL, Davis WC (1976): Reconstruction of defects of the mandible. Surgery $\underline{79}, 638-643$

McCormack N, O'Dea S (2013): Regulation of Epithelial to Mesenchymal Transition by Bone Morphogenetic Proteins. Cell Signal $2 \underline{5}$ (12), 2856-2862

Moghadam HG, Sándor GK, Holmes HH, Clokie CM (2004): Histomorphometric evaluation of bone regeneration using allogeneic and alloplastic bone substitutes. J Oral Maxillofac Surg $\underline{62}, 202-213$

Moore WR, Graves SE, Bain GI (2001): Synthetic bone graft substitutes. ANZ J Surg 71, 354-361

Nade S, Armstrong L, McCartney E, Baggaley B (1983): Osteogenesis after bone and bone marrow transplantation. The ability of ceramic materials to sustain osteogenesis from transplanted bone marrow cells: preliminary studies. Clin Orthop Relat Res $\underline{181}$, 255-263

Pecora G, Kim S, Celetti R, Davarpanah M (1995): The guided tissue regeneration principle in endodontic surgery: one-year postoperative results of large periapical lesions. Int Endod J $\underline{28}, 41-46$

Pecora G, Leonardis D de, Ibrahim N, Bovi M, Cornelini R (2001): The use of calcium sulphate in the surgical treatment of a 'through and through' periradicular lesion. Int Endod J $\underline{34}, 189-197$

Posner AS (1985): The mineral of bone. Clin Orthop Relat Res $\underline{200}, 87-99$ 
Röser K, Donath K, Schnettler R: Beeinflussung der knöchernen Wundheilung durch Knochenersatzstoffe und sog. Wundverschlußmaterialien. In: Schnettler R, Markgraf E (Hrsg.): Knochenersatzmaterialien und Wachstumsfaktoren. Thieme, Stuttgart, New York 1997, 54-59

Rothamel D, Schwarz F, Herten M, Engelhardt E, Donath K, Kuehn P, Becker J (2008): Dimensional ridge alterations following socket preservation using a nanocrystalline hydroxyapatite paste. A histomorphometrical study in dogs. Int J Oral Maxillofac Surg $\underline{37}$, $741-747$

Rübsamen-Waigmann H: Virussicherheit von Blutspenden und Knochentransplantaten. In: Schnettler R, Markgraf E (Hrsg.): Knochenersatzmaterialien und Wachstumsfaktoren. Thieme, Stuttgart, New York 1997, 1-7

Rud J, Andreasen JO, Möller Jensen J (1972): A follow-up study of 1,000 cases treated by endodontic surgery. Int J Oral Surg 1 (4), 215-228

Rueger JM (1998): Bone replacement materials - state of the art and the way ahead. Orthopäde $\underline{27}, 72-79$

Sailer H, Weber F (2000): Knochenersatzmaterialien. Mund Kiefer GesichtsChir 4, 384-391

Schiebler TH: Anatomie: Histologie, Entwicklungsgeschichte, makroskopische und mikroskopische Anatomie, Topographie ; unter Berücksichtigung des Gegenstandskatalogs, 9. Auflage; Springer, Heidelberg 2005

Schmitz JP, Hollinger JO (1986): The critical size defect as an experimental model for craniomandibulofacial nonunions. Clin Orthop Relat Res $\underline{205}$, 299-308

Schneider CA, Rasband WS, Eliceiri KW (2012): NIH Image to ImageJ: 25 years of image analysis. Nat Meth $\underline{9}, 671-675$

Schnettler R, Dingeldein E: Untersuchungen zur knöchernen Integration einer Hydroxylapatitkeramik (HAK) (Endobon) und bFGF im Vergleich zu autogenen Spongiosazylindern. In: Schnettler R, Markgraf E (Hrsg.): Knochenersatzmaterialien und Wachstumsfaktoren. Thieme, Stuttgart, New York 1997, 31-42

Schnettler R, Stahl J, Alt V, Pavlidis T, Dingeldein E, Wenisch S (2004): Calcium Phosphate-Based Bone Substitutes. Eur J Trauma 30, 219-229

Schwarz F, Bieling K, Latz T, Nuesry E, Becker J (2006): Healing of intrabony periimplantitis defects following application of a nanocrystalline hydroxyapatite (Ostim®) or a bovine-derived xenograft (Bio-Oss ${ }^{\mathrm{TM}}$ ) in combination with a collagen membrane (BioGide $\left.^{\mathrm{TM}}\right)$. A case series. J Clin Periodontol $\underline{33}, 491-499$ 
Silva MA, Wolf U, Heinicke F, Bumann A, Visser H, Hirsch E (2008): Cone-beam computed tomography for routine orthodontic treatment planning. A radiation dose evaluation. Am J Orthod Dentofac Orthop 133 (5), 640.e1-5

Sitzmann F (1993): Wann sind zur Sicherung von Diagnose und Therapie Röntgenaufnahmen nötig? Wissenschaftliche Stellungnahme der DGZMK. DZZ $\underline{48}(3), 147-148$

Smeets R, Kolk A (2011): Osteokonduktive und -induktive Knochenersatzmaterialien. [http://www.zmk-aktuell.de/zahnheilkunde/implantologie/story/osteokonduktive-undinduktive-knochenersatzmaterialien-teil-1.html] abgerufen am: 08.11.2016

Smeets R, Grosjean MB, Jelitte G, Heiland M, Kasaj A, Riediger D, Yildirim M, Spiekermann H, Maciejewski O (2008): Hydroxylapatit-Knochenersatzmaterial (Ostim®) bei der Sinusbodenelevation. Schweiz Monatsschr Zahnmed 118, 203-208

Sogal A, Tofe AJ (1999): Risk assessment of bovine spongiform encephalopathy transmission through bone graft material derived from bovine bone used for dental applications. $\mathrm{J}$ Periodont $\underline{70}, 1053-1063$

Soldner E, Herr G (2001): Knochen, Knochentransplantate und Knochenersatzmaterialien. Trauma und Berufskrankheit $\underline{3}, 256-269$

Spies C, Schnürer S, Gotterbarm T, Breusch S (2008): Tierexperimentelle Untersuchung des Knochenersatzstoffs Ostim ${ }^{\circledR}$ im knöchernen Lager des Göttinger Miniaturschweins. Z Orthop Unfall 146, 64-69

Stimson BB (1947): The use of internal fixation in compound fractures. Am J Surg $\underline{74}, 697-$ 704

Strietzel FP, Reichart PA, Graf H (2007): Lateral alveolar ridge augmentation using a synthetic nano-crystalline hydroxyapatite bone substitution material (Ostim $\AA$ ): preliminary clinical and histological results. Clin Oral Implant Res $\underline{18}, 743-751$

Tadic D, Epelle M (2004): A thorough physicochemical characterisation of 14 calcium phosphate-based bone substitution materials in comparison to natural bone. Biomaterials $\underline{25}$, 987-994

Tadic D, Peters F, Epple M (2002): Continuous synthesis of amorphous carbonated apatites. Biomaterials $\underline{23}, 2553-2559$

\section{Takamoto M, Takechi M, Ohta K, Ninomiya Y, Ono S, Shigeishi H, Tada M, Kamata N} (2013): Risk of bacterial contamination of bone harvesting devices used for autogenous bone graft in implant surgery. Head Face Med $\underline{9}, 3$ 
Tallgren A (1972): The continuing reduction of the residual alveolar ridges in complete denture wearers: a mixed-longitudinal study covering 25 years. J Prosth Dent $\underline{27}, 120-132$

Tan WL, Wong TLT, Wong MCM, Lang NP (2012): A systematic review of post-extractional alveolar hard and soft tissue dimensional changes in humans. Clin Oral Implant Res $\underline{23}$ (5), 1-21

ten Heggeler JMAG, Slot DE, van der Weijden GA (2011): Effect of socket preservation therapies following tooth extraction in non-molar regions in humans: a systematic review. Clin Oral Implant Res $\underline{22}, 779-788$

Thomsen FS, Peña JA, Lu Y, Huber G, Morlock M, Glüer CC, Delrieux CA (2016): A new algorithm for estimating the rod volume fraction and the trabecular thickness from in vivo computed tomography. Med Phys $\underline{43}$ (12), 6598-6607

Thorwarth M, Schultze-Mosgau S, Kessler P, Wiltfang J, Schlegel KA (2005): Bone Regeneration in Osseous Defects Using a Resorbable Nanoparticular Hydroxyapatite. J Oral Maxillofac Surg $\underline{63}, 1626-1633$

Tomford WW (2000): Bone allografts: past, present and future. Cell Tissue Bank 1, 105-109

Tröster S, Liebendörfer A: Biokeramik Endobon im klinischen Einsatz: Erfahrungen, Ergebnisse, Perspektiven. In: Schnettler R, Markgraf E (Hrsg.): Knochenersatzmaterialien und Wachstumsfaktoren. Thieme, Stuttgart, New York 1997, 149-157

Uchida A, Nade SM, McCartney ER, Ching W (1984): The use of ceramics for bone replacement. A comparative study of three different porous ceramics. J Bone Joint Surg Br $\underline{66}, 269-275$

Urist MR, Strates BS (1971): Bone Morphogenetic Protein. J Dent Res $\underline{50}, 1392-1406$

Urist MR, Silverman BF, Büring K, Dubux FL, Rosenberg JM (1967): The Bone Induction Principle. Clin Orthop Relat Res $\underline{53}$, 243-283

van der Weijden F, Dell'Acqua F, Slot DE (2009): Alveolar bone dimensional changes of post-extraction sockets in humans: a systematic review. J Clin Periodontol $\underline{36}, 1048$ 1058

van Eeden SP, Ripamonti U (1994): Bone differentiation in porous hydroxyapatite in baboons is regulated by the geometry of the substratum: implications for reconstructive craniofacial surgery. Plast Reconstr Surg 93, 959-966

van Lieshout EMM, van Kralingen GH, El-Massoudi Y, Weinans H, Patka P (2011): Microstructure and biomechanical characteristics of bone substitutes for trauma and orthopaedic surgery. BMC Musculoskelet Disord 12, 34 
Varshowsaz M, Goorang S, Ehsani S, Azizi Z, Rahimian S (2016): Comparison of Tissue Density in Hounsfield Units in Computed Tomography and Cone Beam. J Dent (Teheran) $\underline{13}(2), 108-115$

Vittorini Orgeas G, Clementini M, Risi V de, Sanctis M de (2013): Surgical Techniques for Alveolar socket preservation: A Systematic Review. Int J Oral Maxillofac Implants $\underline{28}$, 1049-1061

Wilke A, Orth J, Landgraf M, Griss P: Biokompatibilitätstestung von Keramiken im Vergleich zu Metallen und Polymeren mit Hilfe einer humanen Knochenmarkzellkultur. In: Schnettler R, Markgraf E (Hrsg.): Knochenersatzmaterialien und Wachstumsfaktoren. Thieme, Stuttgart, New York 1997, 111-117

Wolff J: Das Gesetz der Transformation der Knochen. August Hirschwald, Berlin 1892 Yasar F, Apaydin B, Yilmaz H (2012): The effects of image compression on quantitative measurements of digital panoramic radiographs. Med Oral Patol Oral Cir Bucal $\underline{17}$, 1074-1081

Young MPJ, Carter DH, Worthington H, Korachi M, Drucker DB (2001): Microbial analysis of bone collected during implant surgery: a clinical and laboratory study. Clin Oral Implant Res 12, 95-103 


\section{Danksagung}

An dieser Stelle möchte ich mich bei allen bedanken, die mich bei der Erstellung dieser Arbeit unterstützt haben.

Ein besonderer Dank gilt Herrn PD Dr. med. Dr. med. dent. Arwed Ludwig für die Überlassung des Themas, Betreuung bei der Planung und Durchführung der Untersuchungen und Erstellen der schriftlichen Arbeit. Weiterhin möchte ich mich bei dem Personal der MGK-Klinik für die Unterstützung während der Untersuchung bedanken.

Des Weiteren möchte ich mich bei Herrn Prof. Rainer Hilgers und den wissenschaftlichen Mitarbeitern des Instituts für Medizinische Statistik für die Unterstützung bei der Planung und Auswertung der Ergebnisse der Voruntersuchung bedanken. Weiterer Dank geht an Frau Xenia Schulz aus demselben Institut für die statistische Auswertung der klinischen und radiologischen Untersuchungsergebnisse.

Danken möchte ich ebenfalls meinen ehemaligen Arbeitgebern Hendrik Matthies, Dr. med. dent. Shekufeh Balouch und Dr. med. dent. Alireza Amir Sayfadini für das Schaffen von Freiräumen für den Besuch von Kongressen, Durchführen von Untersuchungen und statistischen Analysen sowie Rat und Tat.

Ein großer Dank geht auch an meine Familie fürs Korrekturlesen und vielfältige Unterstützung während des Studiums und der Doktorarbeit. Zu guter Letzt bedanke ich mich riesig bei meiner Frau Dr. med. dent. Franziska Geiger für die ständige Unterstützung, wissenschaftliche Hilfestellung und Motivation, die Arbeit endlich fertig zu stellen! 